\title{
UNDERSTANDING DISTRIBUTIONS OF INVASIVE MAMMALS IN URBAN ENVIRONMENTS USING REMOTE CAMERAS AND CITIZEN SCIENCE
}

\author{
VICTOR ANTON
}

A thesis submitted to the Victoria University of Wellington

in fulfilment of the requirements for the degree of Doctor of Philosophy

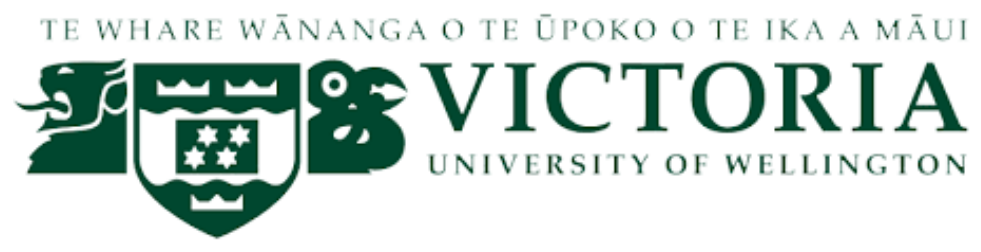

February 2019 

Invasive mammals in urban environments, citizen science and remote cameras.

Ph.D. thesis (C) Victor Anton 2019

\section{SUPERVISORS:}

Dr. Heiko U. Wittmer

Dr. Stephen Hartley

\section{LOCATION:}

Victoria University of Wellington, Wellington, New Zealand 



\section{ACKNOWLEDGMENTS}

Many people have helped me make this thesis possible. I specially thank my family and Amy Brasch for supporting me from the beginning until the end of this research. I also thank both my supervisors, Heiko Wittmer and Stephen Hartley, for giving me much time and suggestions to successfully carry out multiple aspects of my PhD.

I thank Jason Preble and Grace Shaw for their help collecting data, my lab colleagues Johannes Fischer and Samhita Bose, and Andre Geldenhuis. Thanks to everyone who helped me setting up cameras around Wellington and the thousands of online volunteers that classified the photographs, particularly John Innes and Craig Gillies for their help identifying photographs of rats to the species level.

I am also grateful to the tenants and landowners who granted me access to their property to collect the data and the local councils (Greater Wellington Regional Council and Wellington City Council) for providing geographical information about the traps and poison bait stations.

I appreciate all the comments and feedback received from the members of the "bug club", and the reviewers of the published version, as journal articles, of this research.

I am very grateful for the funding provided by the Wellington City Council as part

of the "Our Natural Capital Research Grant", the tuition scholarship from Victoria University of Wellington and the research funding from the Centre for Biodiversity and Restoration Ecology (CBRE) of Victoria University of Wellington. 



\begin{abstract}
Preserving biodiversity in urban environments is crucial not only for preventing local extinctions of native species, but also for educating the public about the importance of species conservation. Invasive mammalian species can have negative impacts for both people and biodiversity in urban environments. Understanding the factors influencing the distribution of these invasive species is crucial to comply with the ethical, ecological, and practical concerns associated with their management. Remote cameras are an increasingly popular tool for investigating the distribution and abundance of mammals. Yet few studies have used these cameras in urban environments. The time and effort required to classify remote camera data is the main constraint of this monitoring technique.
\end{abstract}

To determine whether employing citizen science could facilitate the use of remote cameras in urban environments, I investigated the engagement, accuracy, and efficiency of volunteers (i.e., citizen scientists) in classifying animal images recorded by remote cameras in Wellington, New Zealand. Classifications from citizen scientists were in $84.2 \%$ agreement with classifications of expert ecologists. However, accuracy varied significantly among species and volunteers. Aggregating multiple classifications per image and highlighting animal movement in the images improved the accuracy of citizen scientists. Additionally, weighting their classifications based on previous accuracy, selfassessed confidence, and the species reported reduced the number of volunteer classifications required to achieve levels of accuracy comparable to that of experts. These results illustrate that citizen science allows for accurate and efficient classifications of remote camera data from urban areas. 
Using the classifications provided by citizen scientists, I then evaluated the suitability of remote cameras to monitor invasive mammals in urban environments. Based on data collected from forest and residential areas of Wellington, New Zealand, remote cameras detected significantly more European hedgehogs (Erinaceus europaeus) and rats (Rattus spp.) than tracking tunnels. Cameras, however, missed recording house mice (Mus musculus) on some occasions where tracking tunnels detected them, and vice-versa. Overall, my results demonstrate that remote cameras are a more efficient multi-species monitoring tool than tracking tunnels. Independent of habitat type, cats (Felis catus), hedgehogs, and mice were the species most frequently recorded. Data from remote cameras subsequently helped quantify differences in the occupancy rates of species between residential and forested areas furthering our ecological understanding of the distribution of invasive species in peopled landscapes.

To identify the underlying processes influencing the distribution and abundances of invasive mammals found in urban patches of vegetation, I also used remote cameras to investigate the influence of habitat quality, management efforts, interspecific interactions and seasonality on the occupancy and relative abundance of invasive mammals in 47 patches of forest within Wellington. My results indicate that distance to forest edge influences positively on the relative abundance of rodents and negatively on the relative abundance of common brushtail possums (Trichosurus vulpecula), cats, European rabbits (Oryctolagus cuniculus), and hedgehogs. The cameras also revealed a positive interaction between the occupancy of ship rats (Rattus rattus) and the abundance of Norway rats (Rattus norvegicus), a positive influence of the nearby buildings on the occupancy of cats, and how management control reduces the occupancy of target species, particularly 
during spring. These results illustrate the importance of using season- and speciesspecific approaches to identify the most important factors influencing the distribution of invasive species in urban environments.

Overall, my research highlights the benefits of engaging the public with scientific research, the advantages of using remote cameras to monitor mammals in urban environments and the importance of controlling invasive species at adequate spatial and temporal scales to ensure effective conservation management. 



\section{TABLE OF CONTENTS}

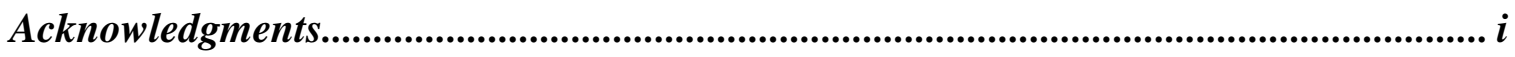

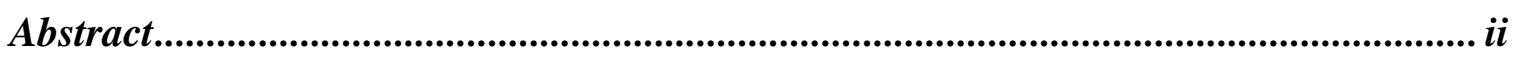

List of tables ....................................................................................................... viii

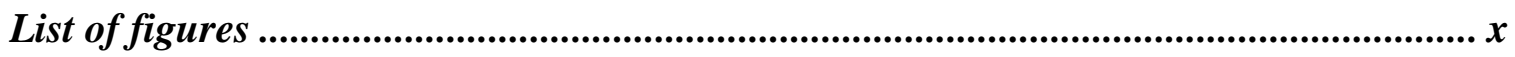

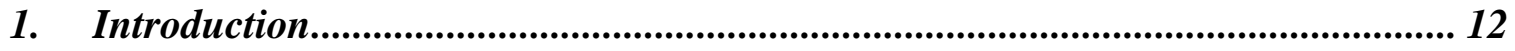

Citizen science ......................................................................................................................................12

Urban biodiversity ..................................................................................................................................................17

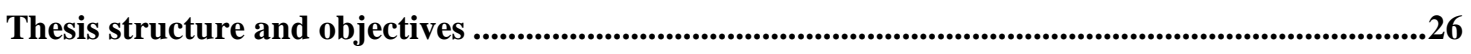

2. Monitoring the mammalian fauna of urban areas using remote cameras and citizen science ............................................................................................................................ 28

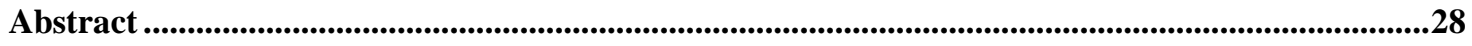

Introduction ................................................................................................................................................................30

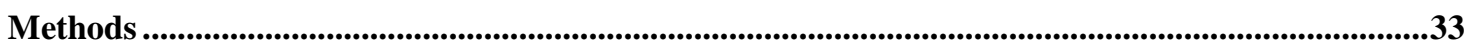

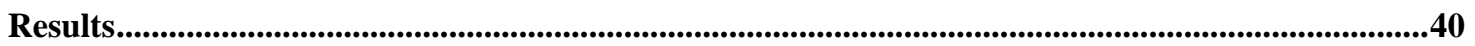

Discussion and conclusion ..........................................................................................................................51

Acknowledgements ..................................................................................................................................55

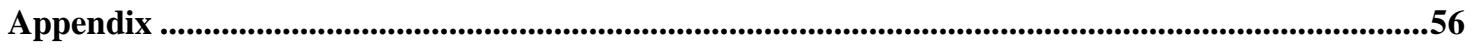

3. Evaluation of remote cameras for monitoring multiple invasive mammals in residential and forested areas of New Zealand........................................................60

Abstract .........................................................................................................................................................60

Introduction ...........................................................................................................................................................62

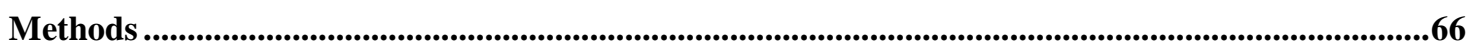

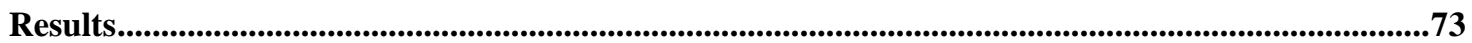

Discussion and conclusion ..........................................................................................................................78

Acknowledgements ..............................................................................................................................................................85

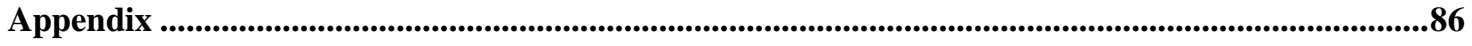

4. Habitat quality, interspecific interactions and anthropogenic activities influence the distribution of urban invasive mammals.................................................................. 88

Abstract .............................................................................................................................................................................88

Introduction .............................................................................................................................................................99

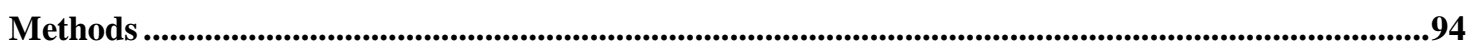

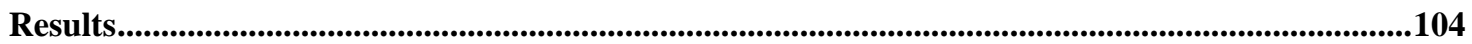

Discussion and conclusion ........................................................................................................................114

Acknowledgements ...........................................................................................................................................120 


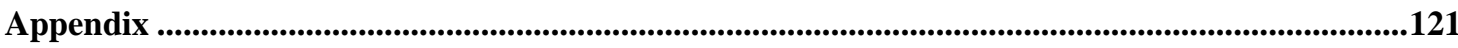

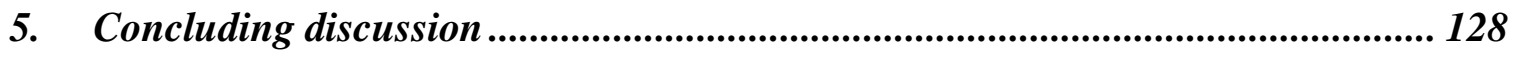

Urban ecology ..............................................................................................................................................................128

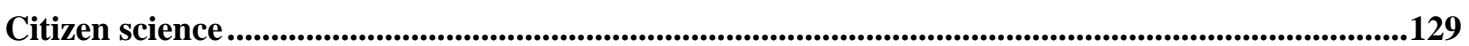

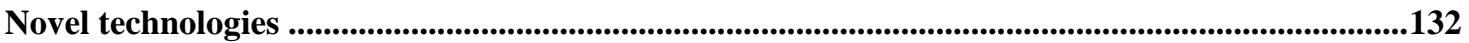

Urban invasive mammals.........................................................................................................................135

Conclusion .....................................................................................................................................................137

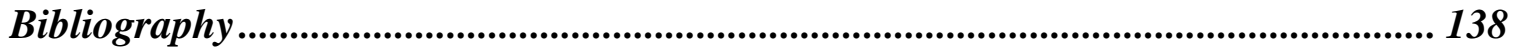




\section{LIST OF TABLES}

Page

Table 2.1 Confusion matrix of the citizen scientist and expert classifications used to calculate the accuracy of citizen scientists

Table 2.2 Results of the GLM predicting number of classifications provided per citizen scientist based on their age and ecological knowledge.

Table 2.3 Confusion matrix of the classifications provided by experts compared to those provided by individual citizen scientists for sequences without movement highlighted.

Table 2.4 Output of the meta-model used to predict the likelihood that citizen scientists had of correctly classifying a sequence.

Table 2.5 Number of sequences containing common mammalian introduced predators of New Zealand and the proportion of sequences correctly classified by one, two, and three citizen scientists.

Table 3.1 Results from generalised linear mixed models used to determine the effect of monitoring device and bait treatment on the detection probability of possums, hedgehogs, rats and mice

Table 3.2 Species detected by remote cameras and tracking tunnels during 4 non-consecutive nights at 40 sites across Wellington City..... 75

Table 3.3 Main advantages of using remote cameras or tracking tunnels as a multispecies monitoring tool.

Table 4.1 Covariates included in modelling of the occupancy of mammalian invasive non-native species in patches of forest within Wellington, New Zealand

Table 4.2 Logit-transformed estimates of slopes of the Zero Inflated Poisson models used to estimate the influence of distance to the forest edge and seasonality in the capture rates of medium-sized invasive mammals

Table 4.3 Logit-transformed estimates of slopes of the Zero Inflated Poisson models used to estimate the influence of distance to the forest edge and seasonality in the capture rates of small invasive mammals recorded by the cameras

Table 4.4 Parameters used to model probability of occupancy and detection probability of the best performing models predicting the occupancy of invasive mammalian species in urban patches of forest 



\section{LIST OF FIGURES}

Page

Figure 1.1 Students from Hampton Hill School (Wellington, New Zealand) using a citizen science website to identify animals in photographs taken by remote cameras. Photograph taken by Carol Brieseman..... 13

Figure 1.2 Location of the biodiversity hotspots and populated places with more than 10,000 people in the world 18

Figure 2.1 Snapshot of the website's interface used to classify the events 34

Figure 2.2 Engagement of citizen scientists according to their age and ecological knowledge.

Figure 2.3 Performance of citizen scientists in classifying remote camera data collected from Wellington, New Zealand into thirteen different categories

Figure 2.4 Comparison between the accuracy of citizen scientists to correctly classify events, with and without the movement highlighted, into thirteen categories

Figure 2.5 Accuracy of citizen scientists classifying remote camera data based on the level of confidence they reported for each classifications and their previous accuracy

Figure 3.1 Location of the 40 remote cameras and tracking tunnels in Wellington, New Zealand

Figure 3.2 Diagram of the remote camera and tracking tunnel deployment 68

Figure 3.3 Photographs of a Norway rat (Rattus norvegicus), a ship rat ( $R$. rattus) and a rat that was unable to be identified to species level.

Figure 3.4 Number of detection events of possums, hedgehogs, rats and mice across 4 non-consecutive days by remote cameras and tracking tunnels under different bait treatments

Figure 3.5 Occupancy estimates obtained from unbaited remote cameras of invasive mammals recorded in $>20 \%$ of the 40 residential and forested locations in Wellington, New Zealand.

Figure 4.1 Location of the 47 patches of forest in Wellington, New Zealand. .95

Figure 4.2 Diagram of the location of remote cameras at each patch of forest 97 
Figure 4.3 Predicted capture rates by cameras during spring, summer, autumn, and winter of invasive mammalian species that were statistically influenced by distance to forest edge.

Figure 4.4 Predicted occupancy estimates at different trap and poison devices densities during autumn and spring of invasive mammalian species targeted in mammalian control management

Figure 5.1 Resources available for researchers of multiple disciplines to collect environmental and social data of cities 


\section{INTRODUCTION}

\section{Citizen science}

Citizen science describes a research approach undertaken by professional scientists in association with the general public to study questions of scientific relevance (Cohn 2008). Citizen science arose from crowdsourcing, where an undefined group of people carry out a job traditionally executed by a designated agent, usually an employee (Howe 2008). The main difference between citizen science and crowdsourcing is the public contribution towards scientific research (Wiggins \& Crowston 2011). Citizen science has facilitated the expansion of scientific knowledge in numerous disciplines, including astronomy, palaeontology and history (Bonney et al. 2009). Throughout this document I focus on the use of citizen science in the field of ecology, where this research approach has made contributions to understanding phenology, behaviour, distributions, and population trends of numerous organisms across time and space (Dickinson et al. 2010).

Citizen science provides numerous advantages for both professional scientists and the general public compared to traditional approaches of ecological research. The main benefit of citizen science projects for professionals is the capability to collect data over large geographical areas and long periods of time (Bonney et al. 2009). Citizen science projects reduce the costs associated with the collection, analysis and interpretation of data, enabling researchers investigations at unprecedented spatial and temporal scales (Aceves-Bueno et al. 2015). Volunteers of citizen science projects learn in ways that can lead to meaningful ecological and social outcomes (Figure 1.1) (Dillon et al. 2016). For example, citizen science can increase awareness of participants about species conservation (Dickinson et al. 2012). Increasing public awareness can ultimately lead to 
gains in public support and engagement in controversial aspects of biodiversity policies and wildlife management (e.g. the control of invasive species) (Novoa et al. 2017).

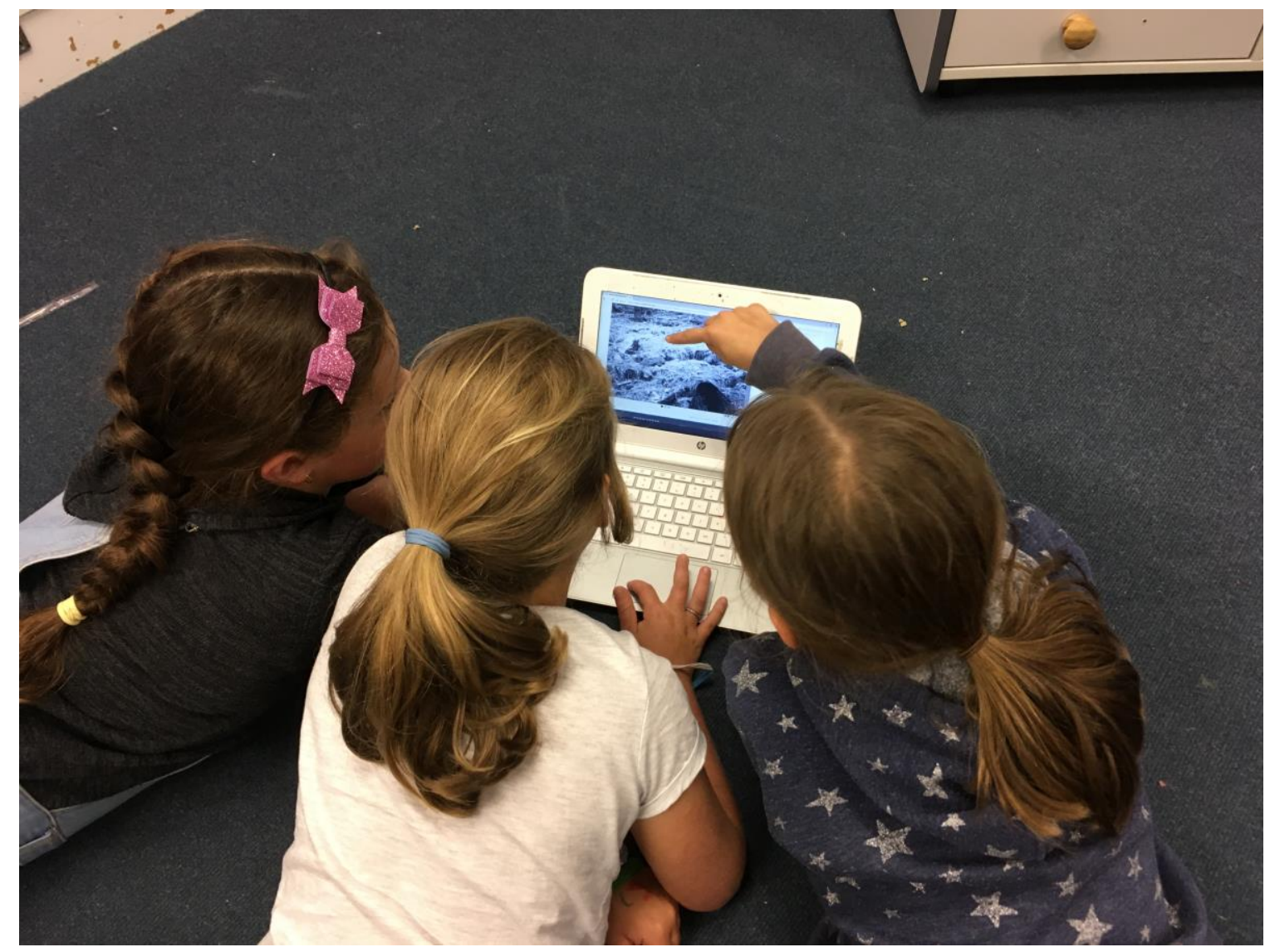

Figure 1.1 Students from Hampton Hill School (Wellington, New Zealand) using a citizen science website to identify animals in photographs taken by remote cameras. Photograph taken by Carol Brieseman.

Citizen science also presents many challenges and limitations, including the bias in spatiotemporal coverage, the inconsistent accuracy of citizen scientists and their irregular degree of involvement with the project. For example, potential hazardous conditions, physical barriers, and other impediments restricting the accessibility to sites can limit the spatial representation of the data collected by citizen scientists (Wiggins \& Crowston 2011). Another limitation of citizen science research is the insufficient levels of volunteer engagement. Research questions that stimulates widespread interest (e.g. 
animal behaviour, water quality and studies involving charismatics species) are likely to gather more citizen scientists, and those with a higher level of commitment, than projects looking at less popular topics (McKinley et al. 2017). Furthermore, complex tasks, overestimating the scope of the project, and inappropriate long-term planning are components of projects that can also lead to insufficient levels of engagement (Jennett et al. 2016; Sprinks et al. 2017; Aceves-Bueno et al. 2017). Citizen science is not an appropriate approach for all scientific research. For example, the involvement of volunteers in research projects that require highly-trained participants might be ineffective, or even impractical (Dickinson et al. 2012). For projects where citizen science is appropriate, researchers need to ensure the quality of the data is high. Citizen scientists can be less accurate in the collection, analysis, and interpretation of data than professional scientists (Catlin-Groves 2012). If not managed appropriately, poor quality data can erroneously guide science and policy (Kosmala et al. 2016).

There is a growing number of guidelines, methods, and techniques that researchers can use to overcome the previous challenges and limitations. Some of these processes include standard sampling techniques, comprehensive tutorials for citizen scientists, statistical tools, and iterative project designs (Kosmala et al. 2016). Researchers with a clear understanding of the characteristics of the target citizen scientists (e.g. demography, reasons for participation and level of expertise) are more likely to identify the key processes required to achieve the goals of the project (Dickinson et al. 2012). For example, understanding the characteristics of the citizen scientists can facilitate the most efficient approach to provide feedback and research updates to the volunteers (i.e. crucial processes to achieve and maintain sustainable engagement of 
citizen scientists) (Morais et al. 2015). To prevent and filter poor quality data, researchers can train citizen scientists, design the project to produce spatial and temporal replications or weight the information collected by citizen scientists based on user-specific accuracy (Isaac et al. 2014; Kosmala et al. 2016). However, the technology available, the proposed timeframe of the study, and other project-specific characteristics ultimately determine the appropriate methods required to overcome the limitations of citizen science (Specht 2018).

\section{Citizen science in urban ecology}

Citizen science is an ideal research approach for studies in urban ecosystems (Cooper et al. 2007). The growing momentum to conserve biodiversity in urban environments (Hess et al. 2014) highlights the interest of the general public to get engaged in urban conservation. The number of stewardship projects aiming to protect and restore biodiversity in urban environments has increased over the last two decades (Andersson et al. 2014; Cerra 2017). The outcomes of these citizen-based and often unstructured stewardship projects, however, are poorly understood (Connolly et al. 2013). As a form of collaborative scientific research, citizen science can determine the efficiency of such initiatives and provide evidence-based guidelines to maximise their efforts (Francis \& Lorimer 2011). Citizen science is also suited to investigating urban ecology because it minimises some of the common challenges associated with urban environments. For example, citizen science facilitates the collection of ecological data from privately owned land, increases the spatial and temporal scope of the research and facilitates the collection of human attributes needed to explore the socioecological dynamics of urban environments (Lye et al. 2011; Dickinson et al. 2012; Aceves-Bueno et al. 2015). 
The recent emergence and broad adoption of information technologies to gather and visualize geographic information has facilitated the number of citizen science projects undertaken in urban environments. Citizen science projects have proliferated in recent decades thanks to the internet and applications with geographic information systems (Dickinson et al. 2012). Based on data gathered by citizen scientists in urban environments, researchers have improved their ecological understanding of numerous taxa including insects, birds and mammals (Weckel et al. 2010; Bates et al. 2014a; Brumby et al. 2015; Newson et al. 2015). Technological advances have also facilitated the number of conservation initiatives that use remote devices (e.g. remote cameras, unmanned aerial vehicles or autonomous sound recorders) to monitor an array of environmental parameters (Rich et al. 2017). However, the number of projects combining remote devices and citizen science in urban environments is limited. This is surprising, given the status of cities as global hubs of technological advances and the interest of the general public to get engaged in urban conservation (Kobori et al. 2016). 


\section{Urban biodiversity}

Currently, more than $50 \%$ of all people worldwide live in cities (World Health Organisation 2016). This number is expected to continue growing and most of the urban development required to host this population growth has yet to occur (World Health Organisation 2016). Cities represent $<1 \%$ of the earth's land surface (Schneider et al. 2010), nevertheless, urban environments can play a crucial role in the conservation of biodiversity. For example, preserving biodiversity in urban environments is crucial not only for preventing the extinction of local species, but also for educating the general public about the importance of global species conservation (McKinney 2002).

Urbanisation is a major driver of contemporary species extinctions (Mcdonald et al. 2008). Urbanisation is the process of modifying natural or rural habitats into habitats with a high proportion of artificial structures (Mcphearson et al. 2016). Overall, urbanisation tends to affect ecological structure and composition in a similar pattern worldwide (McKinney 2006; Groffman et al. 2017). This pattern, known as homogenisation, results in urban environments being characterised by low species richness with few generalist species found at high densities (McKinney 2006). However, the degree to which urbanization changes biodiversity is influenced by numerous cityspecific factors, including the proportion of artificial structures (Beumer \& Martens 2015), the permeability of the urban matrix for species' dispersal (Beninde et al. 2015), and the biogeographic region (Aronson et al. 2014).

Despite the global homogenisation of urban environments, cities can still host numerous species native to the region. Cities are often built in biodiversity hotspots (Figure 1.2), where many native species face habitat loss and degradation (Güneralp \& 
Seto 2013). Some of these native species, including birds (Ives et al. 2016), plants (Hahs et al. 2009), and insects (Guénard et al. 2015), can exploit the resources found in urban environments, overcome the detrimental effects of urbanisation, and use cities as stepping stones between more suitable habitats (Aronson et al. 2014).

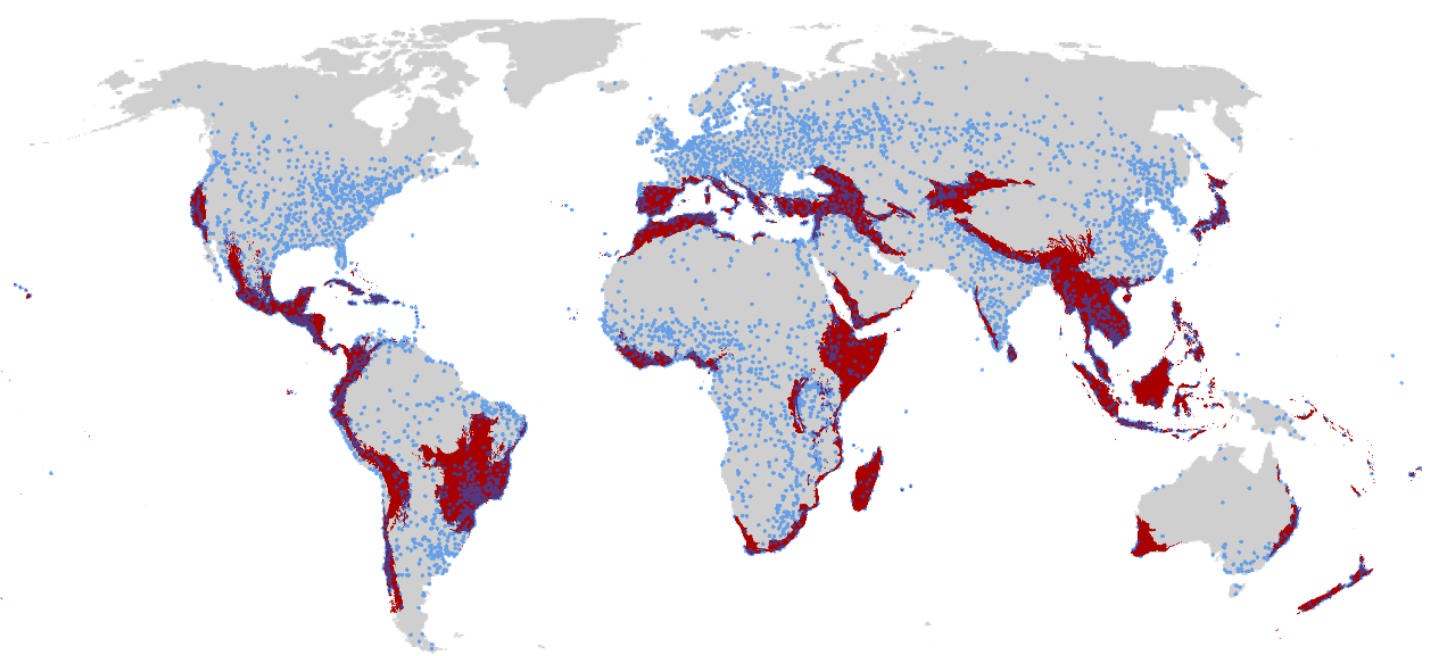

Figure 1.2 Location of the biodiversity hotspots and populated places with more than 10,000 people in the world (red and blue, respectively). Geographical information about the biodiversity hotspots was retrieved from the Critical Ecosystem Partnership Fund (accessed May 24, 2018). Geographical information about the populated places was retrieved from LandScan (accessed May 24, 2018).

Over the last three decades, planners, designers and managers of urban environments have been aiming to protect and restore urban biodiversity to ultimately enhance the resilience, sustainability and liveability of cities (Secretariat of the Convention on Biological Diversity 2012; Beumer \& Martens 2015; Botzat et al. 2016). They have available an array of processes, policies and management strategies for protecting and restoring native species in urban environments. For example, increasing the connectivity among green areas, minimising human-wildlife conflicts or designing urban features that resemble natural habitats (Aronson et al. 2017; Norton et al. 2016). 
Another management programme aiming to conserve native species in urban environments is the control of invasive non-native species (INS). INS are species introduced by humans to areas outside of their native range that threaten or displace native biota (Padayachee et al. 2017). In my thesis, I focus on INS because the control of these detrimental species is becoming widely implemented in cities throughout the world (Gaertner et al. 2017b; Archibald et al. 2017). However, INS are not the only factor influencing native biota in urban environments (Nilon et al. 2017). Other environmental and anthropogenic elements (e.g. pollution, availability of green spaces, and social organization of the city) should be taken into account to understand the bio-physical processes influencing local biodiversity (Farinha-Marques et al. 2011). A thorough understanding of these processes is crucial to identify the most efficient approach, or approaches, to promote native biodiversity in urban environments (Mcphearson et al. 2016).

\section{Urban invasive species}

The impacts of INS in urban environments can be grouped into two categories, the ecological and the social impacts. First, INS impact the ecological structure and composition of cities in diverse ways, including the modification of predator-prey dynamics (Smith et al. 2017), competition for common resources (Howe et al. 2016; Ramírez-Cruz et al. 2018), and transmission of diseases (Saito \& Sonoda 2017). Native species lacking the appropriate behavioural, physiological and morphological mechanisms to overcome the pressures induced by INS decline in number and might ultimately become extinct (Gaertner et al. 2017b). Further examples of the ecological impacts of INS include invasive plants clogging streams and canals and modifying water 
filtration (Gaertner et al. 2016), non-native lianas altering soil nutrient cycles (Bray et al. 2017), and exotic trees increasing soil erosion risk through a higher frequency of wildfires (Gaertner et al. 2017b). Second, INS also impact the people living in cities. For example, INS facilitate the disconnection of urbanites with local nature and culture (Dolan et al. 2015), damage anthropogenic infrastructures (Francis \& Chadwick 2015), disrupt landscape aesthetics (Fuller et al. 2007), and can act as vectors of human diseases (Hulme 2014; Goodman et al. 2018). The detrimental impacts of urban fauna and flora are not limited to INS, native species can also influence negatively to urban people (Soulsbury \& White 2015; Hosaka \& Numata 2016). However, the high densities INS can reach in urban environments can exacerbate the strength and frequency of these human-wildlife conflicts in cities.

There is a growing recognition of the importance that urban environments play in the control of INS worldwide (Hui \& Richardson 2017). Urban environments constitute novel habitats, characterised by highly modified physical characteristics (e.g. hydrology, climate, and soil) and the influence of socio-economic activities (Kowarik 2011). INS tend to be more successful in cities than native species because they are more efficient at adapting to novel environments (Cadotte et al. 2017). Cities, the main hubs of transportation and global trade of goods (Elmqvist et al. 2013), are also identified as facilitators of the global invasion and spread of INS (Padayachee et al. 2017), as they are often the first point of arrival. As a result of the role cities play in the spread of INS, there is an urge for managing INS in urban environments to minimise the extent and number of global biological invasions (Francis \& Chadwick 2015). 
To successfully control INS in urban environments, managers need to overcome several logistic challenges. Methodologies commonly used in non-urban environments to prevent the establishment of INS and mitigate their impacts are often inappropriate to implement in cities (Dearborn \& Kark 2010). Tools to control and monitor INS in urban environments need to be designed to minimise the disruptions associated with humanrelated activities (e.g. vandalism, traffic and presence of pets) (Gaertner et al. 2016). The heterogeneity of land ownership, the connectivity between patches of similar habitat and the rapid changes in the environment are some examples of the distinctive features of cities that also need to be accounted for when designing and implementing monitoring and management of INS (Gaertner et al. 2017b).

There are also many social challenges associated with the management of INS in urban environments. People have different perceptions, interests, and values towards INS and can disagree with the purpose, design or implementation of their management (Estévez et al. 2015). As a consequence, managing INS can become a ground for social conflicts (Crowley et al. 2017b). Disputes over the management of INS are more likely to occur in urban areas than in rural or protected areas due to the greater number of stakeholders involved and their more diverse set of backgrounds, perspectives, and values (Gaertner et al. 2017a). There are, however, guidelines and techniques to prevent these social disputes, including social impact assessments (Crowley et al. 2017a), public education (Crowley et al. 2017b) and pragmatic solutions for situations where conflicts arise (Gaertner et al. 2017a). In addition to guaranteeing the support of the public, the involvement of people in the control and prevention of INS is also crucial to ensure efficient management. People can suppress the negative impacts of INS in urban 
environments by monitoring their distribution (Maistrello et al. 2016) or reducing their numbers (Dolan et al. 2015). Furthermore, given the important role that cities play in the dispersal of INS, the compliance with strict biosecurity policies is also fundamental for preventing the spread of INS (Gaertner et al. 2017b; Yemshanov et al. 2017).

The logistic and social challenges associated with managing INS in urban environments highlight the need for a thorough understanding of the autecology of different INS in order to optimise the expenditure and labour allocated to the management of these species (Adams et al. 2014a). Yet, information about the distribution and abundance of INS in urban environments at the local level is underdocumented (Hawthorne et al. 2015). There are two main reasons for such limited knowledge. First, biological invasions in urban environments have received low priority when compared to other ecosystems (e.g. forests and islands) (Cavin \& Kull 2017). Second, tools commonly used for estimating the distribution of INS (e.g. species distribution models) fail to include the socio-ecological factors that could promote or restrict the spatial ecology of INS in urban environments (Walker et al. 2017). Despite these constraints, novel techniques and research approaches (e.g. remote sensors, unmanned aerial vehicles, and citizen science) are enabling researchers to start unravelling the distribution patterns of INS in cities.

Invasive non-native mammalian species are among the most studied group of INS in regards to their distribution in urban environments. Overall, the distribution of urban invasive mammals is influenced by the traits and guild of the species, suitable ecological conditions and socio-temporal characteristics of the city. Structures commonly found in cities like fences, roads and buildings can act as physical barriers to flightless mammals 
(Gallo et al. 2017). The distribution of those mammalian species associated with green areas of the city is negatively correlated with anthropogenic infrastructures (Bonnington et al. 2014; Brzeziński et al. 2018). However, invasive mammals that live largely off the resources associated with human activity (e.g. compost and food waste) are positively correlated with the proportion of anthropogenic structures (Banks \& Smith 2015). The highly modified habitat and presence of pets in urban environments often lead to novel predator-prey dynamics (Haverland \& Veech 2017). Depending on the traits of the species, these novel predator-prey dynamics can influence their distribution positively or negatively (Muhly et al. 2011). For example, the abundance of mammalian nest predators is positively associated with the amount of urban development (Rodewald et al. 2011). The distribution of urban invasive mammals is also influenced by diverse social components of the cities. For example, the history, structure and organization of the human geography influence the distribution of black rats (Rattus rattus) in Senegal (Lucaccioni et al. 2016). Understanding the species- and city-specific processes involved in the distribution of invasive mammals is crucial for the implementation and design of efficient conservation management and monitoring programmes.

\section{Invasive mammals in urban New Zealand}

The perceptions of New Zealanders towards conservation in urban environments has changed over time. Despite a strong rural economy, New Zealand is a highly urbanised country. Over $87 \%$ of New Zealanders live in cities and towns with populations ranging from 10,000 to over one million (Department of Internal Affairs 2016). Over the last two decades, conservation in urban environments of New Zealand has gained recognition at a national, regional and local level (Department of Conservation and Ministry for the 
Environment 2000; Auckland Council 2012; Wellington City Council 2015). The control of invasive mammals is a major part of current management programmes and policies targeting biodiversity in cities.

Introduced mammals pose a major threat to native biodiversity in New Zealand. The biota of New Zealand has evolved, for over 80 million years, in the absence of native terrestrial mammals apart from bats (Lee et al. 2006). As a result of this unique evolution, a high proportion of New Zealand's endemic flora and fauna lacks adequate mechanisms to overcome the threats associated with most mammals (Diamond \& Veitch 1981).

Currently, introduced mammals threaten the composition and structure of all ecosystems in New Zealand (Goldson et al. 2015). The implementation of policies and management programmes aiming to minimise the socio-ecological impacts of these species represents a costly and long-term commitment for the country (Department of Conservation and Ministry for the Environment 2000; Goldson et al. 2015). To ensure such management programmes are cost-efficient and successful, further studies of introduced mammalian species in urban environments of New Zealand are needed (Norton et al. 2016; Russell et al. 2018).

While the ecology and impacts of mammalian species in non-urban environments of New Zealand have been extensively investigated, studies looking at the ecology of these species in urban New Zealand are limited. As an illustration of the limited number of studies, a literature search in May 2018 using the Web of Science Core Collection database for documents containing the words 'mammal invasive New Zealand', 'forest mammal invasive New Zealand' and 'urban mammal invasive New Zealand' returned 174, 71, and 5 publications, respectively. Most of the studies undertaken in urban 
environments in New Zealand until 2018 provide city-specific information about the ecology of a single mammalian species (van Heezik et al. 2010; Aguilar \& Farnworth 2012; Adams et al. 2013, 2014b; MacLeod et al. 2015; Kikillus et al. 2017). Some exceptions, however, are the mapping of stray domestic cats (Felis catus) at the national level (Aguilar et al. 2015), the estimation of relative abundance of possums (Trichosurus vulpecula) and rats (Rattus spp.) across an urban-rural gradient in the Auckland region (Ruffell et al. 2015), and the inventory of mammalian pests in Hamilton city (Morgan et al. 2009). 


\section{Thesis structure and objectives}

In this thesis, I investigate the use of citizen science and remote cameras to better understand the distribution of invasive mammals in urban environments. The thesis is structured into an introductory section, three main research chapters and a concluding discussion. Two of the three main chapters have been published (Chapter 0 and 1) as articles in peer-reviewed scientific journals and one (Chapter 4) will be submitted for publication.

In chapter 0 , I show how taking advantage of citizen science might help to lessen the time and effort required to classify remote camera data collected in urban environments. This chapter was published in January 2018 in the Journal of Urban Ecology (see Anton et al. 2018a). The co-authors of this article helped me build the citizen science website and analyse the data. They also provided helpful comments on earlier versions of the paper. In chapter 1 , I evaluate the use of remote cameras for monitoring multiple invasive mammals in residential and forested areas. A shorter version of this chapter was published in January 2018 in the New Zealand Journal of Ecology (see Anton et al. 2018b). The co-authors of this article helped me design the study and provided helpful comments on earlier versions of the paper. In chapter 4 , I identify the socio-ecological factors influencing the distribution of invasive mammals across a large gradient of urban patches of vegetation. The different chapters of my thesis showcase how citizen science and remote cameras can be used to further advance our current understanding of understudied topics in urban ecosystems. 


\title{
2. MONITORING THE MAMMALIAN FAUNA OF URBAN AREAS USING REMOTE CAMERAS AND CITIZEN SCIENCE
}

\begin{abstract}
$\underline{\text { Abstract }}$
Remotely activated cameras are increasingly used worldwide to investigate the distribution, abundance and behaviour of animals. The number of studies using remote cameras in urban ecosystems, however, is low compared to use in other ecosystems. Currently, the time and effort required to classify images is the main constraint of this monitoring technique. To determine whether, or not, citizen science might help overcome this constraint I investigated the engagement, accuracy and efficiency of citizen scientists providing crowd-sourced classifications of animal images recorded by remote cameras in Wellington, New Zealand. Classifications from individual citizen scientists were in $84.2 \%$ agreement with the classifications of professional ecologists. Aggregating the classifications from three citizen scientists per image, and excluding false triggers and unclassifiable classifications increased their overall accuracy to $97.6 \%$. Classifications by citizen scientists also improved if animal movement was highlighted in the images. The likelihood of citizen scientists correctly classifying images was influenced by their previous accuracy, their self-assessed confidence, and the species reported. Weighting the citizen scientist classifications based on their ability to correctly identify animals reduced from 3 to 2 the number of classifications required per sequence to classify $>95 \%$ of the photographs containing cats. Citizen science is an accurate and efficient approach for classifying remote camera data from urban areas where most of the animals are familiar to the participants. More importantly, I demonstrated how appropriate tools and accounting for the accuracy of citizen scientists, allows project managers to maximise the effort of citizen scientists while ensuring high quality data.
\end{abstract}


Keywords: camera traps, animal identification, public engagement, conservation volunteers. 


\section{$\underline{\text { Introduction }}$}

Remotely activated cameras are increasingly used worldwide to investigate behaviour, distribution, and abundance of an array of animals (Meek et al. 2014). The availability, efficiency and user-friendly characteristics of remote cameras have contributed to calls for the establishment of a global network for monitoring biodiversity (Steenweg et al. 2017). The number of ecological studies using remote cameras in urban areas, however, is low compared to use in other ecosystems. For example, a literature search in June 2017 using the Web of Science Core Collection database for documents published between 2010 and 2016 containing the words "Camera trap", "Camera trap forest" and "Camera trap urban" returned 2259, 713, and 45 publications, respectively.

The low number of urban studies using remote cameras is surprising given their potential to unravel critical ecological research questions. For example, remote cameras can assist urban ecologists to better understand the impact that invasive species have on native biodiversity, due to their ability to simultaneously monitor a wide range of animal species across multiple sites and over long periods of time (Elmqvist et al. 2013). Ecologists are already using remote cameras under a wide range of conditions including harsh physical environments and locations with limited accessibility (Steenweg et al. 2017). The versatility of this monitoring technique facilitates cross-ecosystem studies that could elucidate how pets, human disturbances, and other elements commonly found in urban environments influence community assemblies, predator-prey dynamics and animal behaviour (Faeth et al. 2005; Kikillus et al. 2017).

A potential constraint on the use of remote cameras, however, is the large number of images they can collect and the time and effort required to classify the species present 
in the images. Remote camera data often include poor quality images (e.g. blurry, pixelated, out of focus and over/underexposed pictures), images of animals camouflaged with the surrounding environment, and partial views of animals (Meek et al. 2014; Swanson et al. 2016). Using appropriate camera deployment, settings and models can minimise the number of poor quality images (Nazir et al. 2017). False triggers, cameras triggered by objects other than target animals, is another challenge that researchers face while classifying remote camera data (Welbourne et al. 2016). False triggers can rapidly increase the number of images requiring classification to the point of unmanageable levels (Swinnen et al. 2014). Despite the recent improvement in algorithms trained to automatically identify false triggers or the animals recorded in the photographs (Norouzzadeh et al. 2017), human validation is still required for collating data from remote cameras (Kumar et al. 2015; He et al. 2016).

Citizen science, involving the general public in scientific research, is increasingly used for classifying large amounts of footage or photographs provided by remote sensing devices (Chandler et al. 2017). Data quality, a major concern in citizen science, can be maximised if citizen scientists are provided with the appropriate tools to accomplish their task (Ellwood et al. 2017). For example, Horn et al. (2015) reported that the interface used for displaying photographs influenced the accuracy of citizen scientists to classifying common bird species found in North America. To ensure high quality data, the performance of citizen scientists is often compared to that of professionals (McShea et al. 2016; Kosmala et al. 2016). If there are differences between the two groups, managers can apply an array of tools to achieve similar results to those provided by professionals (Lewandowski \& Specht 2015; Kosmala et al. 2016). 
In remote camera studies, the number of citizen scientists required to accurately classify the data is influenced by the goals and resources of the project (Swanson et al. 2016). For example, remote camera studies of rare or elusive species may require higher accuracy levels than studies looking at the community composition. Independent of project-specific characteristics, agreement among citizen scientists is considered a versatile tool for increasing the accuracy of citizen scientists (Swanson et al. 2016). The effort of citizen scientists, however, might be maximised by taking into account metadata associated with the individual citizen scientists and their past classifications (Kosmala et al. 2016). For example, participation experience (Kelling et al. 2015), expertise (Pocock et al. 2015), age (Delaney et al. 2008) and how confident citizen scientists are with their prediction (Crall et al. 2011) have previously been linked with the ability of citizen scientists to correctly identify animal species in similar projects. Due to the lower suite of mammalian species compared to urban ecosystems elsewhere (Baker \& Harris 2007; Morgan et al. 2009; Widdows et al. 2015), remote camera data collected in urban New Zealand is well suited to investigate algorithms for citizen scientists to reach the same levels of classification accuracy as professionals.

To determine whether, or not, citizen science can overcome the time and effort required to classify remote camera data from urban areas, I investigated the engagement, accuracy and efficiency of citizen scientists classifying remote camera data collected in Wellington, New Zealand. 


\section{Methods}

\section{Data collection}

I used 4,466 sequences of still photographs from remote cameras deployed at forested areas and private backyards in Wellington, New Zealand. Remote cameras (Bushnell 119537) were deployed for three months in 2014 and captured a sequence of three photographs per trigger over a two-second period (henceforth a set of three images equals one sequence).

I uploaded all the sequences to a citizen science website (www.identifyanimals.co.nz) open to any member of the public. I promoted the website via local newspapers, social media and school visits. Upon arriving at the website, participants were required to create an account (username and password) before they could start classifying sequences. Participants also needed to report their age (years) and self-assess their knowledge of invasive mammals in New Zealand as poor, basic, good or excellent. Once registered, citizen scientists were able to classify the sequences into one of 15 categories available and report how confident they were with each classification (unsure, reasonable or very confident) (Figure 2.1). Citizen scientists were also able to use a comment box on each sequence to classify the animal further (e.g. to the species level) or to report any concerns. The website included a tutorial page and a classification guide with "how-to-use" instructions, but citizen scientists were not required to complete any training before starting to classify the sequences. 


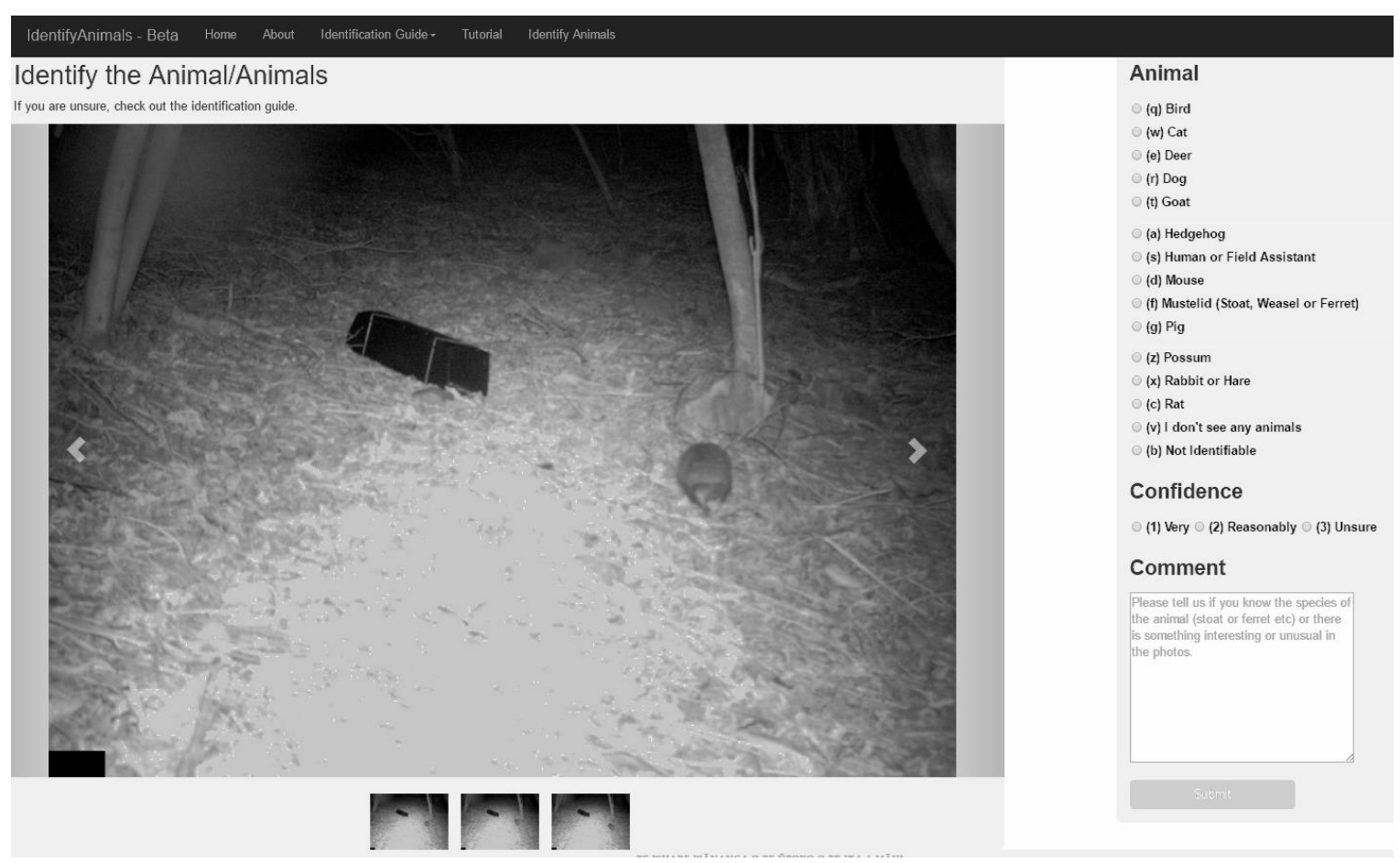

Figure 2.1 Snapshot of the website's interface used to classify the events. Citizen scientists could enlarge any of the three photographs (bottom of the screen) of each event. Citizen scientists needed to select one category and their confidence level (right hand side of the screen) before submitting their classification. Citizen scientists were also able to classify the animal to the species level or report any anomaly using the comment box.

To estimate the accuracy and efficiency of citizen scientists, all sequences were classified by at least three citizen scientists, and by at least two different experts (i.e., professionals with formal qualifications in the field of ecology). If there was disagreement among expert classifications, I classified the sequence.

For 1,671 randomly selected sequences I also provided a fourth image in which areas of change between the three original images were highlighted in purple in order to draw attention to potential animal movement in the sequence (Appendix 2.1). This was achieved using the functions "ImageChops.difference" and "Image.blend", from the 
Python image library. I then compared the classification accuracy of users for sequences with and without the fourth image of highlighted movement.

\section{Data analysis}

I did all statistical analyses in R version 3.1.2 (R Core Team 2016). To simplify the interpretation of the results, I excluded two of the 4,466 sequences from the accuracy and efficiency analyses because, based on the comments provided by experts and citizen scientists, these sequences contained two different animals (i.e., hedgehogs and cats) and the user interface only allowed one option to be chosen.

\section{Engagement of citizen scientists}

To study how the age and self-assessed ecological knowledge of the citizen scientists influenced engagement with the project I fitted a generalised linear model (GLM). Engagement, the response variable, was measured as the total number of classifications provided by each citizen scientist. The explanatory variables were age and self-assessed ecological knowledge of the citizen scientist. I considered variables with $P$ values $<0.05$ as significantly correlated with the number of classifications provided by each citizen scientist.

\section{Accuracy of citizen scientists}

I randomly selected three citizen scientist classifications per sequence and estimated the accuracy of individual citizen scientists and of their aggregated classifications. To estimate the accuracy of individual citizen scientists I compared each classification to those provided by experts, and calculated the true positive rate (TPR or sensitivity) and 
positive predictive value (PPV) (Table 2.1). To estimate the accuracy of the aggregated classifications of citizen scientists I identified the aggregated classification for each sequence based on the category with the highest number of citizen scientist classifications. If all three classifications were different, I randomly selected one of them as their aggregated classification. I considered a classification being "correct" if the aggregated classification provided by citizen scientists agreed with the classification provided by experts.

Table 2.1 Confusion matrix of the citizen scientist and expert classifications used to calculate the sensitivity and positive predictive value of citizen scientists for category $i$ (e.g., $i=$ deer, pig, $\operatorname{dog}$....). Sensitivity (or true positive rate, TPR) was calculated as: $a /(a+c)$. Positive predictive value (PPV) was calculated as: $a /(a+b)$.

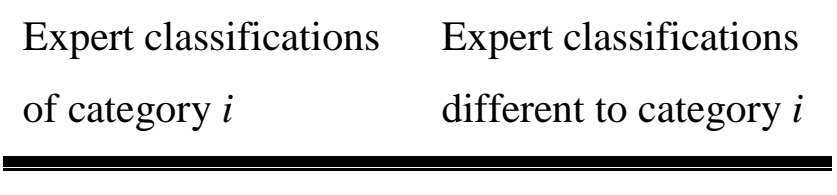

Citizen scientist classifications of category $i$

Citizen scientist classifications different to category $i$ $a \quad b$

\section{$b$}

$c \quad d$

I tested whether, or not, highlighting areas of movement across the three images of 1,672 sequences influenced the ability of citizen scientists to make correct classifications. I randomly selected three citizen science classifications per sequence and per treatment (with and without the movement highlighted) and used Fisher's exact tests to evaluate statistical differences in the number of correct vs incorrect individual citizen scientist classifications between treatments. 
I used generalised linear mixed models (GLMM) to investigate what metadata best predicts the likelihood of a citizen scientist making a correct classification. I ran the models using two-thirds of the sequences uploaded to the website $(n=2,978)$. I used the complementary one-third of sequences to validate the efficiency of these models, as explained later. The response variable of the model was the accuracy of the classification provided by an individual citizen scientist (correct vs incorrect), for which I used the binomial family with log link. The explanatory variables of the model were: age of the citizen scientists, their knowledge of New Zealand invasive mammals, the confidence level they reported for the classification, previous accuracy (positive predictive value), and number of classifications submitted by each citizen scientist. I estimated the previous accuracy of citizen scientists to classify each taxon category because the animals recorded in the photographs influence the ability of citizen scientists to correctly classify them (McShea et al. 2016). I calculated the previous accuracy of a citizen scientist per category for those categories (species) in which the citizen scientist had classified at least two previous sequences. For those citizen scientists that had not classified at least two sequences of that category, I used the average accuracy that all citizen scientists had in classifying that category (species). To improve numerical stability, I subtracted the mean of the variables age, previous accuracy and number of sequences classified per participant and divided them by their corresponding standard deviation (Gelman \& Hill 2007). After running a Tukey's Honest Significant Difference, I simplified the variable ecological knowledge into "poor or basic", "good" and "excellent" due to the lack of significant differences $(P>0.05)$ between citizen scientists with poor or basic ecological knowledge and their accuracy. I also used the category reported by the citizen scientists 
as a random effect because the ability of citizen scientists to correctly classify remote camera data is species-specific (McShea et al. 2016). I determined the best model to predict the likelihood of a citizen scientist being correct using an information-theoretic approach to avoid over-fitting and to acknowledge uncertainty in model specification (Burnham \& Anderson 2002). I generated all possible models $(n=16)$ and ranked them based on the Akaike's Information Criteria (AIC). I then averaged the models within 4 AIC of the "best" model, using the MULMN package, to determine a parsimonious metamodel with the best overall support from the data (Arnold 2010; Barton 2015). I determined the influence of each variable for predicting the likelihood of a citizen scientist being correct based on the parameter estimates and standard errors of the averaged model. I used the marginal and conditional $\mathrm{R}^{2}$ (Nakagawa \& Schielzeth 2013) to estimate goodness of fit of the meta-model.

\section{Efficiency of citizen scientists}

I determined whether weighting the classifications, based on metadata associated with the accuracy of citizen scientists, influenced the number of citizen scientists required to correctly classify sequences containing invasive mammals commonly found in urban areas of New Zealand. Following Morgan et al. (2009), I considered the following species as common mammalian species of New Zealand urban areas: possums (Trichosurus vulpecula), cats (Felis catus), mustelids (Mustela spp.), hedgehogs (Erinaceus europaeus), rats (Rattus spp.) and mice (Mus musculus). Based on expert classifications I selected one-third of the sequences containing these invasive species to validate whether weighting the classifications had an effect on the sensitivity (TPR) of citizen scientists' classifications. 
I weighted the classifications provided by citizen scientists based on the likelihood that each citizen scientists had of being correct, as predicted by the averaged GLMM, using the predict function from the 'lme4' package (Bates et al. 2014b). I, then, calculated the most likely classification based on the predicted accuracy of each citizen scientist. For example, if three citizen scientists provided classifications ("cat", "cat" and "possum") with modelled individual accuracies of 60, 60 and 90\% respectively, possum was selected as the aggregated classification because the likelihood of getting this set of classifications if the image contained a possum $\left(0.4^{*} 0.4^{*} 0.9\right)$ was greater than the likelihood of getting these classifications if the image contained a cat $(0.6 * 0.6 * 0.1)$. I used Fisher's exact tests to compare the proportion of sequences correctly classified by citizen scientists based on two and three weighted and unweighted classifications. 


\section{$\underline{\text { Results }}$}

\section{Engagement of citizen scientists}

A total of 504 citizen scientists submitted 24,956 classifications over the seven months that my website was active. The classifications submitted by the top ten contributors represented $34.5 \%$ of the total classifications received (Appendix 2.2). The number of classifications that citizen scientists submitted was significantly correlated with their age $(P<0.001)$ but not with their self-assessed knowledge of invasive mammals (Table 2.2). Citizen scientists between 35 - 55 years old provided more classifications than younger or older volunteers (Figure 2.2). Despite the statistical significance of age, the model explained little of the variation in the number of classifications provided per citizen science $\left(R^{2}=0.14\right)$.

Table 2.2 Results of the GLM predicting number of classifications provided per citizen scientist based on their age and ecological knowledge (poor/basic, good or excellent). $P$ values $<0.01$ are represented as $* * *$. The marginal $\mathrm{R}^{2}$ of the model was 0.14 .

\begin{tabular}{lll} 
Variable & $\hat{\beta} \pm \mathrm{SE}$ & $P$ value \\
\hline \hline Intercept & $2.42 \pm 0.61$ & $<0.01 * * *$ \\
Age & $0.03 \pm 0.01$ & $<0.01 * * *$ \\
Ecological knowledge (poor/basic) & $0.21 \pm 0.61$ & 0.74 \\
Ecological knowledge (good) & $0.21 \pm 0.60$ & 0.72 \\
& & 0.18
\end{tabular}



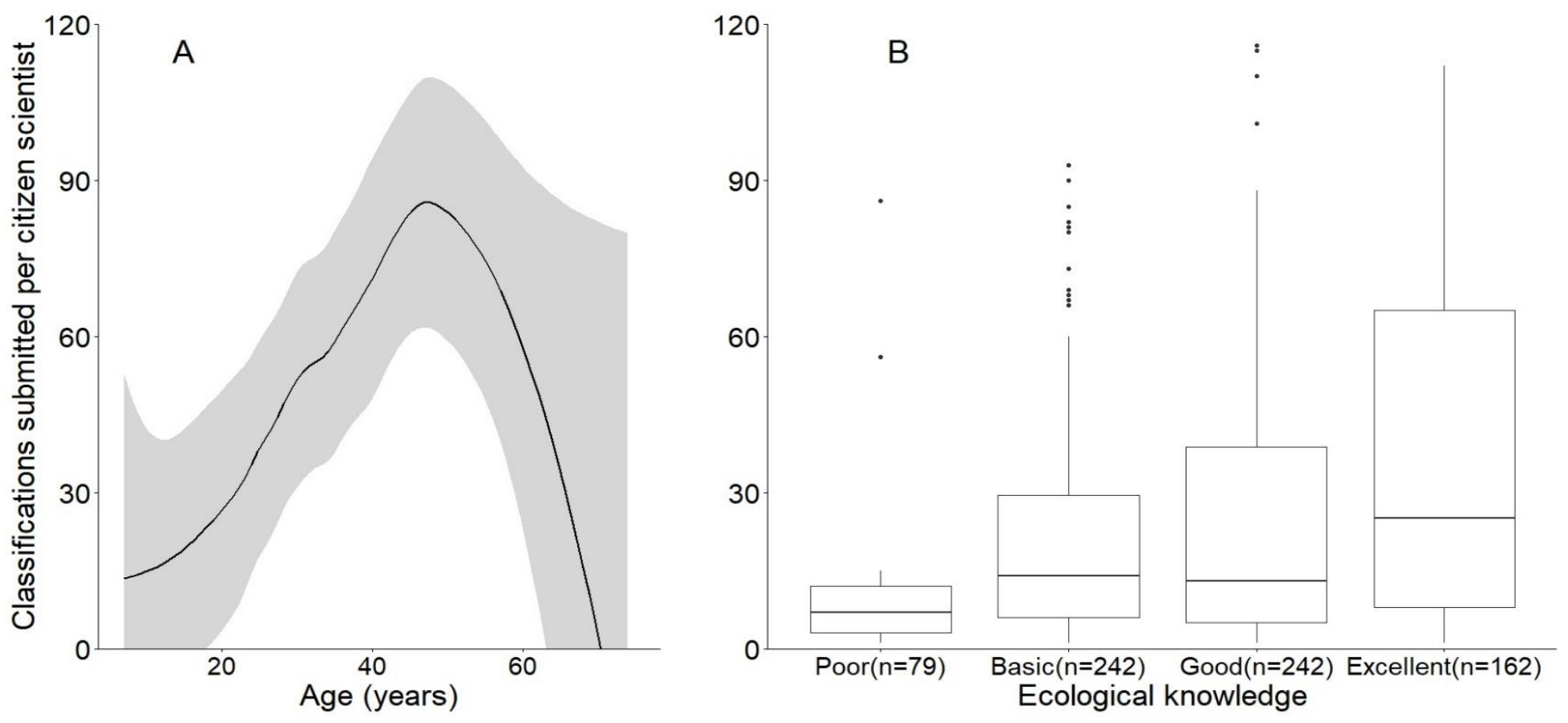

Figure 2.2 Engagement of citizen scientists according to a) their age and b) ecological knowledge. Engagement of citizen scientists is represented as the number of classifications submitted per citizen scientist. The loess method was used to estimate the mean number of classifications submitted per citizen scientist and the corresponding 95\% confidence intervals. Previous knowledge of New Zealand invasive mammals was used to represent the influence that ecological knowledge of citizen scientists had in the number of classifications submitted. Boxes in the boxplots plots represent the median and interquartile ranges. 


\section{Accuracy of citizen scientists}

Classifications from individual citizen scientists were in $84.2 \%$ agreement with the classifications provided by experts. The accuracy of individual citizen scientists was influenced by the animal recorded in the photographs (Figure 2.3); for example, citizen scientists correctly classified $>90 \%$ of the sequences containing deer or cats but $<70 \%$ of the sequences containing mustelids or mice. Citizen scientists often misclassified, as false triggers, sequences that experts were unable to classify and those containing birds (48.4\% and $14.4 \%$, respectively) (Table 2.3). Excluding the false triggers and unclassifiable classifications, individual citizen scientists were in $97.0 \%$ agreement with the classifications provided by experts.

The aggregated classification of citizen scientists increased the number of images correctly classified. For example, the aggregated classification of three citizen scientists was in $87.8 \%$ agreement with the classification of experts, $3.6 \%$ more than the classifications of individual citizen scientists. Excluding false triggers and unclassifiable sequences, the aggregated classifications of citizen scientists were in $97.6 \%$ agreement with the classification of experts.

The number of citizen scientists that used the comment box to classify the animal to species level was influenced by the animal recorded in the photograph. The proportion of citizen scientists that classified lagomorphs, mustelids, birds, and rats to the species level were $9.4 \%, 18.7 \%, 17.6 \%$, and $3.7 \%$, respectively (Appendix 2.23). 


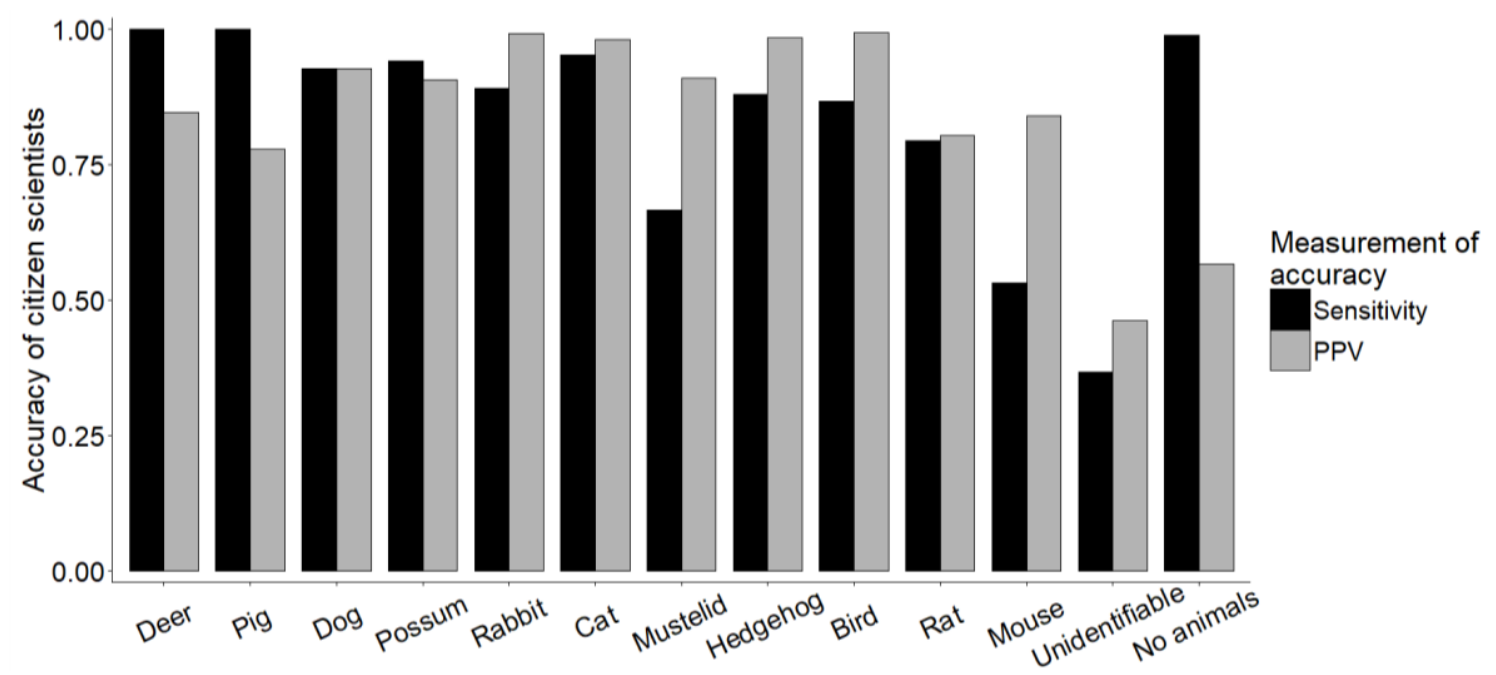

Figure 2.3 Performance of citizen scientists in classifying remote camera data collected from Wellington, New Zealand into thirteen different categories. Performance was based on the comparison (sensitivity and positive predictive value) between the aggregated classifications of three citizen scientists and at least two experts per event. Sensitivity is the proportion of events classified by experts as category " $i$ " that were correctly classified by citizen scientists, positive predictive value (PPV) is the proportion of events classified by citizen scientists as category " $i$ " that were correctly classified (see Table 2.1). Taxa are ordered according to average body size, from largest to smallest. 
Table 2.3 Confusion matrix of the classifications provided by experts (columns) compared to those provided by individual citizen scientists (rows) for sequences without movement highlighted. Number of sequences per category is reported under the classifications provided by experts. The intensity of the shaded background corresponds with the number of sequences.

\begin{tabular}{|c|c|c|c|c|c|c|c|c|c|c|c|c|c|c|c|c|}
\hline & & \multicolumn{15}{|c|}{ Classifications provided by experts } \\
\hline & & $\begin{array}{l}\text { Human } \\
\mathrm{n}=0\end{array}$ & $\begin{array}{l}\text { Deer } \\
n=7\end{array}$ & $\begin{array}{l}\text { Goat } \\
n=0\end{array}$ & $\begin{array}{l}\text { Pig } \\
n=3\end{array}$ & $\begin{array}{l}\text { Dog } \\
n=21\end{array}$ & $\begin{array}{l}\text { Poss } \\
n=146\end{array}$ & $\begin{array}{l}\text { Rabbit } \\
\mathrm{n}=356\end{array}$ & $\begin{array}{l}\text { Cat } \\
n=965\end{array}$ & $\begin{array}{l}\text { Must } \\
\mathrm{n}=35\end{array}$ & $\begin{array}{l}\text { Hedg } \\
\mathrm{n}=459\end{array}$ & $\begin{array}{l}\text { Bird } \\
n=1575\end{array}$ & $\begin{array}{l}\text { Rat } \\
n=94\end{array}$ & $\begin{array}{l}\text { Mouse } \\
\mathrm{n}=105\end{array}$ & $\begin{array}{l}\text { Unid } \\
\mathrm{n}=156\end{array}$ & $\begin{array}{l}\text { No ani } \\
\mathrm{n}=542\end{array}$ \\
\hline \multirow{15}{*}{$\begin{array}{l}\text { Classifications } \\
\text { provided by } \\
\text { citizen } \\
\text { scientists }\end{array}$} & Human & 0 & 0 & 0 & 0 & 0 & 1 & 0 & 1 & 0 & 0 & 1 & 0 & 0 & 2 & 1 \\
\hline & Deer & 0 & 23 & 0 & 0 & 1 & 0 & 0 & 1 & 0 & 0 & 1 & 0 & 0 & 3 & 0 \\
\hline & Goat & 0 & 1 & 0 & 0 & 0 & 0 & 1 & 3 & 0 & 1 & 2 & 0 & 0 & 0 & 0 \\
\hline & Pig & 0 & 0 & 0 & 19 & 1 & 0 & 1 & 4 & 0 & 0 & 1 & 0 & 0 & 1 & 1 \\
\hline & Dog & 0 & 0 & 0 & 0 & 75 & 0 & 0 & 8 & 0 & 0 & 0 & 0 & 0 & 3 & 0 \\
\hline & Possum & 0 & 0 & 0 & 0 & 0 & 589 & 7 & 61 & 0 & 8 & 2 & 3 & 0 & 4 & 1 \\
\hline & Rabbit & 0 & 0 & 0 & 0 & 0 & 3 & 1325 & 4 & 0 & 7 & 5 & 1 & 0 & 17 & 1 \\
\hline & Cat & 0 & 0 & 0 & 0 & 7 & 17 & 2 & 3716 & 1 & 3 & 15 & 1 & 0 & 44 & 4 \\
\hline & Mustelid & 0 & 0 & 0 & 0 & 0 & 3 & 4 & 6 & 95 & 5 & 7 & 13 & 1 & 8 & 1 \\
\hline & Hedgehog & 0 & 0 & 0 & 0 & 0 & 0 & 12 & 0 & 1 & 1657 & 6 & 5 & 2 & 13 & 2 \\
\hline & Bird & 0 & 0 & 0 & 0 & 0 & 1 & 8 & 6 & 0 & 5 & 5514 & 1 & 1 & 13 & 14 \\
\hline & Rat & 0 & 0 & 0 & 0 & 0 & 0 & 5 & 1 & 12 & 63 & 20 & 288 & 22 & 6 & 0 \\
\hline & Mouse & 0 & 0 & 0 & 0 & 0 & 0 & 4 & 1 & 10 & 2 & 6 & 29 & 218 & 3 & 3 \\
\hline & Unidentifiable & 0 & 0 & 0 & 0 & 1 & 20 & 68 & 98 & 13 & 89 & 158 & 16 & 18 & 262 & 83 \\
\hline & No animals & 0 & 0 & 0 & 0 & 1 & 16 & 128 & 115 & 31 & 163 & 965 & 47 & 161 & 355 & 2099 \\
\hline
\end{tabular}


Highlighting areas of movement in the photographs had a positive effect on the ability of citizen scientists to correctly classify sequences. The sensitivity of the aggregated classification of three citizen scientists was $7.8 \pm 0.6 \%$ (mean $\pm \mathrm{SE}$ ) greater for those sequences with the movement highlighted compared to sequences without the movement highlighted. In particular, highlighting areas of movement significantly improved identification of hedgehogs, birds, mice, and false triggers (Figure 2.4).

The classification accuracy of individual citizen scientists can be predicted by their self-declared confidence with the classification, and their previous accuracy. Based on the meta-model used to predict the likelihood of being correct, citizen scientists that were "reasonably confident" and "very confident" with their classification were $12.9 \pm$ $1.8 \%$ and $36.9 \pm 1.5 \%$ more likely $(P<0.05)$ of being correct compared to those unsure with their classifications (Table 2.4). Citizen scientists were also more likely to correctly classify a sequence $(P<0.05)$ if they had been accurate in classifying other sequences of the same category previously. Previous accuracy and the likelihood of a citizen scientist being correct followed a linear relationship (Figure 2.5). 


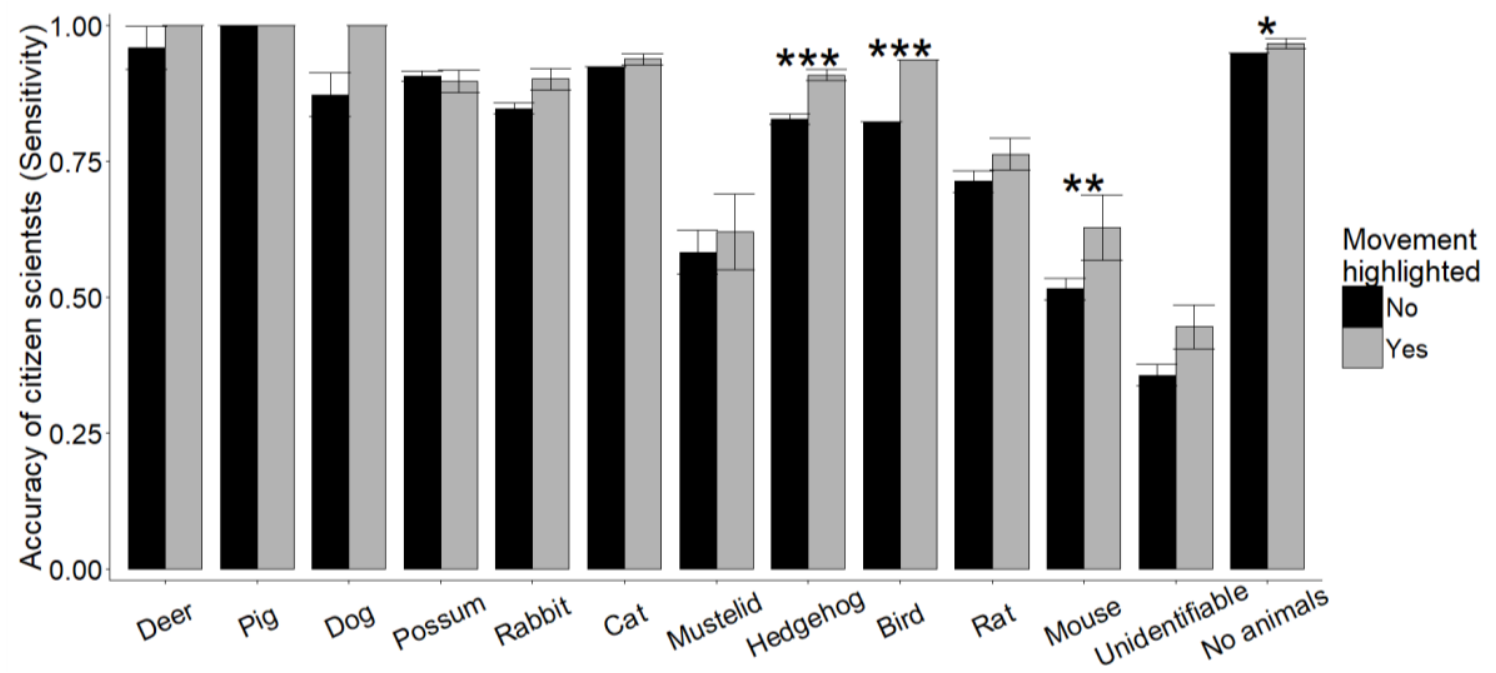

Figure 2.4 Comparison between the accuracy of citizen scientists to correctly classify events, with and without the movement highlighted, into thirteen categories. Accuracy (sensitivity) was based on the comparison between the aggregated classifications of three citizen scientists and at least two experts per event. The events were collected using remote cameras from Wellington, New Zealand. Error bars represent standard errors; significant differences in the accuracy between events with and without movement highlighted are represented as $* * *$ and $* * *(P<0.05,<0.01$ and $<0.001$, respectively $)$. 
Table 2.4 Output of the meta-model used to predict the likelihood that citizen scientists had of correctly classifying a sequence (marginal $\mathrm{R}^{2}=0.14$ and conditional $\mathrm{R}^{2}=0.42$ ). The most parsimonious models were estimated by averaging the models with the lowest AIC ( $\triangle 4$ AIC). The fixed effects of the model were: age, confidence level (unsure, reasonable or very confident), ecological knowledge (poor \& basic, good or excellent) and previous accuracy of the citizen scientists. The category reported by the citizen scientist (e.g. cat, rat or mouse) was treated as a random effect. $P$ values $<0.01$ are represented with $* * *$.

\begin{tabular}{lll} 
Model term & $\hat{\beta} \pm \mathrm{SE}$ & $P$ value \\
\hline \hline Intercept & $0.33 \pm 0.35$ & 0.35 \\
Age (years) & $0.00 \pm 0.02$ & 0.97 \\
Ecological knowledge (good) & $0.07 \pm 0.08$ & 0.38 \\
Ecological knowledge (excellent) & $0.12 \pm 0.11$ & 0.30 \\
Confidence level (reasonable) & $1.35 \pm 0.11$ & $<0.01^{* * *}$ \\
Confidence level (very confident) & $2.09 \pm 0.12$ & $<0.01^{* * *}$ \\
Previous accuracy (\%) & $0.50 \pm 0.05$ & $<0.01^{* * *}$ \\
Number of classifications & $0.00 \pm 0.02$ & 0.88
\end{tabular}



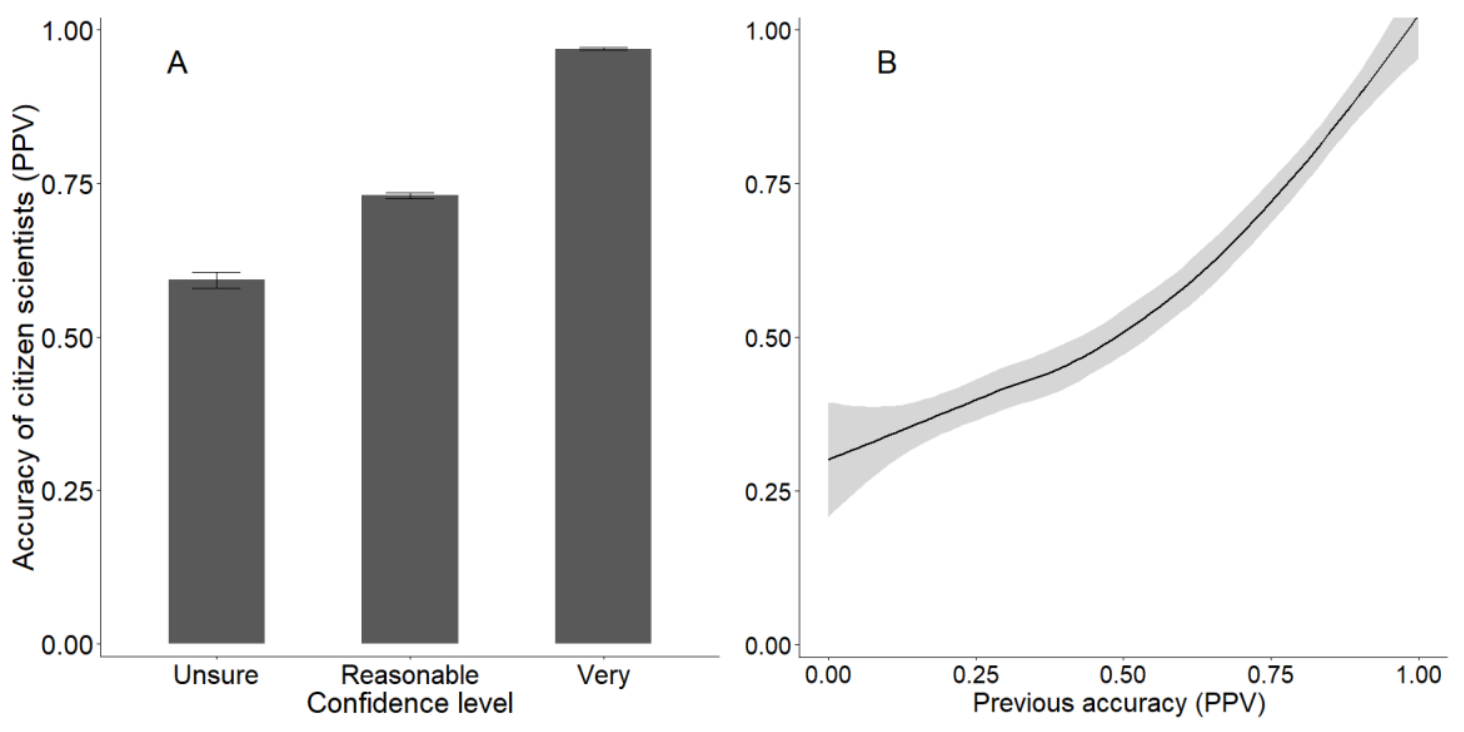

Figure 2.5 Accuracy of citizen scientists classifying remote camera data based on a) the level of confidence they reported for each classifications and b) their previous accuracy. Accuracy (positive predictive value) was based on the proportion of events in which the citizen scientist classification matched the classification of experts. Mean accuracy and standard errors are represented for different levels of confidence citizen scientists had with their classification. The loess method was used to estimate the positive predictive value of citizen scientists in relation to their previous accuracy. The line represents the loess curve and the shaded background the $95 \%$ confidence intervals. 


\section{Efficiency of citizen scientists}

The number of citizen scientists required to correctly classify remote camera data was influenced by the desired levels of accuracy and by the species of interest. For example, one citizen scientist per sequence was sufficient to correctly classify $>90 \%$ of the sequences containing images of possums or cats (Table 2.5).

Weighting the citizen scientist classifications based on their previous accuracy and self-assessed confidence levels did not statistically increase the accuracy of classifying common invasive mammals of New Zealand urban areas. However, the classification accuracy for these species never decreased after weighting classifications. Furthermore, depending on the desired accuracy levels, weighting the classifications reduced the number of citizen scientists required per sequence. For example, weighting the citizen scientist classifications reduced from 3 to 2 the number of classifications required per sequence to classify $>95 \%$ of the photographs containing cats. 
Table 2.5 Number of sequences containing common mammalian introduced predators of New Zealand and the proportion of sequences correctly classified by one, two, and three citizen scientists based on weighted and unweighted classifications.

Classifications were weighted based on the animal citizen scientists reported, their level of confidence and their previous accuracy.

Proportions in bold indicate an increase in the accuracy of citizen scientists after weighting their classifications.

\begin{tabular}{|c|c|c|c|c|c|c|}
\hline Animal & Sequences & $\begin{array}{l}\text { One citizen } \\
\text { scientist }\end{array}$ & $\begin{array}{l}\text { Two citizen } \\
\text { scientists }\end{array}$ & $\begin{array}{l}\text { Two citizen scientists } \\
\text { with model weighting }\end{array}$ & $\begin{array}{c}\text { Three citizen } \\
\text { scientists }\end{array}$ & $\begin{array}{l}\text { Three citizen scientists } \\
\text { with model weighting }\end{array}$ \\
\hline
\end{tabular}

$\begin{array}{llllll}\text { Possum } & 49 & 93.9 \% & 91.8 \% & 91.8 \% & 93.9 \%\end{array}$

y Cat

$\begin{array}{lll}\text { Cat } & 322 & 92.2 \%\end{array}$

\begin{tabular}{|c|c|c|c|c|c|c|}
\hline Mustelid & 12 & $75.0 \%$ & $66.6 \%$ & $75.0 \%$ & $75.0 \%$ & $75.0 \%$ \\
\hline Hedgehog & 153 & $83.7 \%$ & $85.0 \%$ & $88.9 \%$ & $88.9 \%$ & $91.5 \%$ \\
\hline Rat & 32 & $75.0 \%$ & $81.3 \%$ & $81.3 \%$ & $84.4 \%$ & $87.5 \%$ \\
\hline Mouse & 35 & $54.3 \%$ & $57.1 \%$ & $68.6 \%$ & $54.3 \%$ & $77.1 \%$ \\
\hline
\end{tabular}




\section{$\underline{\text { Discussion and conclusion }}$}

\section{Engagement of citizen scientists}

Citizen science is an important tool to increase nature awareness in urban environments (Wei et al. 2016). Online citizen science projects provide an easy-to-access opportunity to engage large segments of the general public in scientific research (Kosmala et al. 2016). Involving large numbers of people in citizen science projects thus requires understanding their motivations for participation as well as level of engagement (Singh et al. 2014). In my study, citizen scientists differed widely in their level of engagement; most volunteers classified less than 10 sequences while a few individuals $(n=3)$ classified over 1,000 sequences. These results are consistent with previous studies showing that a small number of citizen scientists often provide the majority of contributions (Laut et al. 2017).

In my study, professionals aged 35-55 years old were most engaged with the project website. Age of these highly-engaged citizen scientists was lower than the average age of participants commonly involved in conservation and restoration activities (e.g., planting, weeding or wildlife monitoring) (Peters et al. 2015). This may suggest that modern technologies can be used effectively to engage with demographic groups that are usually underrepresented in conservation activities.

There are numerous characteristics involved in the level of engagement of participants in online citizen science projects. For example, the relationship of participants with researchers, the friendliness of the web interface, the diversity in the experience of citizen scientists with the project and their level of education (Laut et al. 2017). Due to privacy issues and technological limitations, I was only able to collect information related to the age of the participants and their previous knowledge of 
invasive mammals in New Zealand. This limited number of variables might have influenced the low variance reported in my models. Further investigations looking at the motivations for volunteers to become citizen scientists and to cease their engagement with the project are required to improve and homogenise participation (Lewandowski \& Specht 2015; Laut et al. 2017).

\section{Accuracy of citizen scientists}

The aggregated classifications from three citizen scientists were in $87.8 \%$ agreement with the classification of experts. This accuracy was greater than that reported in similar projects (e.g., Kosmala et al. 2016, McShea et al. 2016). The relatively low number of categories in my project can explain the increased accuracy. Specifically, I enabled citizen scientists to classify sequences into 15 different categories, substantially less than the 48 and 22 categories to choose from in remote camera studies by Swanson et al. (2016) and McShea et al. (2016), respectively. While this meant that some animals in my study were not classified at the species level, the ecological benefits of more detailed classifications were likely low compared to benefits of not overwhelming citizen scientists with demands for knowledge usually limited to experts which could risk reducing their engagement. The low variance explained by the accuracy models used in this study highlights the need to investigate how the characteristics related to the quality of the photo can influence the accuracy of citizen scientists (Swanson et al. 2016).

The high overall accuracy found in my study can also have been influenced by the familiarity citizen scientists had with the animals recorded. The fauna found in urban environments in New Zealand is relatively species-poor, particularly in mammals (Morgan et al. 2009). However, a limited number of "urban-adaptable" species have 
become widespread and locally abundant in cities all over the world, a common phenomenon known as biotic homogenisation (McKinney 2006). My results thus highlight that involving citizen scientists in remote camera studies might be particularly suitable for urban environments because the general public is often familiar with most of the animals found in urban areas.

\section{Efficiency of citizen scientists}

Studies based on remote camera data should try to engage as many citizen scientists as possible because increased participation is linked to improved accuracy classifying images (Swanson et al. 2016). To make best use of volunteer efforts, project managers need to define the minimum number of citizen scientists required to achieve desired accuracy levels. Consistent with McShea et al. (2016) and Swanson et al. (2016), my results highlight that the number of citizen scientists required per sequence is category specific. I also showed how self-assessed confidence and previous accuracy can be used to reduce the number of classifications required without compromising data quality (Table 2.5). Weighting classifications of citizen scientists based on their ability to correctly identify animals can be particularly beneficial to increase volunteer efficiency for studies of complex ecological systems or species that are often misclassified by the general public (He et al. 2016). However, experts might be required to classify categories that, independent of the number of citizen scientist classifications received, do not reach desired levels of accuracy.

Remote cameras are a relatively novel technology for monitoring wildlife in urban environments. Remote cameras have great potential to further our understanding of topical research, including invasive species, human-wildlife conflicts (Murray et al. 2016; 
Kahle et al. 2016), animal behaviour (Widdows et al. 2015), and trophic dynamics (Inger et al. 2016) in cities. Improvements in the capabilities of the cameras (Hobbs \& Brehme 2017) and gradual decrease in equipment costs (Nazir et al. 2017) will continue to facilitate the use of remote cameras to better understand relationships between fauna, people, and the urban landscape. The main constraint is still the time and effort required to classify the camera data. In my study, I highlighted how citizen scientists can efficiently classify most of this data at similar accuracy levels as professionals. Classifications provided by professionals are commonly accepted as the "ultimate truth" in research involving remote cameras (Swanson et al. 2016). However, further studies looking at the identification skills of the professionals are required to elucidate any potential source of bias (i.e. blind trials where professionals classify photographs of animals that have been previously identified at the species level). Urban ecologists should also take into consideration other project-specific characteristics (e.g. vandalism, privacy issues (Chapter 3), study design, and camera specifications) before using remote cameras in urban environments (O’Connor et al. 2017).

In conclusion, involving citizen scientists with the use of remote cameras can facilitate a wider use of this technology, including in urban areas, while simultaneously improving knowledge of participants about wildlife (e.g., Forrester et al. 2017). To maximise the efficiency of volunteer' efforts while ensuring high quality data, project managers need to account for the accuracy of citizen scientists and provide them with appropriate tools that facilitate data classification. Used in this way, citizen scientists can provide invaluable help classifying the large amount of data collected by camera studies. 


\section{$\underline{\text { Acknowledgements }}$}

I thank all 504 citizen scientists for their help classifying my camera data and Jason Preble, Johannes Fischer, and Amy Brasch for comments on an earlier version of this manuscript. Funding for this project was provided by Victoria University of Wellington, the Centre for Biodiversity and Restoration Ecology (CBRE), and Wellington City Council. I am grateful for a tuition scholarship from Victoria University of Wellington. I appreciate comments from 2 anonymous reviewers that greatly improved the article version of this chapter. 


\section{$\underline{\text { Appendix }}$}

Appendix 2.1 Example of a sequence of photographs with the movement highlighted. I used the "ImageChops.difference" and "Image.blend" functions from the Python Image library for generating the photograph at the bottom right with the movement highlighted in purple.

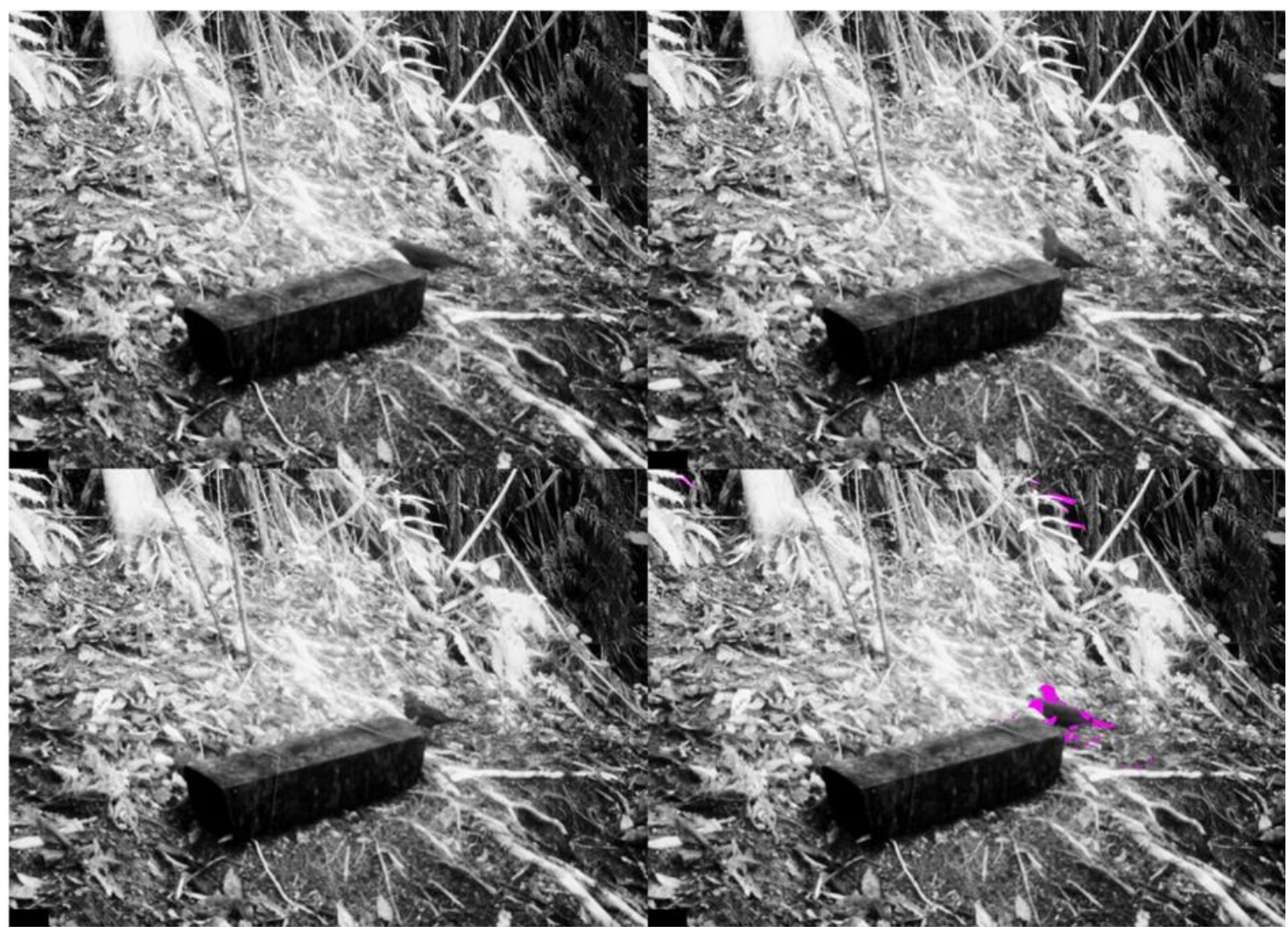


Appendix 2.2 Number of citizen scientists registered in the website according to their age.

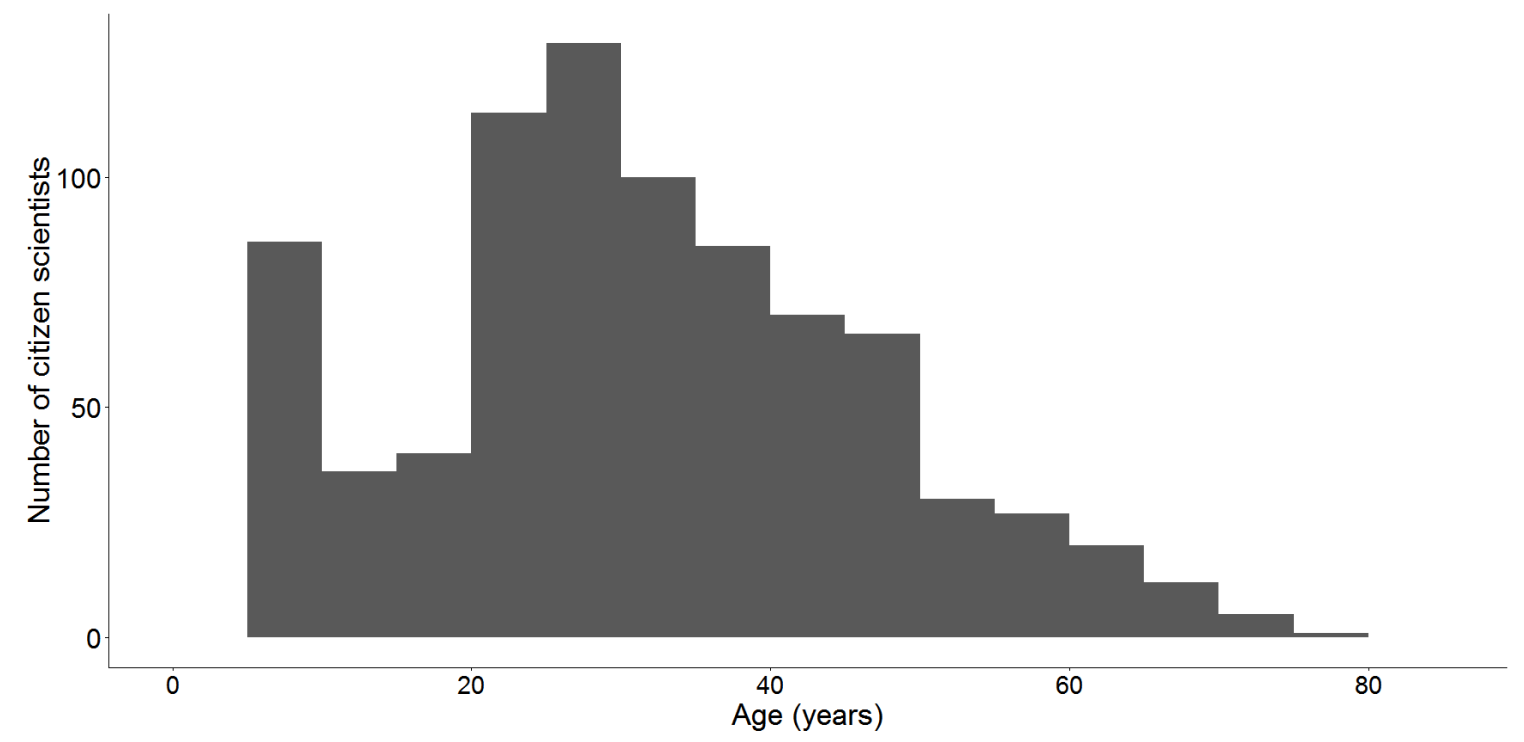


Appendix 2.3 Number of classifications provided by citizen scientists that used the comment box to identify lagomorphs, mustelids, birds and rats to the species level. Citizen scientist classifications were compared to expert classifications to estimate the accuracy (positive predicted value *100) of citizen scientists. Standard errors of the positive predicted value are provided for species that received $>2$ classifications.

\begin{tabular}{|c|c|c|c|c|}
\hline Category & $n$ & Species & $n$ & Accuracy $(\%) \pm \mathrm{SE}$ \\
\hline \multirow[t]{2}{*}{ Lagomorphs } & \multirow[t]{2}{*}{1621} & $\begin{array}{l}\text { European rabbit } \\
\text { (Oryctolagus cuniculus) }\end{array}$ & 131 & $69.5 \pm 4.0$ \\
\hline & & $\begin{array}{l}\text { Brown hare } \\
\text { (Lepus europaeus) }\end{array}$ & 22 & $81.8 \pm 8.4$ \\
\hline \multirow[t]{2}{*}{ Mustelids } & \multirow[t]{2}{*}{187} & $\begin{array}{l}\text { Stoat } \\
\text { (Mustela erminea) }\end{array}$ & 30 & $86.7 \pm 6.3$ \\
\hline & & $\begin{array}{l}\text { Weasel } \\
\text { (Mustela nivalis) }\end{array}$ & 5 & $0.0 \pm 0.0$ \\
\hline \multirow[t]{14}{*}{ Birds } & \multirow[t]{14}{*}{8065} & $\begin{array}{l}\text { Eurasian blackbird } \\
\text { (Turdus merula) }\end{array}$ & 1243 & $99.2 \pm 0.3$ \\
\hline & & $\begin{array}{l}\text { Common chaffinch } \\
\text { (Fringilla coelebs) }\end{array}$ & 13 & $100.0 \pm 0.0$ \\
\hline & & $\begin{array}{l}\text { Dunnock } \\
\text { (Prunella modularis) }\end{array}$ & 12 & $75.0 \pm 13.1$ \\
\hline & & $\begin{array}{l}\text { Swamp harrier } \\
\text { (Circus approximans) }\end{array}$ & 1 & 0.0 \\
\hline & & $\begin{array}{l}\text { Kaka } \\
\text { (Nestor meridionalis) }\end{array}$ & 30 & $100.0 \pm 0.0$ \\
\hline & & $\begin{array}{l}\text { New Zealand pipit } \\
\text { (Anthus novaeseelandiae) }\end{array}$ & 1 & 0.0 \\
\hline & & $\begin{array}{l}\text { California quail } \\
\text { (Callipepla californica) }\end{array}$ & 5 & $100.0 \pm 0.0$ \\
\hline & & $\begin{array}{l}\text { NI saddleback } \\
\text { (Philesturnus rufusater) }\end{array}$ & 7 & $71.4 \pm 18.4$ \\
\hline & & $\begin{array}{l}\text { Song thrush } \\
\text { (Turdus philomelos) }\end{array}$ & 35 & $22.9 \pm 7.2$ \\
\hline & & $\begin{array}{l}\text { House sparrow } \\
\text { (Passer domesticus) }\end{array}$ & 64 & $4.7 \pm 2.7$ \\
\hline & & $\begin{array}{l}\text { Common starling } \\
\text { (Sturnus vulgaris) }\end{array}$ & 4 & $0.0 \pm 0.0$ \\
\hline & & $\begin{array}{l}\text { Tomtit } \\
\text { (Petroica macrocephala) }\end{array}$ & 1 & 0.0 \\
\hline & & $\begin{array}{l}\text { Tui } \\
\text { (Prosthemadera novaeseelandiae) }\end{array}$ & 1 & 0.0 \\
\hline & & $\begin{array}{l}\text { Weka } \\
\text { (Gallirallus australis) }\end{array}$ & 1 & 0.0 \\
\hline \multirow[t]{2}{*}{ Rats } & \multirow[t]{2}{*}{566} & $\begin{array}{l}\text { Norway rat } \\
\text { (Rattus norvegicus) }\end{array}$ & 3 & $0.0 \pm 0.0$ \\
\hline & & $\begin{array}{l}\text { Ship rat } \\
\text { (Rattus rattus) }\end{array}$ & 18 & $94.4 \pm 5.6$ \\
\hline
\end{tabular}





\title{
3. EVALUATION OF REMOTE CAMERAS FOR MONITORING MULTIPLE INVASIVE MAMMALS IN RESIDENTIAL AND FORESTED AREAS OF NEW ZEALAND
}

\begin{abstract}
$\underline{\text { Abstract }}$
Numerous conservation projects in urban New Zealand aim to reduce populations of invasive mammalian predators to facilitate the recovery of native species. However, results of control efforts are often uncertain due to insufficient monitoring. To evaluate the use of remote cameras as a multi-species and habitat-independent monitoring tool I compared: 1) the detection rates of remote cameras and tracking tunnels and 2) the occupancy estimates of invasive mammals based on remote camera data in residential and forested habitats. On average, cameras detected significantly more hedgehogs (Erinaceus europaeus) and rats (Rattus spp.) than tracking tunnels. Cameras missed recording mice (Mus musculus) on some occasions where tracking tunnels detected them, and vice-versa. The ability of remote cameras to simultaneously monitor multiple species enabled me to unravel differences in the occupancy rates of possums (Trichosurus vulpecula), rabbits (Oryctolagus cuniculus), and cats (Felis catus) between residential and forested areas. Independently of habitat type, I found that cats and hedgehogs were the most common invasive mammals. These findings highlight the suitability of using remote cameras to understand patterns of distribution and abundance of multiple invasive mammals and the need for better management of invasive species in New Zealand urban environments.
\end{abstract}

Keywords: invasive species, mammalian pests, ecological restoration, trail cameras, urban ecology. 


\section{$\underline{\text { Introduction }}$}

The number of projects aiming to conserve native biodiversity in urban areas of New Zealand has increased considerably over recent decades (Norton et al. 2016b). However, the ecological outcomes of many conservation projects are often uncertain due to insufficient monitoring (Anton et al. 2015). Conservation managers in New Zealand primarily use traps and poisons to reduce the number of invasive species including possums (Trichosurus vulpecula), mustelids (Mustela spp.) and rats (Rattus spp.) to levels that allow for the recovery of native species (Pech \& Maitland 2016). The most efficient approach to reducing numbers of invasive mammals is to simultaneously control multiple species (Pech \& Maitland 2016). However, controlling multiple invasive species in urban environments is challenging because the diversity, abundance and distribution of these species might differ from those observed in non-urban environments (Morgan et al. 2009). For example, possums not only select urban forest fragments but they can also be found in residential areas, albeit at different densities (Adams et al. 2014a). Overall, the current ecological knowledge of invasive mammals in urban environments of New Zealand is restricted by the low number of studies of ecosystems other than forests (Pickerell et al. 2014). Thus, urban-driven studies are required to better understand the ecology of invasive mammals in New Zealand cities and towns (Adams et al. 2013).

Conservation managers rely on monitoring tools that record population changes in multiple species over time to measure the success of invasive species management (Ruffell et al. 2015). For example, tracking tunnels baited with peanut butter are the national standard technique in New Zealand for monitoring rodents (Gillies \& Williams 2013). Tracking tunnels have also been used to simultaneously monitor rodents and other 
mammals including possums and hedgehogs (Erinaceus europaeus) (Morgan et al. 2009; Carter et al. 2016). Tracking tunnels, using a meat-based bait, have also been used to monitor mustelids (i.e. stoats (Mustela erminea) and weasels (Mustela nivalis); Pickerell et al. 2014). However, the use of tracking tunnels as a multi-species monitoring tool has several limitations; for example, tracking tunnels do not allow for identification at the species level of mustelids and rats (Morgan et al. 2009). Another drawback that tracking tunnels share with other monitoring techniques is the variable probability of animal detection. The probability of tracking tunnels detecting animals can be biased depending on species interference (which animal gets there first), the bait used, food availability and weather conditions (Pickerell et al. 2014; Carter et al. 2016). Inconsistent detection probabilities are an impediment in comparing relative densities among different species and/or ecosystems (Burge et al. 2017). Due to limitations associated with tracking tunnels and other techniques commonly used (e.g. chew cards and WaxTags ${ }^{\odot}$ ), multiple monitoring tools are currently deployed to successfully monitor invasive mammals (Pickerell et al. 2014). However, the use of multiple monitoring tools increases both labour and financial costs associated with monitoring programmes. To maximise the efficiency of control operations of invasive species, conservation managers require novel approaches to monitoring mammals at spatial extents and with accuracy levels that allow them to judge the appropriate management intervention (Norton et al. 2016a).

Camera trapping, the use of remotely-activated cameras to record animals, is used to provide information on the distribution, density and behaviour of many mammals worldwide (Magle et al. 2014; Allen et al. 2016a, 2016b). To effectively monitor mammals using remote cameras, researchers need to account for the imperfect detection 
of animals by the devices. Previous research has suggested that animal detection rates from cameras might differ based on the methodology (e.g. baited or unbaited stations, horizontal or vertical camera set up, and camera models), animal traits (e.g. body size and speed) and environmental conditions (e.g. temperature, precipitation and seasonality) (Rowcliffe et al. 2011; Haverland \& Veech 2017; Nichols et al. 2017). In New Zealand, remote cameras have successfully been used to monitor feral cats (Felis catus) and European rabbits (Oryctolagus cuniculus), as well as interspecific interactions at bait stations (Sam 2011; Latham et al. 2012; Glen et al. 2016). However, field trials using remote cameras and other conventional monitoring methods are needed to better understand the benefits and the cost of these devices for monitoring invasive mammals in New Zealand (Glen et al. 2014).

A major advantage of cameras is their ability to simultaneously monitor populations of multiple species across different habitats. Compared to other monitoring methods, cameras allow ecologists to monitor multiple species without interspecific interferences (Rowcliffe et al. 2011). Monitoring multiple invasive species in towns and cities of New Zealand can provide crucial information related to the spatial ecology of these species. For example, understanding whether an invasive species is only found within specific habitats of the city or understanding possible seasonal changes in their occurrence can provide guidelines to refine the policies and management programmes aiming to control their numbers in urban environments (Ruffell et al. 2015). Cameras, thus, have the potential to untangle some of the complex socio-ecological processes influencing invasive species in the urban environments of New Zealand. 
I had two objectives: First, to compare the efficiency (relative sensitivity and specificity) of remote cameras and tracking tunnels for monitoring four common invasive mammals found across urban New Zealand: possums, hedgehogs, rats, and mice (Mus musculus). Second, I used remote camera data to compare the occupancy estimates of invasive mammals in residential and forested areas of a city. Such an understanding would help to close the existing gap in current knowledge of the spatial ecology of invasive species in New Zealand's urban environments. 


\section{Methods}

\section{Study sites}

I evaluated the use of remote cameras for monitoring multiple invasive mammals in Wellington, New Zealand (Figure 3.1). Wellington city $\left(41.17^{\circ} \mathrm{S}, 174.46^{\circ} \mathrm{E}\right)$ has a human population of around 200,000 people and is located in a temperate broadleaf mixed forest ecoregion (Statistics New Zealand 2013). I collected the data from 40 different locations. Half of these locations were in forested sites (i.e. regenerating native forest) and the other half were in residential sites (i.e. backyards and gardens). The vegetation in the forested sites included broadleaved native trees such as mahoe (Melicytus ramiflorus), kōhūhū (Pittosporum tenuifolium), and whauwhaupaku (Pseudopanax arboreus). The vegetation in residential sites ranged from lawns with large ornamental trees to small patches of native shrub species including makomako (Aristotelia serrata), ngaio (Myoporum laetum), and karamu (Coprosma robusta). 

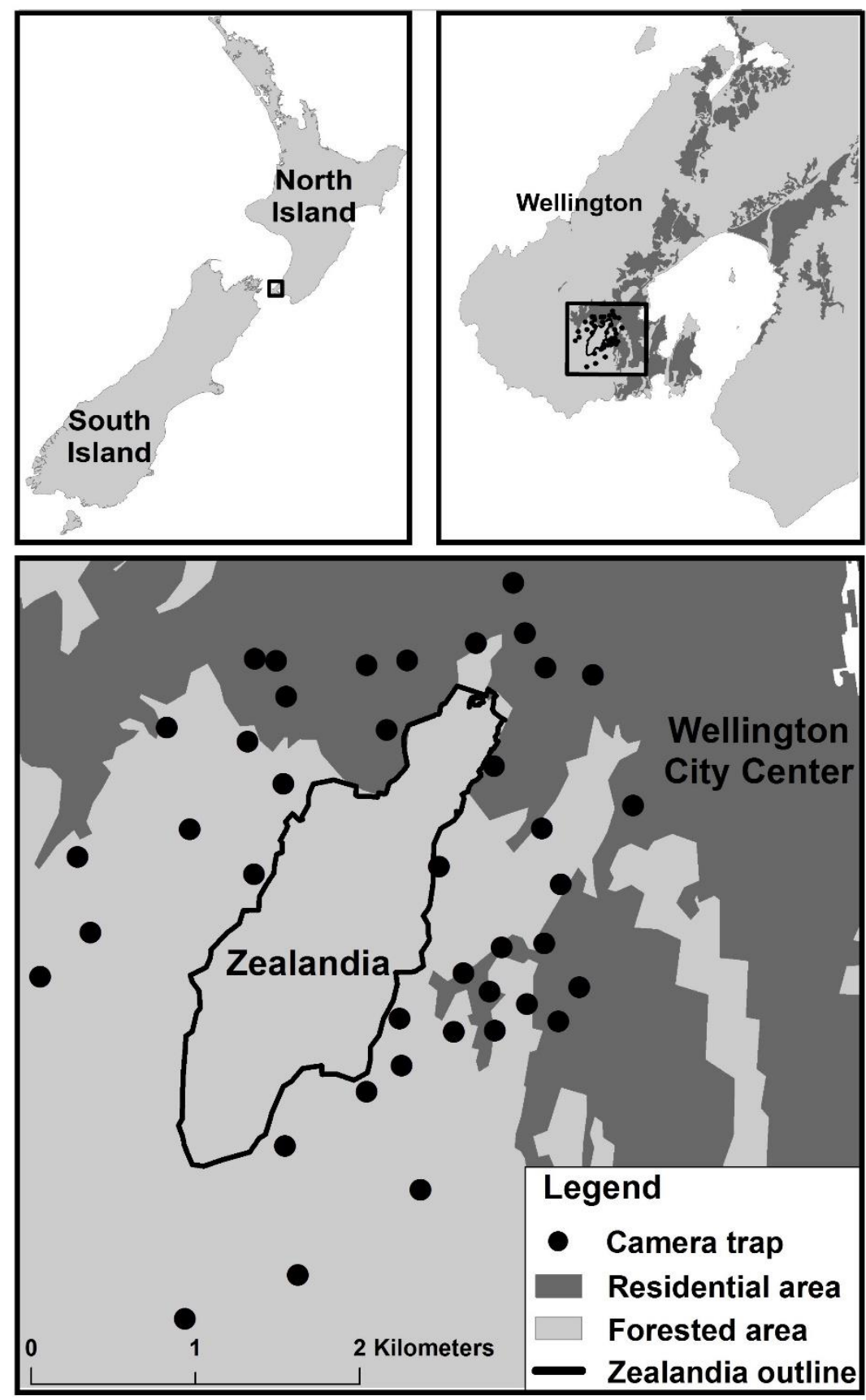

Figure 3.1 Location of the 40 remote cameras and tracking tunnels in Wellington, New Zealand. The cameras were set up around Zealandia, a predator-free fenced area containing abundant native forest. 


\section{Data collection}

To compare the efficiency of remote cameras and tracking tunnels, I deployed one passive infrared triggered camera (Bushnell, model: 119537) and one plastic tracking tunnel (500 × $100 \times 100 \mathrm{~mm}$; Connovation Limited, Auckland, New Zealand) at each of the 40 locations. I set up the cameras to record three still photographs (8 megapixels) per trigger. According to the manufacturer's specifications, the trigger speed of the cameras after activation by an animal was 0.6 seconds. I set cameras to the highest sensor level, the lowest flash level and a medium shutter speed. I chose a delay of 30 seconds between triggers to avoid collecting an excessive number of additional photos of the same individual and to maximise memory storage. I attached the cameras to trees $50 \mathrm{~cm}$ above the ground and with a $20^{\circ}$ downward tilt (Figure 3.2). The field of detection of the cameras was approximately $2.6 \mathrm{~m}^{2}$ at ground level.

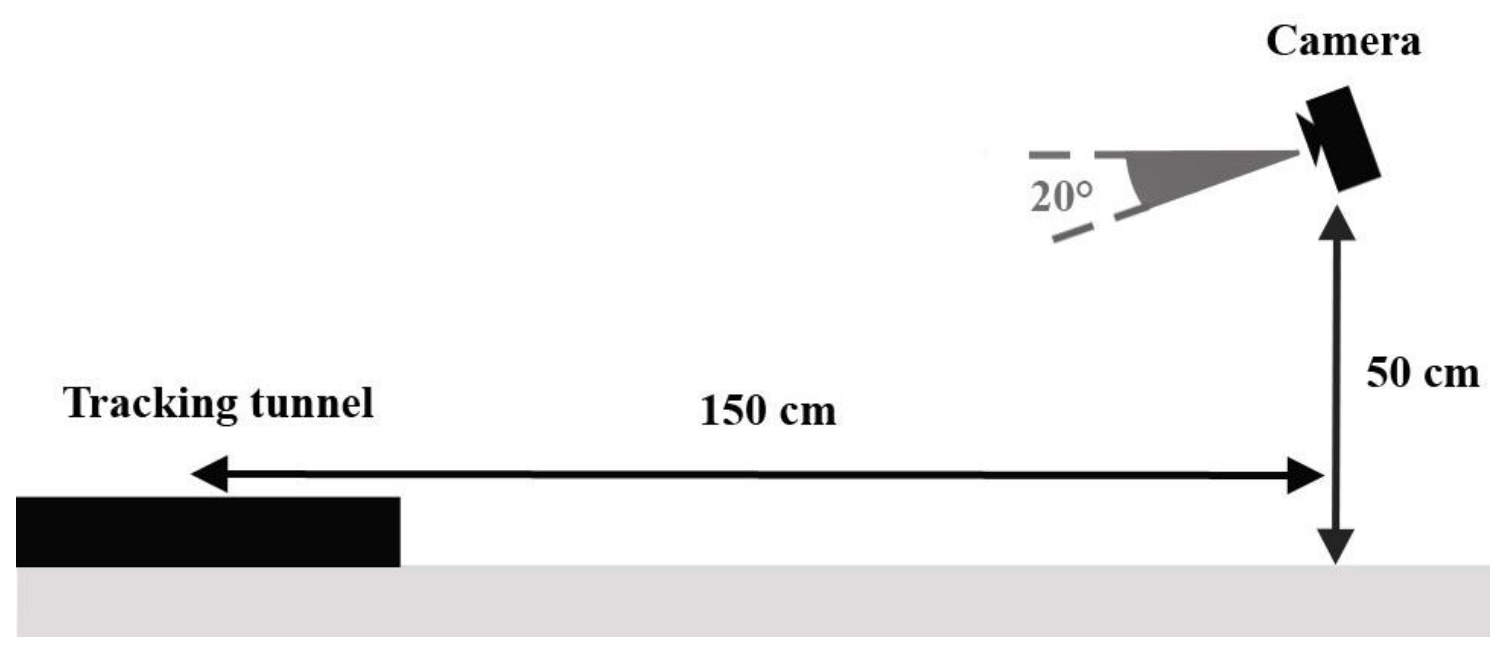

Figure 3.2 Schematic diagram of the remote camera and tracking tunnel deployment.

I deployed tracking tunnels $1.5 \mathrm{~m}$ in front of the cameras baited with peanut butter in the middle (all other specifications as per Gillies \& Williams 2013) and following standard procedures (i.e. Gillies \& Williams 2013) left them overnight on two occasions 
(21 April 2014 and 9 May 2016). To estimate how the use of bait influences the detectability of species by remote cameras, I also inserted unbaited tracking cards into the tracking tunnels and recorded photos on two other occasions (26 April 2014 and 15 May 2016). To minimise neophobic responses from the animals, tunnels were left open for at least 14 days before each recording session (Gillies \& Williams 2013).

To estimate the differences in the occupancy of invasive mammals in residential and forested areas, I deployed a camera at each of the 40 sites during the austral autumn and spring of 2015 (March-May and September-November, respectively). Cameras were active during 75-90 days at each site per season.

I examined each tracking card and identified the animals recorded in them. To identify the animals recorded by the remote cameras, I uploaded the photos to a citizen science website (www.identifyanimals.co.nz). In the website volunteers from the public classified the photos into one of the thirteen different animal categories available. Volunteers were asked to classify the photographs and report whether they were "confident" or "unsure" with their classification. Based on the accuracy of volunteers when compared to experts (Chapter 0 ), I considered the photographs to be correctly classified if one of the following three criteria was met: 1) the first two volunteers classified the photograph as "cat" or "bird" and both volunteers were confident with their classifications, 2) the first three volunteers classified the photograph as the same category, except for rodents and mustelids, and all three volunteers were confident with their classifications, or 3) at least 5 out of 7 volunteers classified the photograph into the same category. I classified to the species level photographs that did not meet any of the previous criteria and, when photo quality allowed, I identified those classified by 
volunteers as rats into ship rats (Rattus rattus) and Norway rats (Rattus norvegicus)

(Figure 3.3). I was unable to identify rats detected by the tracking tunnels to species level.

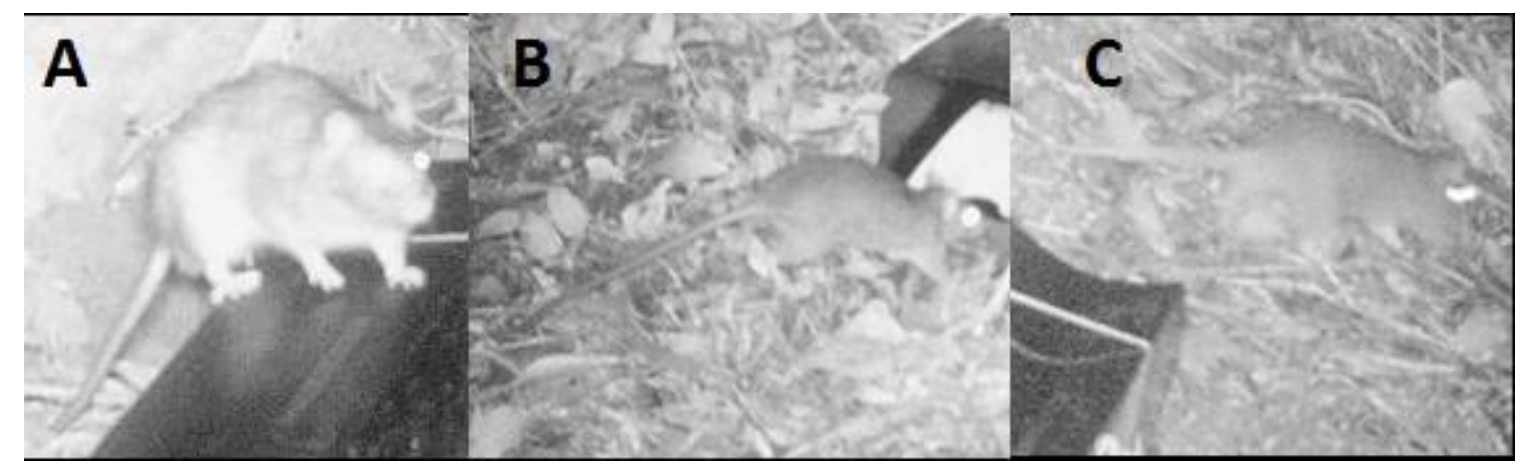

Figure 3.3 Photographs of (A) Norway rat (Rattus norvegicus), (B) ship rat (R. rattus) and $(\mathrm{C})$ a rat that was unable to be identified to species level.

\section{Data analysis}

To compare tracking tunnels and cameras, I calculated the number of trap-nights that possums, hedgehogs, rats, and mice were present and absent based on information provided by tunnels and cameras during 2014 and 2016. I used generalised linear mixed models to determine the influence of monitoring device (camera vs tunnel) and bait treatment (baited vs unbaited) on the detection of each species. I omitted an interaction term between device and bait treatment because it was never significant $(P>0.15)$. The dependent variable was species' presence/absence and the independent variables were monitoring device and bait treatment. Due to the repeated measures design of my study, I treated site as a random effect (allowing only its intercept to vary) in the model. I used $P$ $<0.05$ as my threshold of significance.

To investigate the differences in the occupancy of invasive mammals between residential and forested sites, I modelled the occupancy of any invasive mammalian species recorded by the cameras during the autumn and spring of 2015. I used occupancy 
models because they enabled me to account for the cameras' imperfect detection of animals (MacKenzie et al. 2017). The occupancy model of each species consisted of two parameters, the probability of the species presence $(\psi)$ and the conditional probability of detecting the species by the camera assuming it was present in the area $(p)$. During each season, I assumed species did not become locally extinct or colonise new patches of forest. In other words, I assumed closed populations (Mackenzie et al. 2002). Before I generated the occupancy models, I calculated the naïve occupancy of each species to identify periods of time for which the proportion of sites occupied by the species was insufficient to make any statistical inferences. Naïve occupancy is essentially $\psi$ assuming perfect probability of detection (i.e. $p=1$ ). To calculate the naïve occupancy of each animal, I divided the number of sites at which the species was detected by the total number of sites. I excluded species for which the naïve occupancy estimates were lower than 0.20 from further analyses (O'Connell et al. 2006).

I followed a model inference approach to evaluate the underlying processes influencing the occupancy of invasive mammals. First, I generated the detection history of the species at each site. To increase detection probability of mammals found at low densities, I grouped daily detection/non-detection of each species into surveys of 3 days (i.e. 25-30 surveys per site) (Ehlers Smith et al. 2018). Second, I tested whether different covariates influenced the probability of cameras detecting each species. The covariates I tested were: mean temperature of the three day period, presence of precipitation $(>1 \mathrm{~mm}$ of rainfall) and mean Julian date of each survey (Haverland \& Veech 2017). I generated four models, three models with $p$ as a function of the three covariates respectively and a null model. I kept the occupancy estimate constant in all the models (i.e. $\psi()$.$) . I$ 
compared the models based on their AICc (Akaike's Information Criterion corrected for small sample sizes) values and considered the best $p$ model the one with the lowest $\mathrm{AIC}_{\mathrm{c}}$. If the null model was $2 \Delta \mathrm{AIC}_{\mathrm{c}}$ of the best model, I selected the null model as the best model (Burnham \& Anderson 2002). Finally, I compared the best $p$ model, from above, with and without habitat (residential and forest) as a covariate of $\psi$ to determine whether habitat influenced the occupancy of the species. I considered habitat to be influential if the habitat covariate reduced by $>2 \Delta \mathrm{AIC}_{\mathrm{c}}$ compared to the best $p$ model (Burnham \& Anderson 2002).

The statistical analyses were done in R (R Core Team 2016) using the Rpresence (MacKenzie \& Hines 2018) and lme4 package (Bates et al. 2014b). 


\section{$\underline{\text { Results }}$}

\section{Cameras and tunnels}

Remote cameras detected significantly more hedgehogs and rats than tracking tunnels $(P$ $<0.05$ ) (Table 3.1). Indeed, remote cameras recorded all hedgehogs and rats detected by tracking tunnels (Figure 3.4). Tracking tunnels failed to detect some animals recorded by the cameras. For example, tracking tunnels missed recording seven of the ten possums, 13 of the 26 hedgehogs and 11 of the 24 rats detected by cameras (Appendix 3.1).

Table 3.1 Results from generalised linear mixed models used to determine the effect of monitoring device (remote cameras and tracking tunnels) and bait treatment on the detection probability of possums, hedgehogs, rats and mice. A negative coefficient for 'device' indicates that cameras detected more animals than tracking tunnels. A positive coefficient for 'bait' indicates that monitoring devices with bait detected more animals than devices without bait. $P$ values $<0.05$ are represented with $*$.

\begin{tabular}{llll} 
Species & Term & $\hat{\beta} \pm \mathrm{SE}$ & $P$ value \\
\hline \hline Possum & Device & $-1.35 \pm 0.69$ & 0.05 \\
& Bait & $0.54 \pm 0.61$ & 0.38 \\
\hline Hedgehog & Device & $-0.95 \pm 0.40$ & $0.02^{*}$ \\
& Bait & $0.22 \pm 0.38$ & 0.57 \\
Rat & Device & $-0.79 \pm 0.39$ & $0.04^{*}$ \\
& Bait & $1.56 \pm 0.44$ & $0.00^{*}$ \\
Mouse & Device & $0.30 \pm 0.45$ & 0.51 \\
& Bait & $1.11 \pm 0.48$ & $0.02^{*}$
\end{tabular}




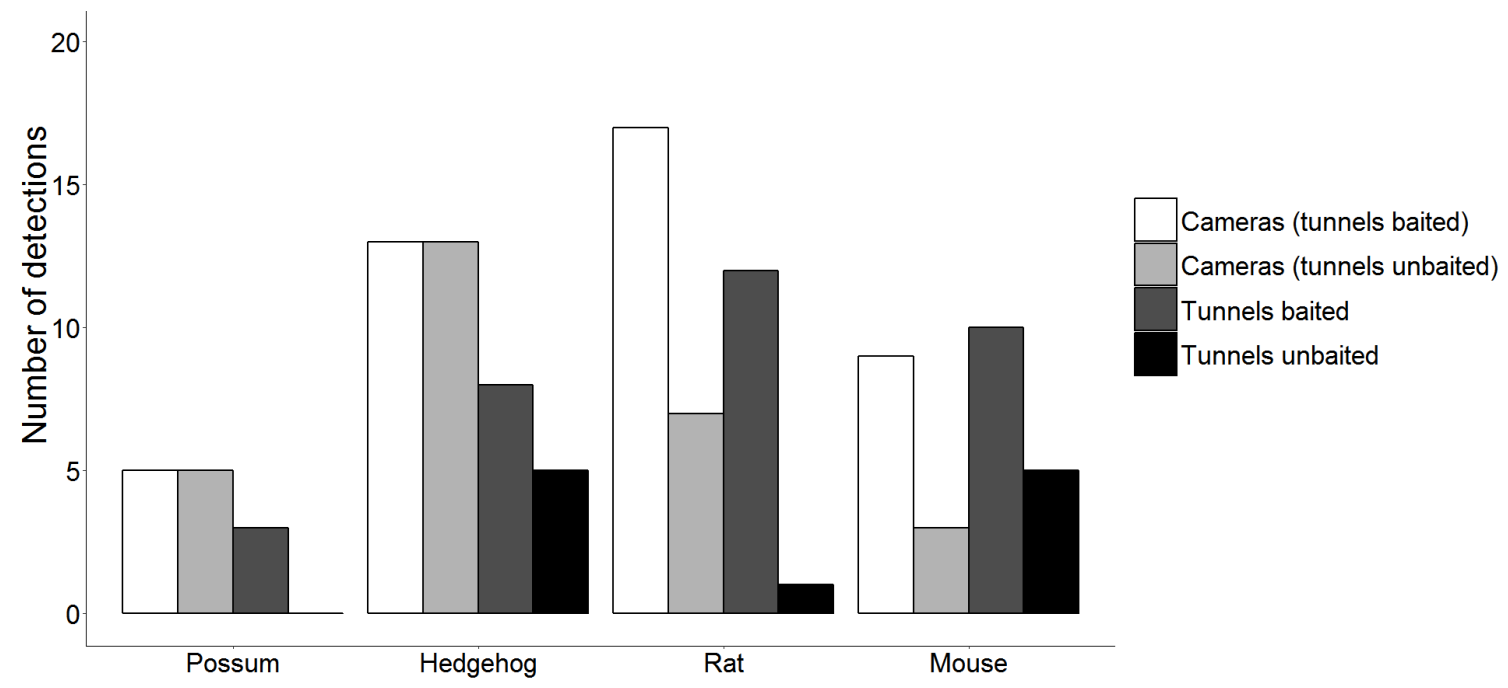

Figure 3.4 Number of detection events of possums, hedgehogs, rats and mice across 4 non-consecutive days by remote cameras and tracking tunnels under different bait treatments. Bait treatment included: tracking tunnels baited with peanut butter and unbaited tracking tunnels.

Both tracking tunnels and remote cameras occasionally failed to record mice detected by the other device. Tracking tunnels missed detecting mice during 5 of the 12 trap-nights that cameras recorded mice; but, cameras missed detecting mice during 8 of the 15 trap-nights that tracking tunnels recorded mice (Appendix 3.1).

The use of peanut butter as bait increased by $363 \%$ and $238 \%$ the detection rates of rats and mice $(P<0.01$ and $P<0.05$, respectively) regardless of device (Figure 3.4$)$. In addition to rodents, hedgehogs, and possums, both devices recorded other species including skinks, birds and other introduced mammals (Table 3.2). 
Table 3.2 Species detected by remote cameras and tracking tunnels during 4 nonconsecutive nights (two unbaited and two baited with peanut butter) at 40 sites across Wellington City.

Animal Remote cameras Tracking tunnels

\begin{tabular}{lcc}
\hline \hline Dog (Canis familiaris) & 1 & 0 \\
Possum (Trichosurus vulpecula) & 14 & 0 \\
Cat (Felis catus) & 42 & 0 \\
Rabbit (Oryctolagus cuniculus) & 6 & 13 \\
Hedgehog (Erinaceus europaeus) & 28 & 13 \\
Rat (Rattus spp.) & 24 & 15 \\
Mouse (Mus musculus) & 12 & 0 \\
Blackbird (Turdus merula) & 21 & 0 \\
Dunnock (Prunella modularis) & 3 & 0 \\
Goldfinch (Carduelis carduelis) & 1 & 0 \\
Saddleback (Philesturnus carunculatus) & 2 & 3 \\
Skink (Oligosoma spp.) & 0 & 0
\end{tabular}




\section{Cameras in residential and forested areas}

The cameras recorded a total of 12 mammalian species, including sambar deer (Cervus unicolor), pigs (Sus scrofa), dogs (Canis familiaris), possums, hares, rabbits, cats, stoats, hedgehogs, ship rats, Norway rats, and mice. Cats and hedgehogs were the most widespread species during the spring of 2015. Cats were recorded in all residential sites. Deer, pigs, dogs, hares, stoats and Norway rats were the least frequent animals, recorded in less than $20 \%$ of sites.

The occupancy estimates of medium-sized mammals (e.g. possums, rabbits, and cats) differed between residential and forested locations (Figure 3.5). Possums and rabbits were recorded more frequently in forested sites than residential sites. Cats occupied residential sites more than forested sites. Hedgehogs and rodents occupied similar proportion of sites across both forested and residential sites.

The Julian date influenced the detection probabilities of rabbits and hedgehogs. Julian date was the only covariate that influenced the probability of cameras to detect species of invasive mammals. Temperature and precipitation did not affect detection probabilities of invasive mammals by the cameras. 


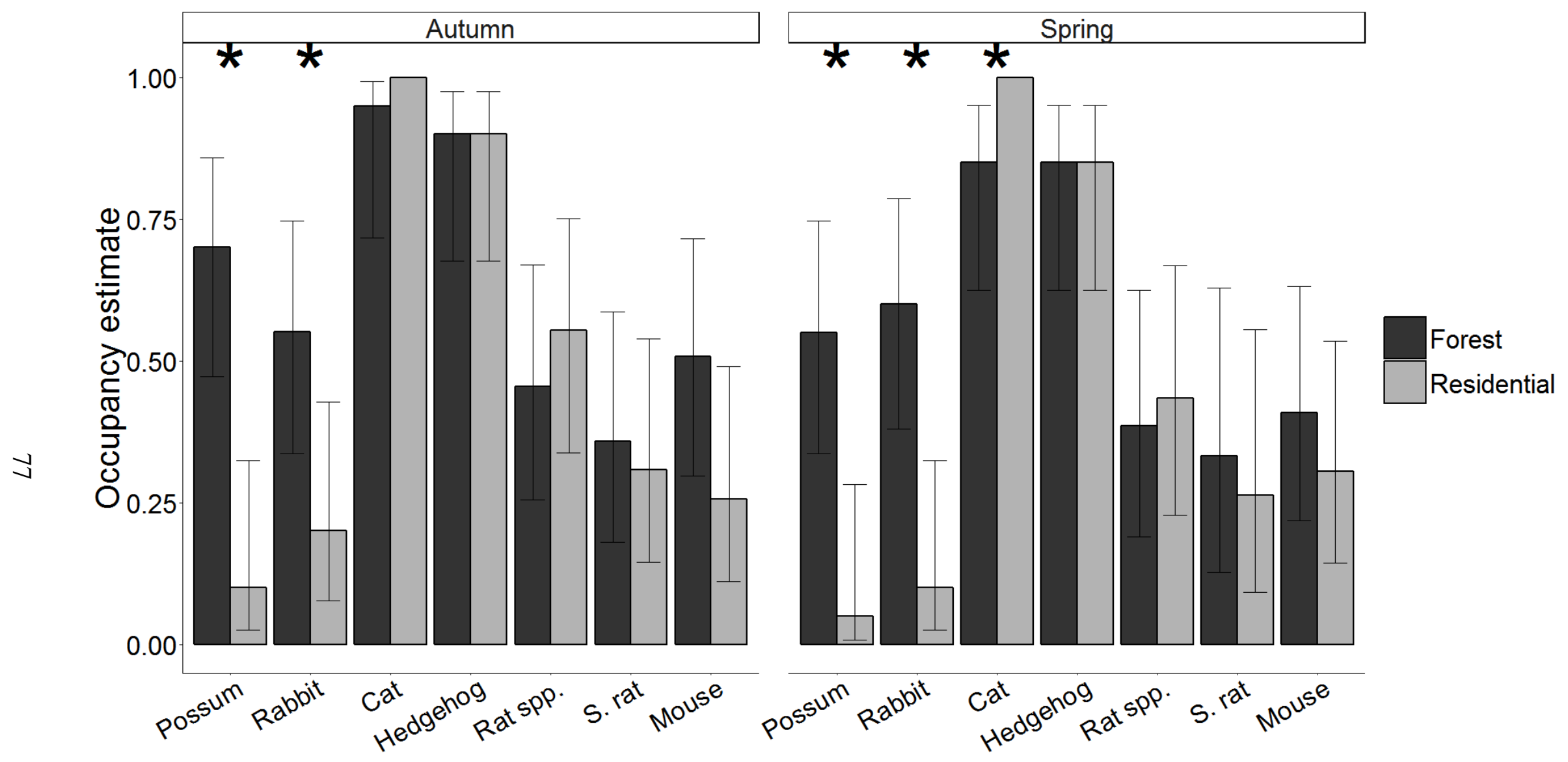

Figure 3.5 Occupancy estimates ( $\pm 95 \%$ confidence intervals) obtained from unbaited remote cameras of invasive mammals recorded in $>20 \%$ of the 40 residential and forested locations in Wellington, New Zealand. Stars represent significant differences in the occupancy estimates between residential and forested sites. Ship rat is represented as "S. rat". 


\section{$\underline{\text { Discussion and conclusion }}$}

Remote cameras are more efficient than tracking tunnels for detecting multiple invasive mammals. Remote cameras recorded significantly more hedgehogs and rats than did the tracking tunnels. During some occasions, cameras recorded rats interacting with the tracking tunnels, but not entering them. Abundance of other food sources and the neophobic character of the animals might have caused the lower detection rates provided by tracking tunnels (Pickerell et al. 2014). Remote cameras were not significantly better at detecting mice. I recommend that conservation managers deploy remote cameras if the objective is to simultaneously monitor multiple invasive mammals and/or if high sensitivity to rat presence is required. Tracking tunnels on the other hand should be considered if the objective is to index rodents in comparison to other monitoring schemes using the national standard method.

Remote cameras and tracking tunnels both missed recording mice on some occasions. I deployed the tracking tunnels and pointed the cameras at the effective detection distance for rats (1.5 m; Rowcliffe et al. 2011). Mice are smaller than rats and often used only one end of the tracking tunnel, impeding their detection by the camera because they were screened by the tracking tunnel. These two factors likely contributed towards the lower mice detection rates recorded by cameras compared to tracking tunnels. As pointed out by Rowcliffe et al. (2011), the effective detection distance of cameras differs for each species. Conservation managers aiming to monitor mice in particular should consider adjusting the effective detection distance for this species when setting up the cameras (i.e. setting the cameras closer to the ground). 
The use of bait in studies with remote cameras to lure animals to the camera's field of view has been widely discussed (e.g. Glen et al. 2013; Rocha et al. 2016). In my study, I detected more target species, especially rodents, when baiting the cameras. The use of bait shortens the number of days required to detect species present in an area (Rocha et al. 2016). Bait also facilitates animal identification because it encourages animals to remain in the camera's field of view for longer periods of time (Glen et al. 2013). However, the use of bait violates the assumptions required for determining species richness and accurate density estimates (Rowcliffe et al. 2008). For example, baits are likely to bias the identity and relative numbers of different species recorded by cameras because they favour those species that respond more strongly to the chosen bait (Lazenby et al. 2015). The number of species recorded by remote cameras is also likely to be influenced by species interactions at and around the bait (Allen et al. 2016a). Based on my results, monitoring schemes targeting single species or species at low densities might consider baiting the camera traps to minimise trapping effort and costs. However, monitoring schemes aiming to monitor multiple species at medium or high densities should use unbaited camera traps (e.g. Rowcliffe et al. 2011; Rocha et al. 2016).

Cameras detect a greater variety of species than tracking tunnels. In my study, in addition to the possums, mustelids, hedgehogs and rodents that tracking tunnels can detect (Carter et al. 2016), remote cameras recorded deer, pigs, dogs, hares, rabbits and cats. Remote cameras also enabled me to identify rats to species level in $59 \%$ of the photographs. The higher proportion of sites occupied by ship rats compared to sites occupied by Norway rats is consistent with the dominance of ship rats observed in other cities (Morgan et al. 2009; Feng \& Himsworth 2014). The low number of sites where I 
recorded deer, pigs, dogs, hares, stoats and Norway rats prevented the investigation of how forest and residential habitats affect their site occupancy rates. To monitor these species found at low densities in urban environments, conservation managers using remote cameras may need to increase the number of camera stations, deploy the devices for longer monitoring periods, or use species-appropriate bait.

Using unbaited cameras, I was able to simultaneously monitor seven medium- and small-sized invasive mammals during the autumn and spring of 2015. The outcomes of such multi-species monitoring schemes provide three main insights for better management of invasive species in urban environments. First, consistent with similar studies (e.g. Harper 2005; Adams et al. 2013), I found that possums and rabbits were more abundant in forested habitats, but they also occurred in residential areas. To efficiently control the number of such species, urban conservation managers should therefore target forested sites but consider residential areas as potential sources of reinvasion. Second, the large number of sites occupied by cats and hedgehogs in my study urges managers to review current policies for management of free-ranging cat populations and hedgehogs because both species pose a major threat to New Zealand native biodiversity (Jones et al. 2005; Wood et al. 2016). Contrary to studies that report how habitat type influences the number of hedgehogs, rats, and mice (Hubert et al. 2011; Feng \& Himsworth 2014; Johnson et al. 2014; Klimant et al. 2017), I did not find differences in the occupancy of these small-sized mammals between residential and forested areas. The high adaptability of these species (Banks \& Smith 2015) and the low number of competitors and predators they encounter in New Zealand urban environments (Morgan et al. 2009) can explain the lack of differences observed in my study. The 
similar proportion of sites occupied by hedgehogs and rodents also highlights the importance of involving the general public to actively control small-sized mammals in residential areas (Parkes et al. 2017). Third, timing the control efforts of invasive species is often regarded as crucial to regulate their densities and consequently reduce the threats they pose for native biota (Pech \& Maitland 2016). A common management approach to prevent invasive species from reaching high densities is to concentrate the management efforts on specific times of the year (Zabala et al. 2010). However, based on the similar number of invasive species I recorded over spring and autumn, in urban environments, where resources can be available all year around, management control throughout the year may be needed to reduce the abundances and distribution of such species (see Chapter 4 for a more details about the influence of seasonality in urban invasive mammals).

Remote cameras have few limitations compared to tracking tunnels. The main limitation is the labour required to classify the footage or photos. However, using public participation (Chapter 0) and automatic animal identification software can minimise the time required to collate data provided by cameras (He et al. 2016). The initial capital costs of remote cameras are also considerably higher than those of tracking tunnels (Pickerell et al. 2014). Despite the gradual decrease in equipment costs and the long periods of time that cameras can be active without requiring maintenance, the costefficiency of remote cameras compared to more traditional monitoring tools is still low, especially in the short term (Glen et al. 2014). Another limitation is the inability that many commercially available cameras have to detect ectothermic animals, such as lizards and insects, whereas tracking tunnels can detect these species (Jarvie \& Monks 2014). A 
further drawback of camera trapping is the responses that some mammals have shown to the cameras. Remote cameras emit sounds and infrared lights that can be perceived by different species (Meek et al. 2016). However, further research is required to understand the disturbance effects of remote cameras on animals, especially on small- and mediumsized mammals. Other drawbacks associated with cameras include privacy issues, vandalism and theft (Glen et al. 2016), although in my study no such instances occurred. Deploying the cameras in private properties, away from footpaths, not using markers to highlight their location and the lower number of human population compared to other urban environments might have contributed to the lack of these issues in my study. In my study, I accounted for variation in animal detectability among sites, devices, bait treatment and Julian date. However, other sources of variation (e.g. interspecies interactions or a species' behaviour) might influence the probability of detection of both cameras and tracking tunnels (Gillies \& Williams 2013; Allen et al. 2016a; Fancourt 2016). Further research on the interactions among animals, their environment, and monitoring devices is required to minimise the number of misdetections (Meek et al. 2016) and to develop new monitoring standards. Meanwhile, to ensure correct interpretation of remote camera and tracking tunnel data, conservation managers are encouraged to account for species-specific imperfect detectability (Rowcliffe et al. 2011; Lazenby et al. 2015).

Overall, my results suggest that remote cameras are a robust technique enabling conservation managers to simultaneously monitor multiple invasive mammals in New Zealand (summarised in Table 3.3). The use of remote cameras represents an improvement over current monitoring techniques as it eliminates the need for multiple 
monitoring devices. The ability of remote cameras to monitor multiple species enabled me to gain further insights about the spatial ecology of New Zealand invasive mammals within an urban environment. Understanding the species-specific habitat preferences provide evidence-based guidelines for better management of invasive species in New Zealand urban environments. 
Table 3.3 Main advantages of using remote cameras or tracking tunnels as a multispecies monitoring tool.

Advantages of remote cameras Advantages of tracking tunnels

Detect higher number of possums, hedgehogs

Can detect endothermic species such and rats

as lizards and large insects

Monitor multiple species without interspecies

Cost and labour efficient in the short interferences term

Detect a broader array of species, including Privacy issues, vandalism and theft cats, pigs, deer and birds are minor considerations

Enables individual identification of some species (e.g. cats)

Record animal behaviour under natural conditions (trigger might alter behaviour of some species)

Cost and labour efficient in the long term 


\section{$\underline{\text { Acknowledgements }}$}

This project would not have been possible without the consent and participation of private landowners and Wellington City Council. I thank Amy Brasch, Kerry Charles, Dannielle Shannahan, Des Smith and an anonymous reviewer for their comments that improved this chapter, John Innes for confirming the identification of rat species and Victoria University of Wellington's Centre for Biodiversity and Restoration Ecology (CBRE) for covering equipment and vehicle costs. 


\section{$\underline{\text { Appendix }}$}

Appendix 3.1 Two-by-two cross classifications of detections and non-detections of possums, hedgehogs, rats and mice recorded by remote cameras and tracking tunnels. I sampled a total of 80 trap-nights for each bait treatment (baited and unbaited tracking tunnels).

a) Possums

\begin{tabular}{|l|l|c|c|}
\cline { 3 - 4 } \multicolumn{2}{c|}{} & \multicolumn{2}{c|}{ Cameras } \\
\cline { 2 - 4 } \multicolumn{2}{c|}{} & Detected & Undetected \\
\hline \multirow{2}{*}{$\begin{array}{l}\text { Baited } \\
\text { tracking tunnel }\end{array}$} & Detected & 3 & 0 \\
\cline { 2 - 4 } & Undetected & 2 & 75 \\
\hline
\end{tabular}

Unbaited tracking tunnel

\begin{tabular}{|l|c|c|}
\hline Detected & 0 & 0 \\
\hline Undetected & 5 & 75 \\
\hline
\end{tabular}

b) Hedgehogs

\begin{tabular}{|l|l|c|c|}
\cline { 3 - 3 } \multicolumn{2}{c|}{} & \multicolumn{2}{c|}{ Cameras } \\
\cline { 3 - 4 } \multicolumn{2}{c|}{} & Detected & Undetected \\
\hline \multirow{2}{*}{$\begin{array}{l}\text { Baited } \\
\text { tracking tunnel }\end{array}$} & Detected & 8 & 0 \\
\cline { 2 - 4 } & Undetected & 5 & 67 \\
\hline
\end{tabular}

Unbaited tracking tunnel

\begin{tabular}{|l|c|c|}
\hline Detected & 5 & 0 \\
\hline Undetected & 8 & 67 \\
\hline
\end{tabular}

c) Rats

\begin{tabular}{|l|l|c|c|}
\cline { 3 - 4 } \multicolumn{2}{c|}{} & \multicolumn{2}{c|}{ Cameras } \\
\cline { 2 - 4 } \multicolumn{2}{c|}{} & Detected & Undetected \\
\hline \multirow{2}{*}{$\begin{array}{l}\text { Baited } \\
\text { tracking tunnel }\end{array}$} & Detected & 12 & 0 \\
\cline { 2 - 4 } & Undetected & 5 & 63 \\
\hline
\end{tabular}

Unbaited tracking tunnel

\begin{tabular}{|l|c|c|}
\hline Detected & 1 & 0 \\
\hline Undetected & 6 & 73 \\
\hline
\end{tabular}


d) Mice

\begin{tabular}{|l|l|c|c|}
\cline { 3 - 3 } \multicolumn{2}{c|}{} & \multicolumn{2}{c|}{ Cameras } \\
\cline { 3 - 4 } \multicolumn{2}{c|}{} & Detected & Undetected \\
\hline \multirow{2}{*}{$\begin{array}{l}\text { Baited } \\
\text { tracking tunnel }\end{array}$} & Detected & 5 & 5 \\
\cline { 2 - 4 } & Undetected & 4 & 66 \\
\hline \multirow{3}{*}{$\begin{array}{l}\text { Unbaited } \\
\text { tracking tunnel }\end{array}$} & Detected & 2 & 3 \\
\cline { 2 - 4 } & Undetected & 1 & 74 \\
\hline
\end{tabular}




\title{
4. HABITAT QUALITY, INTERSPECIFIC INTERACTIONS AND ANTHROPOGENIC ACTIVITIES INFLUENCE THE DISTRIBUTION OF URBAN INVASIVE MAMMALS
}

\begin{abstract}
$\underline{\text { Abstract }}$
Invasive non-native mammalian species can have negative impacts for both people and the environment in cities worldwide. Understanding the factors influencing the distribution of these species is crucial to address ethical, ecological, and practical concerns associated with their management. My objective was to identify the underlying processes influencing distribution and abundances of invasive mammals found in urban patches of vegetation. Using remote cameras, I investigated the influence of habitat quality, management efforts, interspecific interactions and seasonality on the occupancy and relative abundance of invasive mammals in 47 patches of forest within Wellington, New Zealand. Cats (Felis catus), European hedgehogs (Erinaceus europaeus), and house mice (Mus musculus) were the most widespread species, recorded in $>70 \%$ of the patches. Distance to forest edge influenced positively the relative abundance of rodents and negatively the relative abundance of common brushtail possums (Trichosurus vulpecula), cats, European rabbits (Oryctolagus cuniculus), and hedgehogs. The cameras also revealed a positive interaction between the occupancy of ship rats (Rattus rattus) and the abundance of Norway rats (Rattus norvegicus), a positive influence of the nearby buildings on the occupancy of cats, and how management control reduces the occupancy of target species, particularly during spring. My results highlight the importance of using season- and species-specific approaches to identify the most important factors influencing the distribution of invasive species in urban environments. The control of these species at
\end{abstract}


adequate spatial and temporal scales is critical to ensure effective conservation management in urban environments.

Keywords: pest, connectivity, camera trap, fragmentation, introduced predators, remote cameras. 


\section{$\underline{\text { Introduction }}$}

Invasive non-native mammals, hereafter invasive mammals, are one of the major causes of anthropogenic biodiversity loss worldwide (Doherty et al. 2015). These species, established outside of their natural range by humans, are significant contributors to the decline and extinction of native biodiversity (Jones et al. 2016). Over the last two decades, mitigating threats from invasive mammals has become a cornerstone of conservation management worldwide, including in urban environments (Hess et al. 2014; Yemshanov et al. 2017). In urban environments, most native species are restricted to small patches of vegetation that resemble their original habitat (McIntyre 2014). Due to this restricted distribution of native species within the urban matrix, managers coordinating control programmes of invasive species tend to focus on patches of vegetation to maximise the biodiversity outcomes of their efforts (Hess et al. 2014). However, current management of invasive mammals is yet to be refined because despite the extensive literature on invasive mammals, studies of invasive species and their link to patches of vegetation in urban areas are few in number (Gaertner et al. 2017b).

The abundance and diversity of mammals found in urban patches of vegetation are influenced by the socio-ecological characteristics of the patches and their surroundings. The structure and composition of the habitat within patches of vegetation determine the type, quantity, and quality of resources available for mammals (McIntyre 2014). Anthropogenic changes in the biophysical attributes of the patches (e.g. alterations in the vegetation, soil and climate characteristics) thus can lead to drastic modifications in the availability of these resources (Müller et al. 2013; Villaseñor et al. 2014). Urban patches of vegetation are often too small to ensure viable populations of most mammalian 
species (Fernández \& Simonetti 2013). Consequently, connectivity among patches of similar habitat plays an important role in the population dynamics of urban mammals, particularly large and medium size mammals (Gallo et al. 2017). Connectivity, however, might not be as important for invasive species compared to native mammals because these introduced species frequently use more than one type of habitat within the urban environment (Adams et al. 2014b). Even invasive species that are commonly associated with a specific habitat can move across different urban ecological edges according to seasonal changes in food and shelter (Ehlers Smith et al. 2018). Therefore, the spatial organization of human geography and activities, along with the species-specific autecology of the mammals, are crucial to understand the influence people have in the distribution of urban invasive mammals in urban environments (Lucaccioni et al. 2016; Ehlers Smith et al. 2018).

Besides the socio-ecological characteristics of urban environments, interspecific interactions can also influence the abundance and distribution of invasive mammals in patches of vegetation. Predation and competition with other species are known to suppress the abundance of invasive species in non-urban environments (Doherty et al. 2016). However, interspecific interactions between invasive species and native biota in urban ecosystems can differ from those found in non-urban ecosystems due to the highly modified environment and other human disturbances (Wang et al. 2015; Kikillus et al. 2017). The importance of these urban interspecific interactions in the establishment of invasive mammals has been poorly studied (Gallo et al. 2017). The exception being Ahlers et al. (2016), who reported how prey availability affects the occupancy of urban streams by the American mink (Neovison vison; a common invasive species across 
Europe, South America, and Asia). Underestimating the role that interspecific interactions can play on the dynamics of ecosystems can led to detrimental conservation outcomes for native biota (e.g. Ballari et al. 2016). Further studies aimed at disentangling the role of interspecific interactions and anthropogenic food subsidies on the dynamics of invasive species communities are, thus, needed to guide adequate management of these problematic species in urban environments.

Suppressing the abundance of invasive mammals, via lethal control, is a management approach employed worldwide to mitigate negative impacts of invasive species (Doherty \& Ritchie 2017). The risks to non-target species and ethical concerns associated with this management approach influence the design, efficiency, and ultimately the success of management programmes (Lioy et al. 2016). Compared to rural and protected areas, conflicts associated with invasive species management are more likely to occur in urban environments due to the greater number of stakeholders and a wider variety of interests involved (Gaertner et al. 2017a). To prevent social conflicts, urban managers often opt to implement non-lethal management approaches (e.g. habitat modification or the use of physical barriers). However, the limitations in our current understanding of the urban-specific ecology of invasive species, their high adaptability to novel environments, and the high heterogeneity of urban environments frequently hinder the success of such initiatives (Cadotte et al. 2017).

A thorough understanding of the factors influencing the distribution of invasive species in cities is crucial to comply with the ethical, ecological, and practical concerns associated with the management of invasive species (Doherty \& Ritchie 2017). To further advance our current understanding of urban invasive mammals, in this study, I investigate 
the underlying processes influencing the relative abundance and occupancy of mammals in urban patches of vegetation. Specifically, I examine five questions: 1) Does distance to forest edge and 2) seasonality influence the relative abundance of mammals in urban vegetation patches? 3) Do habitat characteristics inside and outside the urban patches of vegetation, 4) management efforts, and 5) interspecific interactions affect the occupancy of said mammals? To answer these questions, I monitored ten mammalian species commonly found in urban areas in New Zealand (Morgan et al. 2009) across 47 habitat patches varying in size from 1 to 100 ha over 4 seasons. 


\section{Methods}

\section{Study sites}

I monitored ten mammalian species across 47 patches of forest in Wellington, New Zealand (Figure 4.1). These species included dogs (Canis familiaris), common brushtail possums (Trichosurus vulpecula), cats (Felis catus), stoats (Mustela erminea), brown hares (Lepus europaeus), European rabbits (Oryctolagus cuniculus), European hedgehogs (Erinaceus europaeus), Norway rats (Rattus norvegicus), ship rats (Rattus rattus) and house mice (Mus musculus). All patches were within $300 \mathrm{~m}$ of residential areas, dominated by 10-25 low-rise single-dwelling houses per hectare. To select forest patches, I followed a stratified sampling design based on the location, size, and forest type. I used a publicly available classification system of New Zealand land cover (Land Cover DataBase, version 4.1) to select patches of native $(n=29)$ and exotic $(n=18)$ forest that range in size from small, medium, and large (1-5, 6-25, and 26-100 ha, respectively). Patches of native forests included mature indigenous forest and early-successional broadleaved indigenous hardwoods. Mature indigenous forest were remnants of native forest, a canopy height $>10 \mathrm{~m}$ and were dominated by indigenous conifer and broadleaved species including rimu (Dacrydium cupressinum), tōtara (Podocarpus totara), tawa (Beilschmiedia tawa) and kohekohe (Dysoxylum spectabile). Patches of early-successional broadleaved indigenous hardwoods were lowland scrub environments with a canopy height of 2-10 m, dominated by indigenous broadleaved shrubs including makomako (Aristotelia serrata), mahoe (Melicytus ramiflorus) and whauwhaupaku (Pseudopanax arboreus). Patches of exotic forest had a canopy height $>10 \mathrm{~m}$ and were dominated by pines (Pinus radiata) or macrocarpa (Cupressus macrocarpa). 


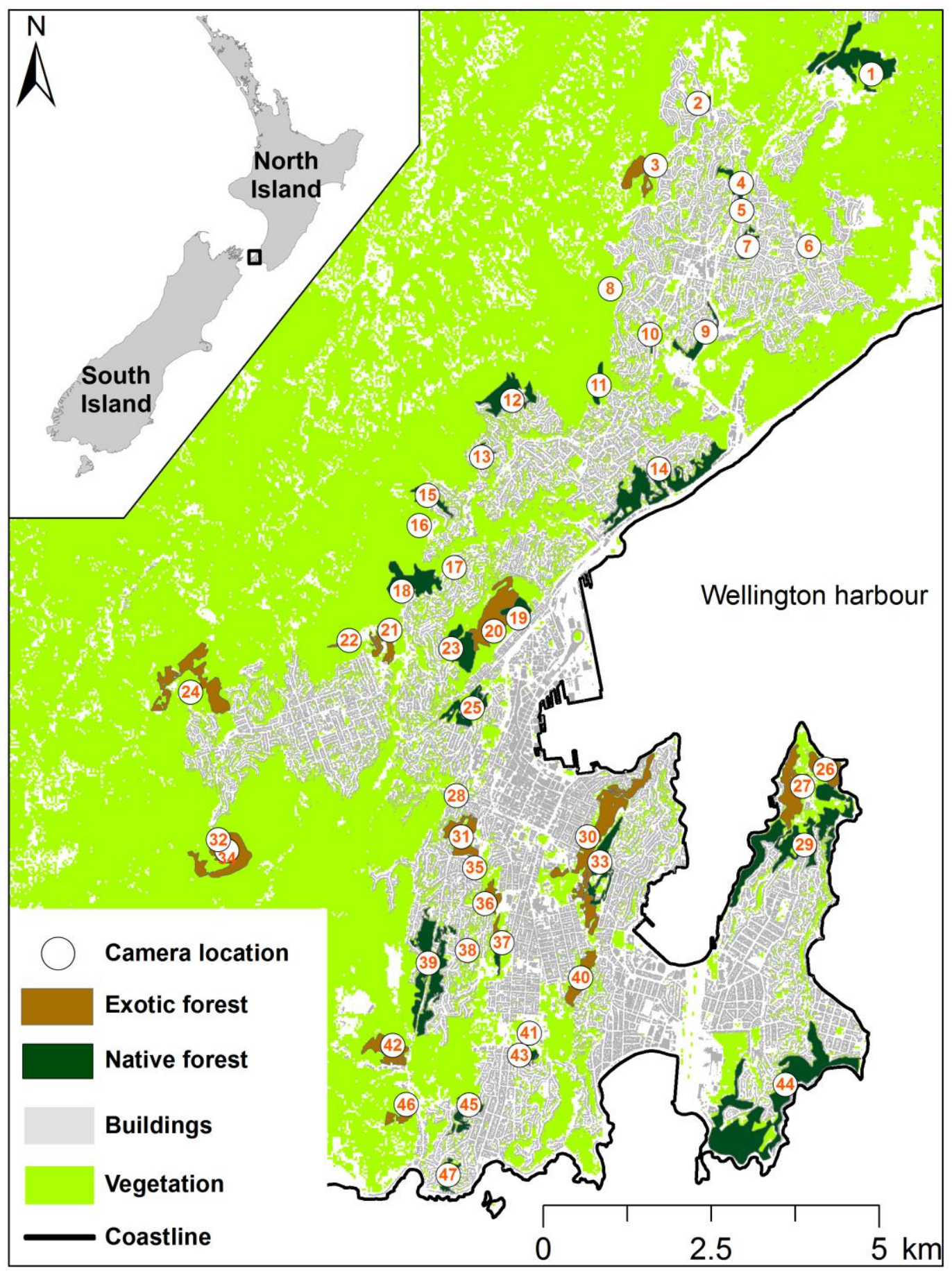

Figure 4.1 Location of the 47 patches of exotic and native forest, the camera located at $40 \mathrm{~m}$ from the boundary of the patch, and the buildings and vegetation in Wellington, New Zealand. Adjacent patches of forest differ in vegetation type. 


\section{Data collection}

\section{Remote camera data}

I deployed remote cameras (Bushnell, model: 119537) between December 2015 and November 2016. Cameras were active at each patch for 30 days per calendar season (i.e. austral summer (Dec-Feb), autumn (Mar-May), winter (Jun-Aug), and spring (Sep-Nov)) with a two-month monitoring gap for each camera site between seasons. I attached the cameras to trees $50 \mathrm{~cm}$ above the ground facing down at $20^{\circ}$ degrees (Chapter 1 ). When triggered, the cameras took a sequence of three photographs within 3 seconds. To investigate how the forest edge influenced the relative abundance of mammals, I deployed the cameras at 10, 40 and $70 \mathrm{~m}$ along a transect that started at a randomly selected point along the patch perimeter and passed through the centroid of the patch (Figure 4.2). In small and non-circular patches $(n=30)$, cameras deployed at the $70 \mathrm{~m}$ mark were closer to a different point on the opposite edge (14-68 $\mathrm{m}$ to the closest forest edge). I used distance to the closest edge to investigate the edge effect. To maximise the field of view of the cameras and standardize the survey methodology, I deployed cameras in places with minimal understory vegetation, gentle slopes and at least $5 \mathrm{~m}$ away from any walking track. The final GPS location of the cameras (hereafter camera sites) never exceeded $10 \mathrm{~m}$ from the initial location and cameras were always at least $20 \mathrm{~m}$ apart from each other.

I uploaded all photos collected to a citizen science website hosted by Zooniverse (www.identifyanimals.co.nz), where volunteers from the public classified them. I used the number of volunteers that have classified each photograph and the agreement amongst their classification as the criterion to ensure volunteers accurately classified the 
photographs (Chapter 0). I classified those photographs for which the volunteer classifications did not reach the accuracy criteria. I also classified to species level photographs classified by volunteers as lagomorphs, mustelids, and rodents. If the quality of the photographs prevented me from classifying the animal recorded to the species level, I identified them to the genus level or classified them as "unclassifiable".

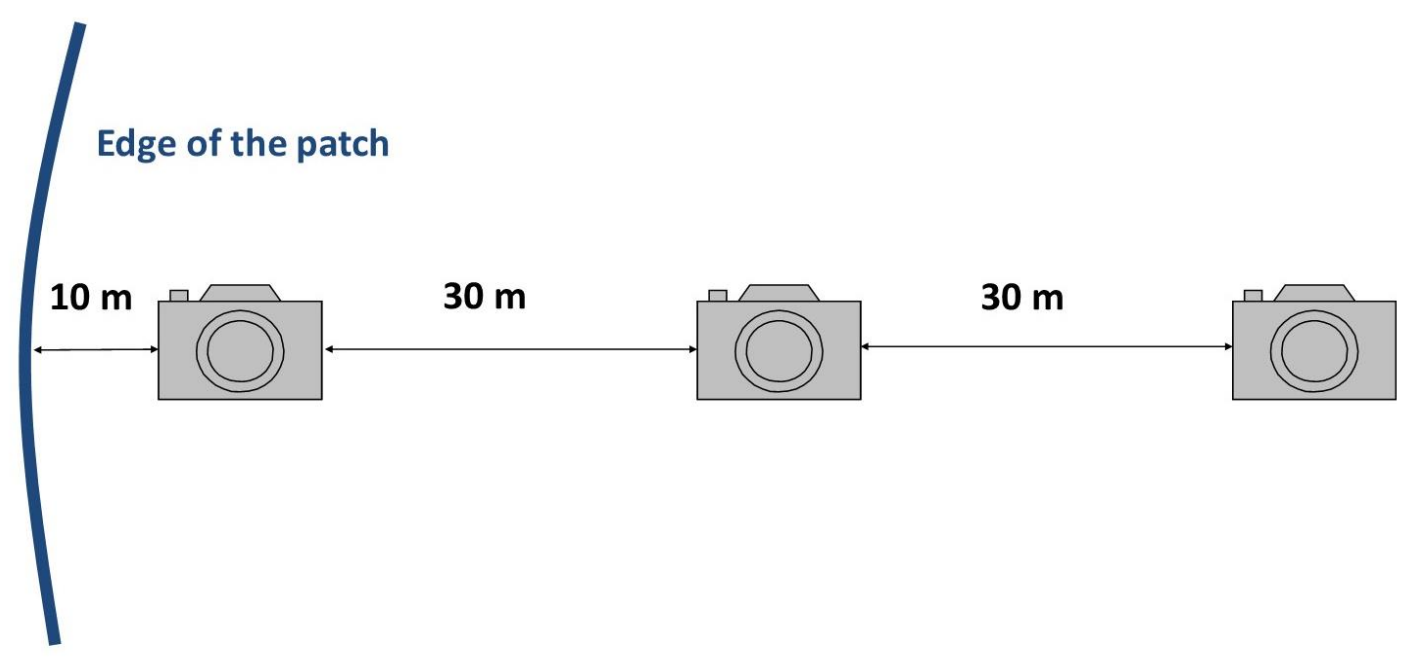

Figure 4.2 Schematic diagram of the location of remote cameras at each patch of forest.

\section{Environmental and anthropogenic covariates}

First, I used the information compiled in the New Zealand land cover database to estimate the size of the patch and its perimeter (measured in hectares and kilometres, respectively). Second, I divided size by perimeter to estimate the shape of the patch. Third, I estimated the percentage of area covered by buildings and vegetation in buffer zones of 50 and 100 meters around each patch to estimate the influence of human-built structures and nearby vegetation on the presence of target species. Note land uses within the buffer zones also included other categories (e.g. bare ground, transport infrastructures and bodies of water), thus, vegetation and building were not always correlated. I calculated the building and vegetation cover at different spatial scales to match them to 
differences in home range sizes of my target species (Table 4.1) (Andren 1994). To estimate the proportion of the buffer area covered by buildings, I used the outlines of building rooftops from the "Wellington City Building Footprints" GIS layer (Retrieved from: https://koordinates.com/layer/1474-wellington-city-building-footprints/). To estimate the proportion of the buffer area covered by vegetation, I used multispectral imagery collected by the satellite Landsat 8 on December 2015. I ran a k-mean clustering unsupervised classification of the multispectral imagery using ENVI version 4.8 (Exelis Visual Information Solutions 2010) to classify the areas within the buffer zone into 25 categories (Wagstaff et al. 2001). I then manually reclassified the categories into vegetation or other land cover using orthophotography of the region taken in 2012-13 (retrieved from: https://data.linz.govt.nz/layer/51870-wellington-03m-rural-aerial-photos2012-2013/). 
Table 4.1 Covariates included in modelling of the occupancy of mammalian invasive non-native species in patches of forest within Wellington, New Zealand. Minimum and maximum values of the covariates are represented for discrete variables.

\begin{tabular}{llll} 
Category & Covariates & Unit & Min.-max. \\
\hline \hline Habitat & Shape & Kilometres/hectare & $1.32-7.57$ \\
characteristics & (perimeter/area) & & \\
& Forest type & Categorical: Native vs exotic & \\
& & canopy & $0.00-29.58$ \\
Buffer area* & Area covered by & Percent & \\
& buildings & & $17.84-100.00$ \\
& Area covered by & Percent & \\
vegetation & Capture rates of other & $0.00-0.75$ \\
Interspecies & Interaction levels & mammalian species per & \\
& & camera trap day & \\
& & &
\end{tabular}

\begin{tabular}{|c|c|c|c|}
\hline \multirow[t]{2}{*}{$\begin{array}{l}\text { Anthropogenic } \\
\text { activities }\end{array}$} & People off-track & $\begin{array}{l}\text { Capture rates of people per } \\
\text { camera trap day }\end{array}$ & $0.00-0.16$ \\
\hline & Trap density & $\begin{array}{l}\text { Number of species-specific } \\
\text { devices per hectare }\end{array}$ & $0.00-5.11$ \\
\hline
\end{tabular}

*The buffer area was $50 \mathrm{~m}$ for hedgehogs and rodents, and $100 \mathrm{~m}$ for dogs, possums, lagomorphs, and cats.

Local authorities and community groups in Wellington use an array of traps and poison-bait stations to control the number of possums, mustelids, hedgehogs, and rodents 
within the city (Greater Wellington Regional Council 2007). The traps were checked at least once per year and included "DOC 200" and "A24" (Department of Conservation and GoodNature ${ }^{\circledR}$ Ltd., respectively) for stoats, hedgehogs, and rodents, “A12" (GoodNature ${ }^{\circledR}$ Ltd.) for possums, "stoat snap trap" $\left(\right.$ Victor $\left.^{\circledR}\right)$ for stoats and rats, and "rat snap trap" $\left(\right.$ Victor $\left.^{\circledR}\right)$ and "Big Snap-E® traps" for rodents. Poison-bait stations were serviced at least twice per year, in spring and summer, with diphacinone or brodifacoum to control the numbers of possums and rodents. Based on the geographical location of the traps and poison-bait stations active at the time of the data collection, I calculated the density of species-specific devices at each patch of forest. Geolocation data of the traps and poison baits was compiled and provided by the Greater Wellington Regional Council and the Wellington City Council.

I used camera detections of each species to better understand the influence of interactions among invasive mammals. First, to estimate the capture rates of each species, I calculated the total number of independent detections per camera over a calendar season. I defined independent detections as photographic events collected from the same camera site and separated by at least 30 minutes (Rich et al. 2017). Second, I divided the total number of independent detections by the number of days that the camera was active to account for camera trap effort and used this as the capture rate per species (Burton et al. 2015). I used the same approach to estimate daily capture rates of people recorded offtrack by the cameras. 


\section{Data analysis}

\section{Edge effect and seasonality}

I used the capture rates of each species to estimate how edge effect and seasonality affect the relative abundance of target species. In addition to the capture rates of Norway and ship rats, I also evaluated the capture rates of Rattus spp. because some photographs of rats could not be identified to the species level. The number of days when the species were not recorded was higher than expected from a Poisson distribution of the same number of total detections. To account for this distribution, I used fixed effect Zero Inflated Poisson models (ZIP). ZIP models enabled me to model the probability of measuring zeroes as a binomial process and the capture rates as a Poisson process (Dénes et al. 2015). I used patch identity as a covariate to model the binomial probability of measuring zeroes. I used distance to the nearest forest edge and calendar season to model the capture rates recorded per day. I used $P<0.05$ as the threshold of significance. I assessed the variance explained by the models using the pseudo $\mathrm{R}^{2}$ (Martin and Hall 2016). The analysis was done in $\mathrm{R}$ ( $\mathrm{R}$ Core Team 2016) using the zeroinfl function in package "pscl" (Jackman et al. 2017).

\section{Patch occupancy}

I used a likelihood based approach to estimate the underlying occupancy of each species in urban patches of forest accounting for detection probabilities of $<1$ (Mackenzie et al. 2002). I only estimated the occupancy of invasive mammals during spring and autumn to investigate factors influencing the distribution of these species when they are particularly

detrimental to native biodiversity (Flux 2007; King \& Powell 2011; Tompkins et al. 
2013). I used the detection/non-detection of each species recorded by the set of three cameras in a patch to construct species-specific detection histories at each of the 47 patches. To increase detection probabilities of species found at low densities, I grouped daily detection/non-detection into surveys of 3 days (i.e. 10 surveys per season) (Ehlers Smith et al. 2018). I used species-specific covariates to evaluate how habitat characteristics, anthropogenic influences, and interspecific interactions influence the occupancy of mammals in urban patches of vegetation (Table 4.1). I selected patch shape instead of patch size because this parameter has been shown to more accurately correlate with mammalian diversity in patches of vegetation within urban environments (Fernández \& Simonetti 2013). I rescaled continuous variables to have a mean of zero and unit variance to improve convergence of model estimates (MacKenzie et al. 2017). I also used the Spearman's rho test to ensure covariates were not correlated (tested with $r<$ 0.5) (Graham 2003).

I fitted single-season occupancy models separately to the spring and autumn detection history of each species. During each month of sampling, I assumed that species did not become locally extinct or colonised new patches of urban vegetation (i.e. closed populations within seasons (Mackenzie et al. 2002)). I calculated the total number of patches in which each species was detected per season (i.e. the naïve occupancy) and modelled the occupancy of species detected in $>20 \%$ of the patches (MacKenzie et al. 2017). I estimated two parameters using these occupancy models: 1) the probability that a species occupies a given patch $(\psi)$ and 2$)$ the probability of detecting the species, provided it occupies the patch $(p)$. I followed a model inference approach to evaluate the underlying processes influencing the occupancy of each species. I modelled $\psi$ using 
covariates (i.e. habitat characteristics, interspecies interactions, and anthropogenic activities) that were biologically relevant for each species (Appendix 4.1 and Appendix 4.2). I modelled $p$ using the number of cameras active per survey and the day of the season (represented as "Cam_n" and "Day_season" in the models, respectively). I modelled day of the season (e.g. the first, second or last day of summer) as the probability of detecting species to account for changes in the activity levels of animals within seasons. I also generated a null and full model to ensure models did not converge on local minima or maxima (MacKenzie et al. 2017). The total number of models per species ranged from 10 to 14 (Appendix 4.1). I calculated the Akaike Information Criterion (AIC) values corrected for small sample sizes $\left(\mathrm{AIC}_{\mathrm{c}}\right)$ and $\mathrm{AIC}_{\mathrm{c}}$ weights of the models (Burnham \& Anderson 2002). AIC $\mathrm{c}$ weights $\left(w_{i}\right)$ provided the proportional weight of each model, $i$, with respect to the best model (the model with the lowest $\mathrm{AIC}_{\mathrm{c}}$ value). To assess the relative importance of each covariate in the occupancy of the species, I summed the $w_{i}\left(\sum w_{i}\right)$ of the models containing the covariate. The threshold of $\sum w_{i}$ for which covariates should be considered important is study-specific (Kolowski \& Forrester 2017). Here, I considered covariates with $\sum w_{i}>0.2$ to have an influence in the occupancy of the species. To test for over-dispersion of the model and lack of fit of the models, I calculated the $\hat{c}$ and assessed model fit with a parametric $\chi 2$ test for the topranked occupancy models (MacKenzie \& Bailey 2004). Occupancy models were estimated using the Rpresence package (MacKenzie \& Hines 2018) in R (R Core Team 2016). 


\section{Results}

\section{Capture rates}

I recorded a total of 18,894 camera days, with an average of 34 days ( $\mathrm{SD} \pm 4$ ) per camera site per season. During all seasons, cats were the most frequently recorded invasive mammal. Cats were recorded an average of 0.20 independent photographic events per day. Hedgehogs and mice were the second and third most frequently recorded species. On average, cameras recorded 0.08 and 0.05 independent photographic events of hedgehogs and mice, respectively, per day. Stoats were the least recorded invasive species with only four independent photographic events $(0.0002$ photographic events per day) over the entire study period.

The number of possums, cats, rabbits and hedgehogs recorded by cameras significantly decreased with increasing distance from the forest edge (Figure 4.3, Table 4.2 and Table 4.3). Distance to forest edge was the most influential in the capture rates of possums $(\hat{\beta}=-0.03, P<0.00)$. Capture rates of rodents were positively influenced by the distance to forest edge (Table 4.3). The capture rates of rat spp., Norway rats and mice significantly increased with distance to the forest edge $(\hat{\beta}=0.01, P<0.00, \hat{\beta}=0.02, P<$ 0.00 , and $\hat{\beta}=0.02, P<0.00$, respectively); the increase in the capture rates of ship rats was not significant.

Seasonality influenced the photographic capture rates of most invasive mammals except for possums, hares and Norway rats (Table 4.2 and Table 4.3). Capture rates of dogs, cats and rabbits all peaked during winter/spring $\left(\mu_{C R}=0.02 \pm 0.00, \mu_{C R}=0.24 \pm\right.$ 0.01 , and $\mu_{C R}=0.06 \pm 0.01$, respectively). The capture rates of hedgehogs were 
significantly lower during winter/spring compared to summer/autumn $\left(\mu_{C R}=0.04 \pm 0.00\right.$ and $\mu_{C R}=0.12 \pm 0.00$, respectively). Capture rates of rodents on the other hand peaked during winter/spring (Table 4.3). 


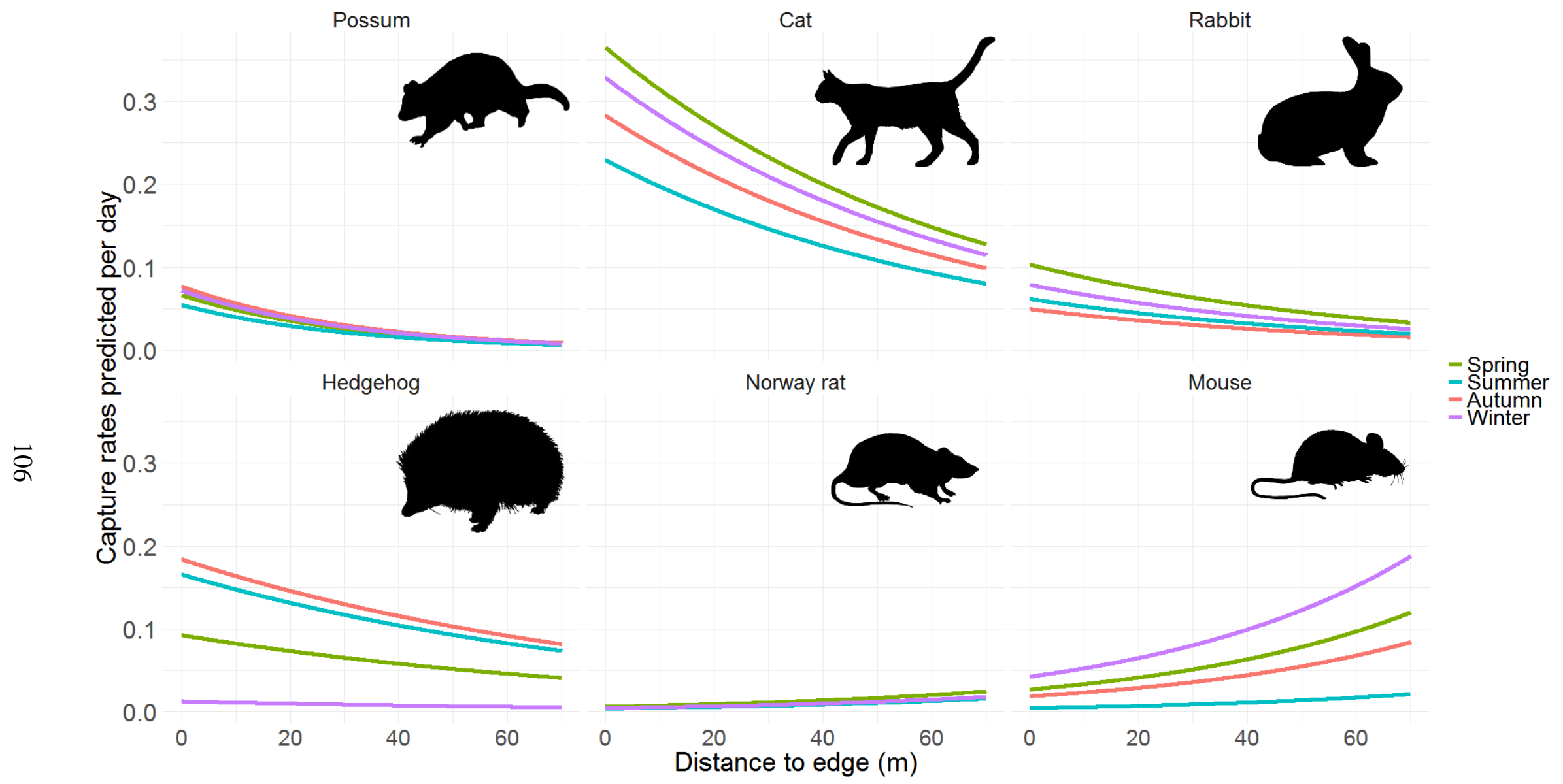

Figure 4.3 Predicted capture rates by cameras during spring, summer, autumn, and winter of invasive mammalian species that were statistically influenced by distance to forest edge. Zero Inflated Poisson models with distance to the forest edge and calendar season were used to predict the capture rates per day. 
Table 4.2 Logit-transformed estimates of slopes $(\widehat{\boldsymbol{\beta}}), \pm$ standard errors $(\mathrm{SE})$, of the Zero Inflated Poisson models used to estimate the influence of distance to the forest edge $(\mathrm{m})$ and seasonality (spring as reference) in the capture rates of medium-sized invasive mammals. Pseudo $\mathrm{R}^{2}$ provided for each species model. Coefficients highlighted in bold were statistically significant.

\begin{tabular}{|c|c|c|c|}
\hline Species & Parameter & $\hat{\beta} \pm \mathrm{SE}$ & $P$ value \\
\hline Dog & Intercept & $-0.61 \pm 0.30$ & 0.04 \\
\hline \multirow[t]{4}{*}{$\mathrm{R}^{2}=0.12$} & Distance & $0.00 \pm 0.01$ & 0.49 \\
\hline & Summer & $-1.38 \pm 0.28$ & 0.00 \\
\hline & Autumn & $-1.27 \pm 0.27$ & 0.00 \\
\hline & Winter & $-1.60 \pm 0.29$ & 0.00 \\
\hline Possum & Intercept & $-0.06 \pm 0.13$ & 0.64 \\
\hline \multirow{4}{*}{$\mathrm{R}^{2}=0.21$} & Distance & $-0.03 \pm 0.00$ & 0.00 \\
\hline & Summer & $-0.19 \pm 0.14$ & 0.16 \\
\hline & Autumn & $0.15 \pm 0.13$ & 0.24 \\
\hline & Winter & $0.08 \pm 0.13$ & 0.53 \\
\hline Cat & Intercept & $0.10 \pm 0.05$ & 0.02 \\
\hline \multirow[t]{4}{*}{$\mathrm{R}^{2}=0.10$} & Distance & $-0.01 \pm 0.00$ & 0.00 \\
\hline & Summer & $-0.46 \pm 0.05$ & 0.00 \\
\hline & Autumn & $-0.25 \pm 0.05$ & 0.00 \\
\hline & Winter & $-0.11 \pm 0.05$ & 0.03 \\
\hline Hare & Intercept & $-2.47 \pm 0.60$ & 0.00 \\
\hline \multirow[t]{4}{*}{$\mathrm{R}^{2}=0.07$} & Distance & $0.01 \pm 0.01$ & 0.18 \\
\hline & Summer & $0.55 \pm 0.45$ & 0.22 \\
\hline & Autumn & $0.61 \pm 0.45$ & 0.17 \\
\hline & Winter & $0.72 \pm 0.44$ & 0.10 \\
\hline Rabbit & Intercept & $0.32 \pm 0.10$ & 0.00 \\
\hline \multirow[t]{4}{*}{$\mathrm{R}^{2}=0.16$} & Distance & $-0.02 \pm 0.00$ & 0.00 \\
\hline & Summer & $-0.51 \pm 0.11$ & 0.00 \\
\hline & Autumn & $-0.73 \pm 0.12$ & 0.00 \\
\hline & Winter & $-0.27 \pm 0.10$ & 0.01 \\
\hline
\end{tabular}


Table 4.3 Logit-transformed estimates of slopes $(\widehat{\boldsymbol{\beta}}), \pm$ standard errors $(\mathrm{SE})$, of the Zero Inflated Poisson models used to estimate the influence of distance to the forest edge $(\mathrm{m})$ and seasonality (spring as reference) in the capture rates of small invasive mammals recorded by the cameras. Pseudo $\mathrm{R}^{2}$ provided for each species model. Coefficients highlighted in bold were statistically significant.

\begin{tabular}{|c|c|c|c|}
\hline Species & Parameter & $\hat{\beta} \pm \mathrm{SE}$ & $P$ value \\
\hline Hedgehog & Intercept & $-0.80 \pm 0.09$ & 0.00 \\
\hline \multirow[t]{4}{*}{$\mathrm{R}^{2}=0.16$} & Distance & $-0.01 \pm 0.00$ & 0.00 \\
\hline & Summer & $0.58 \pm 0.08$ & 0.00 \\
\hline & Autumn & $0.69 \pm 0.08$ & 0.00 \\
\hline & Winter & $-1.97 \pm 0.16$ & 0.00 \\
\hline Rat spp. & Intercept & $-1.37 \pm 0.18$ & 0.00 \\
\hline \multirow[t]{4}{*}{$\mathrm{R}^{2}=0.09$} & Distance & $0.01 \pm 0.00$ & 0.00 \\
\hline & Summer & $-0.53 \pm 0.16$ & 0.00 \\
\hline & Autumn & $-0.27 \pm 0.15$ & 0.07 \\
\hline & Winter & $0.26 \pm 0.14$ & 0.06 \\
\hline Norway rat & Intercept & $-1.18 \pm 0.30$ & 0.00 \\
\hline \multirow[t]{4}{*}{$\mathrm{R}^{2}=0.20$} & Distance & $0.02 \pm 0.00$ & 0.00 \\
\hline & Summer & $-0.44 \pm 0.23$ & 0.06 \\
\hline & Autumn & $-0.40 \pm 0.22$ & 0.06 \\
\hline & Winter & $-0.31 \pm 0.22$ & 0.16 \\
\hline Ship rat & Intercept & $-1.27 \pm 0.17$ & 0.00 \\
\hline \multirow[t]{4}{*}{$\mathrm{R}^{2}=0.28$} & Distance & $0.00 \pm 0.00$ & 0.89 \\
\hline & Summer & $-0.05 \pm 0.18$ & 0.80 \\
\hline & Autumn & $0.48 \pm 0.17$ & 0.00 \\
\hline & Winter & $1.69 \pm 0.15$ & 0.00 \\
\hline Mouse & Intercept & $-1.49 \pm 0.12$ & 0.00 \\
\hline \multirow[t]{4}{*}{$\mathrm{R}^{2}=0.21$} & Distance & $0.02 \pm 0.00$ & 0.00 \\
\hline & Summer & $-1.71 \pm 0.16$ & 0.00 \\
\hline & Autumn & $-0.36 \pm 0.10$ & 0.00 \\
\hline & Winter & $0.45 \pm 0.09$ & 0.00 \\
\hline
\end{tabular}




\section{Patch occupancy}

Cats, hedgehogs, and mice were the most widespread mammalian species recorded during spring and autumn. Cats were recorded in $96 \%$ and $94 \%$ of the patches during spring and autumn, respectively. Hedgehogs and mice were recorded in $70-83 \%$ of the patches during both seasons. All species but stoats, hares and Norway rats were recorded in at least $20 \%$ of the patches ( $\left.\psi_{\text {naive }}>0.2\right)$. These three species were excluded from further analysis due to the limited statistical power to investigate the underlying factors influencing their occupancy. Most of the models identified at least one important covariate influencing their occupancy during spring and autumn (Appendix 4.3 and Appendix 4.4). Only models estimating the occupancy of rats during autumn did not report any covariate as important. There was no evidence of over dispersion for the best models of each species $(\hat{c}=0.4-3.3)$.

Habitat characteristics within and around forest patches influenced the occupancy of possums, cats, rabbits, hedgehogs and rat spp. (Table 4.4). Patch shape influenced the occupancy of possums and hedgehogs during autumn. While, possums were more likely to occupy large rounded-shape patches $\left(\hat{\beta}=-0.51, \sum w_{\text {shape }}=0.41\right)$, hedgehogs were more likely to occupy small patches with irregular shapes $\left(\hat{\beta}=0.54, \sum w_{\text {shape }}=0.39\right)$. The type of forest was also an important covariate to predict occupancy of possums during autumn. Possums were more likely to occupy patches of native forest compared to patches of exotic forest $\left(\widehat{\psi_{\text {natve }}}=0.34 \pm 0.11\right.$ and $\left.\widehat{\psi_{\text {exot }}}=0.53 \pm 0.09\right)$. The proportion of area covered by buildings adjacent to the patches influenced positively the occupancy of cats during spring and autumn $\left(\hat{\beta}=3.09, \sum w_{\text {buildings }}=0.55\right.$ and $\hat{\beta}=3.26, \sum w_{\text {buildings }}=0.55$, 
respectively) and rats spp. during spring $\left(\hat{\beta}=0.59, \sum w_{\text {buildings }}=0.30\right)$. Vegetation surrounding the patches influenced the occupancy of rabbits and hedgehogs. Rabbits were positively influenced by vegetation during spring and autumn $\left(\hat{\beta}=1.17, \sum w_{\text {vegetation }}\right.$ $=0.84$ and $\hat{\beta}=0.77, \sum w_{\text {vegetation }}=0.65$, respectively). Patch occupancy of hedgehogs was negatively influenced by surrounding vegetation during spring but positively during autumn $\left(\hat{\beta}_{\text {spring }}=-0.94, \sum w_{\text {vegetation }}=0.36\right.$ and $\left.\hat{\beta}_{\text {autumn }}=0.17, \sum w_{\text {vegetation }}=0.20\right)$. 
Table 4.4 Parameters used to model probability of occupancy $(\psi)$ and detection probability $(p)$, along with the summary statistics (logit-transformed estimates of the intercepts $(\widehat{\boldsymbol{\alpha}})$, and slopes of the covariates $(\widehat{\boldsymbol{\beta}}), \pm$ standard errors $(\mathrm{SE}))$ of the best performing models (i.e. $\left.\sum w_{i}>0.2\right)$ predicting the occupancy of invasive mammalian species in urban patches of forest. The number of cameras active during the survey and the day of the season are represented as "Cam_n" and "Day_season".

Species Season $\psi$ covariate $\quad p$ covariates $\hat{\alpha} \pm \mathrm{SE} \quad \hat{\beta} \pm \mathrm{SE}$

\begin{tabular}{|c|c|c|c|c|c|}
\hline \multirow[t]{3}{*}{ Possum } & Spring & Traps & Cam_n & $-1.17 \pm 0.39$ & $-0.99 \pm 0.63$ \\
\hline & \multirow[t]{2}{*}{ Autumn } & Shape & Cam_n + Day_season & $-0.18 \pm 0.31$ & $-0.51 \pm 0.32$ \\
\hline & & Forest type & Cam_n + Day_season & $-0.65 \pm 0.51$ & $0.77 \pm 0.63$ \\
\hline \multirow[t]{2}{*}{ Cat } & Spring & Buildings & Cam_n + Day_season & $5.18 \pm 2.85$ & $3.09 \pm 2.40$ \\
\hline & Autumn & Buildings & Cam_n & $5.00 \pm 2.59$ & $3.26 \pm 2.19$ \\
\hline \multirow[t]{2}{*}{ Rabbit } & Spring & Vegetation & Cam_n & $-1.47 \pm 0.45$ & $1.17 \pm 0.42$ \\
\hline & Autumn & Vegetation & Cam_n & $-1.44 \pm 0.41$ & $0.77 \pm 0.38$ \\
\hline \multirow[t]{4}{*}{ Hedgehog } & \multirow[t]{2}{*}{ Spring } & Traps & Cam_n & $-0.72 \pm 0.78$ & $-2.48 \pm 1.02$ \\
\hline & & Vegetation & Cam_n & $1.16 \pm 0.38$ & $-0.94 \pm 0.38$ \\
\hline & \multirow[t]{2}{*}{ Autumn } & Shape & Cam_n + Day_season & $1.71 \pm 0.43$ & $0.54 \pm 0.47$ \\
\hline & & Vegetation & Cam_n + Day_season & $1.64 \pm 0.41$ & $0.17 \pm 0.11$ \\
\hline \multirow[t]{2}{*}{ Rat spp. } & \multirow[t]{2}{*}{ Spring } & Buildings & Cam_n + Day_season & $-0.00 \pm 0.33$ & $0.59 \pm 0.34$ \\
\hline & & Cat & Cam_n + Day_season & $-0.08 \pm 0.32$ & $0.47 \pm 0.32$ \\
\hline \multirow[t]{3}{*}{ Ship rat } & \multirow[t]{2}{*}{ Spring } & Traps & Cam_n + Day_season & $-1.00 \pm 0.39$ & $-0.69 \pm 0.46$ \\
\hline & & N. rat & Cam_n + Day_season & $-1.25 \pm 0.38$ & $0.44 \pm 0.31$ \\
\hline & Autumn & N. rat & Cam_n + Day_season & $-0.60 \pm 0.35$ & $1.20 \pm 0.80$ \\
\hline \multirow[t]{2}{*}{ Mouse } & Spring & Traps & Cam_n & $1.48 \pm 0.48$ & $-1.23 \pm 0.51$ \\
\hline & Autumn & Traps & Cam_n & $1.27 \pm 0.40$ & $-0.67 \pm 0.37$ \\
\hline
\end{tabular}


The influence of management efforts, measured as the density of traps and poison-bait devices, on the occupancy of targeted invasive mammals differed depending on the species and season (Table 4.4). During spring, occupancy models containing density of traps as a covariate had a cumulative $\mathrm{AIC}_{\mathrm{c}}$ weight of 0.49 for possums, 0.40 for hedgehogs, 0.31 for ship rats and 0.64 for mice. Only the best occupancy model of mice during autumn contained density of traps as a covariate (Appendix 4.3 and Appendix 4.4). The occupancy estimates of possums, hedgehogs and ship rats in patches with at least 1.5 trapping device per hectare was estimated to be lower than 0.25 (Figure 4.4). To achieve similar occupancy estimates of mice, patches needed to have at least 3.5 trapping devices per hectare.

There were two important interspecific interactions influencing the occupancy of cats and ship rats. Abundances of cats were positively correlated with the occupancy of rats $\left(\hat{\beta}_{\text {spring }}=0.47\right)$. Ship rats were more likely to occupy patches with high relative abundance of Norway rats than patches with low abundance of Norway rats $\left(\hat{\beta}_{\text {spring }}=0.44\right.$ and $\hat{\beta}_{\text {autumn }}=1.20$ ).

The probability of detecting possums, cats, hedgehogs, rats and ship rats by the cameras was influenced by the day of the season. Possums, hedgehogs, and ship rats were more likely to be detected in early autumn $(\hat{\beta}=-0.02$ for the three species). Cats, rats and ship rats were more likely to be detected in late spring $\left(\hat{\beta}_{\text {Cat }}=0.01, \hat{\beta}_{\text {Rat spp. }}=0.02\right.$, and $\left.\hat{\beta}_{\text {Ship rat }}=0.05\right)$. 


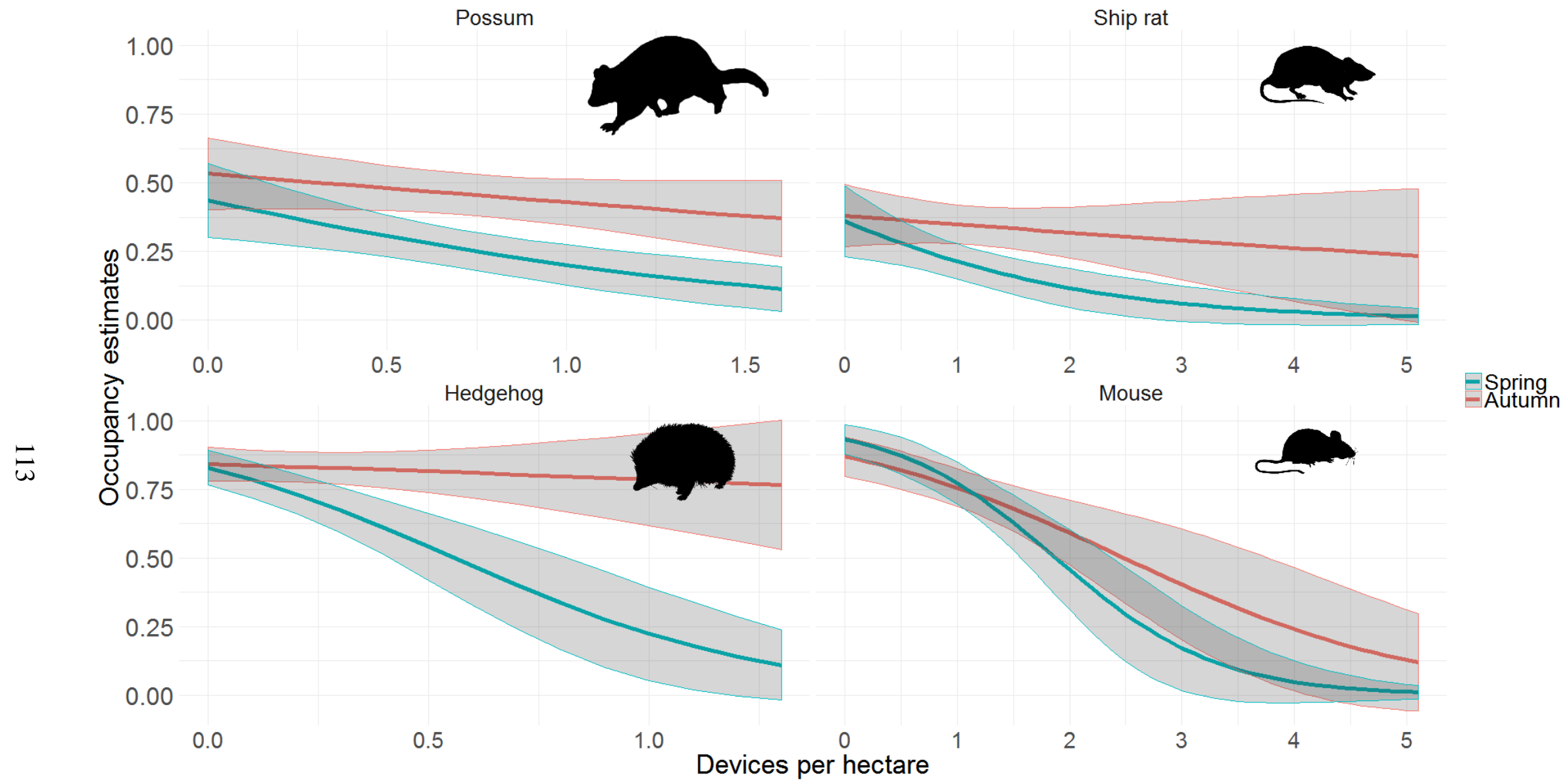

Figure 4.4 Predicted occupancy estimates at different trap and poison devices densities during autumn and spring of invasive mammalian species targeted in mammalian control management. Occupancy models with density of traps as a covariate of occupancy and that best explained the probability of detecting the species were used to predict the occupancy estimates. 


\section{Discussion and conclusion}

The diversity of mammalian species found in urban patches of vegetation is influenced by the habitat quality of the patches (McIntyre 2014). However, urban patches of vegetation are not isolated units within the urban matrix. Surrounding environments and anthropogenic activities also influence the abundance and diversity of mammalian species (Fernández \& Simonetti 2013). In my study, the socio-ecological factors influencing abundance and diversity of invasive mammals in urban patches of forest were species specific and differed depending on a number of variables including calendar season, patch shape, patch vegetation, connectivity, control efforts, and interspecies interactions.

Cats are among the most common species in urban environments (Doherty et al. 2016) and were also the most abundant species recorded in my study. Cat densities in cities are influenced by both bottom-up (e.g. food availability) and top-down processes (e.g. predation or competition with other species) (Flockhart et al. 2016). For cats in urban environments in New Zealand, bottom-up processes likely outweigh the influence of top-down forces due to the lack of natural predators and competitors (Kikillus et al. 2017). However, the abundance of prey, rodents and lagomorphs (Flux 2017), was not a significant predictor of cat occupancy in my study. One explanation may be that other prey species, including lizards and birds influenced their distribution (McDonald et al. 2015) or that cats were not limited by food resources. Further studies are required to better understand the influence predator-prey interactions play in shaping abundance and distribution patterns of cats in urban environments. Consistent with the findings reported by Flockhart et al. (2016), the proportion of surrounding houses and other built-up 
infrastructures influenced cat occupancy in the urban patches of forest I studied. The positive influence of the built-up environment on the occupancy of cats and the great capture rates recorded at the forest edge indicated most of the cats were either stray or domestic (i.e. not feral). My results, thus, suggest domestic and stray cats can be found at high densities in urban patches of forest in Wellington. Cats were also more abundant in spring when native birds and lizards in New Zealand are particularly vulnerable to predation (Heber et al. 2008; Gordon et al. 2010). Management programmes aiming to suppress the abundance of domestic and stray cats, particularly during spring, may be required to minimise the impact these species pose on the native biota found in urban forest patches.

Norway rats, ship rats and mice are among the most ubiquitous urban invasive mammals worldwide (Banks \& Smith 2015). Norway and ship rats, despite having different habitat requirements (Feng \& Himsworth 2014), are both positively affected by density of houses and anthropogenic food resources (Tamayo-Uria et al. 2014). Consistent with the results of Banks and Smith (2015), the data I collected also suggest rats spill over from residential environments to adjacent forest patches. In my study, ship rats were more widespread and abundant than Norway rats. These results are also congruent with those of Lincoln (2016) and Morgan et al. (2009), who reported ship rats outnumber Norway rats in other New Zealand cities (19:2 in Hamilton and 279:9 in Auckland). The abundance of Norway rats was an important predictor of the presence of ship rats in a patch of forest. This co-occurrence suggests that urban forest patches have sufficient resources to meet the needs of both rat species. I also found management efforts aiming to suppress the abundance of rodents had a strong influence on the 
occupancy of ship rats and mice, particularly during spring. My results suggest that control of rodents in patches of vegetation and residential environments throughout the year might be needed if the conservation goal is to eradicate invasive mammals, as recently proposed by the New Zealand government (Russell et al. 2015).

Contrary to findings reported by Adams et al. (2013) and Villaseñor et al. (2014), the relative abundance of possums recorded in urban patches of forest decreased towards the interior of the patch. Camera deployment, at the ground level, might have confounded the capture rates of this mammals. Possums, along with ship rats, were the only two arboreal species recorded in this study (Hooker \& Innes 1995; Carthew et al. 2015). Possums might have been more likely to be recorded by the cameras at the forest edge due to the lower height of the canopy cover at these areas compared to the core of the patch. This idea was further supported when I accounted for the probability of cameras detecting possums. Consistent with Harper et al. (2008) and Adams et al. (2014b), possums in my study had a good congruence with patchy habitat but preferred circular and big patches of forest compared to small and irregular.

The characteristics of the habitat around urban patches of forest influence the abundance and probability of occupancy of rabbits and hedgehogs. Cameras recorded rabbits at greater abundances closer to the forest edge compared to the interior of the patch. Similarly, the results from the occupancy modelling highlighted their affinity with forest edges and surrounding vegetation. My findings suggest rabbits might use urban patches of forest as links between more open, grassy spaces (e.g. wastelands and urban parks). This hypothesis is supported by the habitat preferences of the species reported by Morgan et al. (2009) across different gullies, amenity parks, and residential areas in 
Hamilton, New Zealand. Hedgehogs, the second most abundant species recorded in my study, were also found at greater abundances near the forest edge. These results line up with those reported by Braaker et al. (2014), who emphasized the importance of habitat connectivity for European hedgehogs. The characteristics of the surrounding environments, thus, need to be taken into account when designing and implementing programmes aiming to control rabbits and hedgehogs in urban patches of forest. The great abundance of both species recorded by the cameras highlight the need to revise current management control in urban forest patches in Wellington. Of special mention was the high number of patches occupied by hedgehogs during autumn, independently of the density of traps and poison baits.

While remote cameras enabled me to monitor the occupancy and relative abundance of multiple mammals in urban patches of forest, two characteristics of this monitoring technique need to be accounted for to adequately interpret my results. First, the relative abundance, based on the capture rates recorded by the cameras, might not be related to absolute animal density (Burton et al. 2015). I counted the records of the same species within 30 minutes as an independent event. However, species-specific behaviour and home ranges can influence the number of independent events per day (Appendix 4.7). These species-specific characteristics may have influenced the low variance explained by the capture rates models. Accounting for the probability of detection (i.e. using occupancy models), using informative prior distribution for the home-range-scale of the species (Ramsey et al. 2015), understanding their behaviour and ecology (Burton et al. 2015) and combining the presence/absence camera monitoring with other monitoring techniques (e.g. mark-release recapture studies) can assist identifying the confounding 
elements associated with disparities between capture rates and animal density. Second, I used the distance to the edge of the patch, and the density of traps and poison-bait devices to investigate the overall impact of forest edge and management efforts in invasive mammals. Numerous physical, chemical and environmental characteristics (e.g. soil conditions, canopy cover, and humidity) associated with the Euclidian distance to patch edge are involved in the influence forest edge can have in mammals (Ruffell \& Didham 2016). Furthermore, the efficiency of traps and poison bait devices in mammalian species is also influenced by many factors that I did not measure. These factors include type of device, bait used, frequency of re-setting traps, weather conditions, animal behaviour, and local density of the targeted species (Blackie et al. 2014). Further studies investigating the importance of these species-specific factors are required to better understand the underlying processes involved in the influence forest edge and management control programmes have on the occupancy and abundance of invasive mammals in urban environments. Likewise, further studies may be required to better understand whether the low numbers of stoats and hares recorded by the cameras in my study could be attributed to the control management programmes undertaken by the local councils and community groups (Brockie \& Duncan 2012) or to the inadequate sensitivity of the cameras to record fast moving animals (Glen et al. 2014).

Current understanding and best practices for managing invasive mammals in cities focus on the built-up environment due to the negative economic and health impacts associated with these species (Tamayo-Uria et al. 2014). However, as reported in this study, these species are also found in urban patches of vegetation where they can pose a major threat to native biota (Parsons et al. 2017). Managing mammals in cities, 
particularly those species used as companion animals (e.g. cats), is an emotive topic and a challenging task (Gaertner et al. 2017a). To ensure the social acceptance and maximise the efficiency of management operations aimed to control their populations, managers require a thorough understanding of their distribution. My results highlight the importance of using a season- and species-specific approach to identify the most important factors influencing the occurrence and abundance of invasive mammals in urban environments. The control of these species at adequate spatial and temporal scales is crucial to ensure effective conservation management in urban environments. 


\section{$\underline{\text { Acknowledgements }}$}

I thank Johannes Fischer and Samhita Bose for helping me at multiple stages of this study. Thanks to Amy Brasch, Chris Woolley, Jason Preble, Tamlyn McKenzie, Miguel Angel Canale, and Kerry Charles for their help in the field. I also thank the landowners of the patches of forest for providing access to their property, the local councils (Greater Wellington Regional Council and Wellington City Council) for providing information about the predator control undertaken in the study area and the thousands of Zooniverse users that helped me classifying the photographs recorded by the cameras. This research was financially supported by the Wellington City Council, and the School of Biological Sciences and the Centre for Biodiversity and Restoration Ecology from Victoria University of Wellington. I am also grateful for the tuition scholarship provided by Victoria University of Wellington. 


\section{$\underline{\text { Appendix }}$}

Appendix 4.1 Species-specific covariates used to model the occupancy of mammalian invasive species recorded in at least $20 \%$ of the patches.

\begin{tabular}{|c|c|c|c|c|c|}
\hline Species & Habitat characteristics & Buffer & Interspecies interactions & Anthropogenic activities & Number of covariates \\
\hline Dog & Shape and forest type & Buildings & & People off-track & 4 \\
\hline Possum & Shape and forest type & Vegetation & & Trap density & 4 \\
\hline Cat & Shape and forest type & Buildings & Rabbit and rodent & & 5 \\
\hline Rabbit & Shape and forest type & Vegetation & Cat & & 4 \\
\hline Hedgehog & Shape and forest type & Vegetation & & Trap density & 4 \\
\hline Rat spp. & Shape and forest type & Buildings & Cat & Trap density & 5 \\
\hline Ship rat & Shape and forest type & Buildings & Cat and N. rat & Trap density & 6 \\
\hline Mouse & Shape and forest type & Buildings & Cat and rat spp. & Trap density & 6 \\
\hline
\end{tabular}


Appendix 4.2 Species-specific interactions used to estimate the influence of species B in the occupancy of species A and supporting literature.

$\begin{array}{llll}\text { Species A } & \text { Species B Interaction type References }\end{array}$

Cat Rabbit $\quad$ Prey $\quad$ Calver et al. 2007; Flux 2017

$\begin{array}{lll}\text { Rodent } & \text { Prey } & \text { Gillies \& C } \\ \text { et al. } 2015\end{array}$

European rabbit Cat Predator Calver et al. 2007; Flux 2017

$\begin{array}{lll}\text { Ship rat } & \text { Cat } & \text { Gillies \& } \\ & \text { et al. } 2015\end{array}$

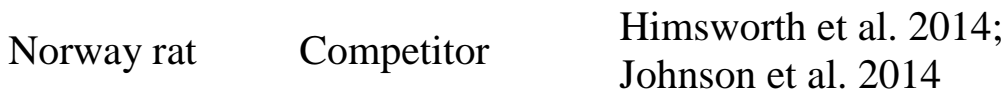

House mouse Cat Predator

Gillies \& Clout 2003; Kauhala et al. 2015

Rat spp. $\quad$ Competitor $\quad$ Feng \& Himsworth 2014 
Appendix 4.3 Occupancy estimates of medium-size invasive mammals in spring $\left(\widehat{\boldsymbol{\psi}_{\boldsymbol{s p}}}\right)$ and autumn $\left(\widehat{\boldsymbol{\psi}_{\boldsymbol{a u}}}\right)$ and cumulative $\mathrm{AIC}_{\mathrm{C}}$ weights $\left(\sum \boldsymbol{w}_{\boldsymbol{i}}\right)$ of covariates influencing the occupancy estimates. Covariates highlighted in bold indicates $\sum \boldsymbol{w}_{\boldsymbol{i}}>0.2$.

\begin{tabular}{|c|c|c|c|c|}
\hline Species & Covariate spring & $\sum w_{i}$ & $\begin{array}{l}\text { Covariate } \\
\text { autumn }\end{array}$ & $\sum w_{i}$ \\
\hline Dog & Shape & 0.19 & People off-track & 0.08 \\
\hline$\widehat{\psi_{s p}} 0.37 \pm 0.12$ & Buildings & 0.18 & Forest type & 0.04 \\
\hline \multirow{2}{*}{$\widehat{\psi_{a u}} 0.46 \pm 0.21$} & People off-track & 0.16 & Shape & 0.02 \\
\hline & Forest type & 0.15 & Buildings & 0.02 \\
\hline Possum & Traps & 0.49 & Shape & 0.41 \\
\hline$\widehat{\psi_{s p}} 0.27 \pm 0.10$ & Forest type & 0.14 & Forest type & 0.23 \\
\hline \multirow[t]{2}{*}{$\widehat{\psi_{a u}} 0.46 \pm 0.12$} & Shape & 0.13 & Traps & 0.13 \\
\hline & Vegetation & 0.13 & Vegetation & 0.11 \\
\hline Cat & Buildings & 0.55 & Buildings & 0.70 \\
\hline$\widehat{\psi_{s p}} 0.94 \pm 0.08$ & Shape & 0.08 & Rodents & 0.08 \\
\hline \multirow[t]{3}{*}{$\widehat{\psi_{a u}} 0.91 \pm 0.08$} & Rabbit & 0.03 & Forest type & 0.03 \\
\hline & Rodents & 0.02 & Shape & 0.02 \\
\hline & Forest type & 0.02 & Rabbit & 0.01 \\
\hline Rabbit & Vegetation & 0.84 & Vegetation & 0.65 \\
\hline$\widehat{\psi_{s p}} 0.24 \pm 0.10$ & Cat & 0.10 & Cat & 0.13 \\
\hline \multirow[t]{2}{*}{$\widehat{\psi_{a u}} 0.22 \pm 0.10$} & Forest type & 0.01 & Forest type & 0.11 \\
\hline & Shape & 0.01 & Shape & 0.10 \\
\hline
\end{tabular}


Appendix 4.4 Occupancy estimates of small-size invasive mammals in spring $\left(\widehat{\boldsymbol{\psi}_{\boldsymbol{s p}}}\right)$ and autumn $\left(\widehat{\boldsymbol{\psi}_{\boldsymbol{a} u}}\right)$ and cumulative $\mathrm{AIC}_{\mathrm{C}}$ weights $\left(\sum \boldsymbol{w}_{\boldsymbol{i}}\right)$ of covariates influencing the occupancy estimates. Covariates highlighted in bold indicates $\sum \boldsymbol{w}_{\boldsymbol{i}}>0.2$.

\begin{tabular}{|c|c|c|c|c|}
\hline Species & Covariate spring & $\sum w_{i}$ & Covariate autumn & $\sum w_{i}$ \\
\hline Hedgehog & Traps & 0.40 & Shape & 0.39 \\
\hline$\widehat{\psi_{s p}} 0.73 \pm 0.13$ & Vegetation & 0.36 & Vegetation & 0.20 \\
\hline \multirow[t]{2}{*}{$\widehat{\psi_{a u}} 0.83 \pm 0.08$} & Shape & 0.09 & Traps & 0.19 \\
\hline & Forest type & 0.01 & Forest type & 0.18 \\
\hline Rat spp. & Buildings & 0.30 & Forest type & 0.12 \\
\hline$\widehat{\psi_{s p}} 0.49 \pm 0.13$ & Cat & 0.23 & Traps & 0.07 \\
\hline \multirow[t]{3}{*}{$\widehat{\psi_{a u}} 0.58 \pm 0.14$} & Forest type & 0.18 & Buildings & 0.02 \\
\hline & Traps & 0.13 & Cat & 0.01 \\
\hline & Shape & 0.09 & Shape & 0.01 \\
\hline Ship rat & Traps & 0.31 & Norway rat & 0.52 \\
\hline$\widehat{\psi_{s p}} 0.24 \pm 0.11$ & Norway rat & 0.29 & Forest type & 0.12 \\
\hline \multirow[t]{4}{*}{$\widehat{\psi_{a u}} 0.35 \pm 0.12$} & Buildings & 0.11 & Buildings & 0.10 \\
\hline & Forest type & 0.10 & Cat & 0.06 \\
\hline & Shape & 0.09 & Traps & 0.05 \\
\hline & Cat & 0.08 & Shape & 0.05 \\
\hline House mouse & Traps & 0.64 & Traps & 0.36 \\
\hline$\widehat{\psi_{s p}} 0.73 \pm 0.15$ & Forest type & 0.10 & Buildings & 0.13 \\
\hline \multirow[t]{4}{*}{$\widehat{\psi_{a u}} 0.73 \pm 0.12$} & Rat spp. & 0.02 & Shape & 0.13 \\
\hline & Buildings & 0.01 & Rat spp. & 0.11 \\
\hline & Cat & 0.01 & Cat & 0.05 \\
\hline & Shape & 0.01 & Forest type & 0.05 \\
\hline
\end{tabular}


Appendix 4.5 Characteristics of the 47 patches of forest selected within Wellington, New Zealand. The perimeter of the patch and its size were used to calculate shape.

\begin{tabular}{|c|c|c|c|c|c|c|}
\hline Patch & Forest type & Size (ha) & Shape & $\begin{array}{c}\text { Buffer } \\
\text { vegetation }\end{array}$ & $\begin{array}{c}\text { Buffer } \\
\text { buildings }\end{array}$ & Traps \\
\hline$\overline{1} 1$ & Secondary & 440.8 & 5.5 & $\overline{773.0}$ & 0.4 & $\overline{18}$ \\
\hline 2 & Secondary & 4.4 & 3.5 & 26.0 & 13.2 & 5 \\
\hline 3 & Exotic & 14.8 & 5.3 & 78.6 & 2.1 & 9 \\
\hline 4 & Secondary & 7.6 & 3.5 & 35.2 & 16.1 & 0 \\
\hline 5 & Secondary & 1.2 & 1.5 & 26.4 & 14.9 & 0 \\
\hline 6 & Secondary & 1.8 & 1.6 & 36.3 & 14.7 & 0 \\
\hline 7 & Secondary & 2.9 & 1.3 & 27.5 & 16.8 & 0 \\
\hline 8 & Exotic & 1.3 & 2.2 & 99.2 & 0.8 & 0 \\
\hline 9 & Secondary & 8.2 & 2.3 & 32.1 & 8.9 & 0 \\
\hline 10 & Secondary & 2.3 & 1.9 & 27.2 & 18.4 & 0 \\
\hline 11 & Primary & 4.5 & 3.1 & 91.7 & 2.1 & 13 \\
\hline 12 & Secondary & 20.8 & 5.4 & 62.8 & 11.3 & 10 \\
\hline 13 & Secondary & 2.8 & 1.9 & 29.8 & 21.5 & 2 \\
\hline 14 & Secondary & 49.7 & 4.3 & 29.6 & 16.2 & 44 \\
\hline 15 & Secondary & 7.4 & 3.1 & 62.2 & 11.0 & 11 \\
\hline 16 & Secondary & 1.6 & 1.8 & 95.7 & 0.2 & 8 \\
\hline 17 & Exotic & 1.2 & 2.6 & 61.4 & 9.2 & 0 \\
\hline 18 & Primary & 24.5 & 6.5 & 78.9 & 5.1 & 47 \\
\hline 19 & Primary & 10.5 & 7.3 & 69.2 & 10.3 & 31 \\
\hline 20 & Exotic & 32.7 & 6.8 & 88.0 & 2.9 & 64 \\
\hline 21 & Exotic & 10.5 & 2.6 & 62.5 & 1.4 & 9 \\
\hline 22 & Exotic & 4.1 & 1.7 & 93.7 & 0.2 & 9 \\
\hline 23 & Primary & 18.8 & 7.6 & 80.5 & 4.8 & 25 \\
\hline 24 & Exotic & 33.9 & 4.2 & 89.8 & 1.0 & 15 \\
\hline 25 & Primary & 17.0 & 3.3 & 44.5 & 15.2 & 0 \\
\hline 26 & Exotic & 11.8 & 6.2 & 64.2 & 1.0 & 11 \\
\hline 27 & Exotic & 25.5 & 5.9 & 56.0 & 4.1 & 5 \\
\hline 28 & Exotic & 1.5 & 2.1 & 23.6 & 26.4 & 1 \\
\hline 29 & Secondary & 61.0 & 4.0 & 40.0 & 9.1 & 118 \\
\hline 30 & Exotic & 53.4 & 4.0 & 42.3 & 14.2 & 109 \\
\hline 31 & Exotic & 16.9 & 4.1 & 31.6 & 17.7 & 42 \\
\hline 32 & Exotic & 27.6 & 5.7 & 99.9 & 0.1 & 46 \\
\hline 33 & Secondary & 17.0 & 2.5 & 49.9 & 9.5 & 27 \\
\hline 34 & Secondary & 3.2 & 3.6 & 100.0 & 0.2 & 3 \\
\hline 35 & Primary & 1.8 & 2.3 & 43.3 & 11.3 & 3 \\
\hline 36 & Exotic & 10.2 & 4.4 & 53.5 & 8.8 & 14 \\
\hline 37 & Secondary & 5.0 & 2.5 & 60.2 & 6.4 & 8 \\
\hline 38 & Secondary & 1.6 & 1.7 & 49.0 & 19.0 & 2 \\
\hline 39 & Secondary & 42.5 & 3.4 & 41.3 & 14.9 & 39 \\
\hline 40 & Exotic & 13.6 & 5.7 & 46.8 & 14.6 & 13 \\
\hline 41 & Exotic & 1.2 & 2.6 & 42.0 & 0.0 & 2 \\
\hline 42 & Exotic & 17.0 & 5.7 & 79.6 & 3.2 & 24 \\
\hline 43 & Secondary & 5.0 & 3.1 & 30.0 & 12.2 & 6 \\
\hline 44 & Secondary & 98.2 & 6.8 & 28.6 & 11.5 & 124 \\
\hline 45 & Secondary & 8.5 & 2.1 & 41.5 & 15.7 & 8 \\
\hline 46 & Exotic & 5.9 & 3.2 & 82.0 & 1.6 & 8 \\
\hline 47 & Secondary & 7.5 & 2.8 & 21.5 & 16.0 & 7 \\
\hline
\end{tabular}


Appendix 4.6 Total number of days cameras were active per patch $(n)$ and capture rates of mammals over an entire year of monitoring. N. rats and S. rats are subsets of Rat spp.

Patch $n$ Dogs Possums Cats Hares Rabbits Stoats Hedg. $\begin{gathered}\text { Rat } \\ \text { spp. }\end{gathered} \begin{gathered}\text { Nots } \\ \text { rats }\end{gathered}$ Mice

\begin{tabular}{|c|c|c|c|c|c|c|c|c|c|c|c|c|}
\hline 1 & 408 & 0 & 0 & 12 & 9 & 66 & 0 & 161 & 8 & 0 & 0 & 8 \\
\hline 2 & 402 & 2 & 10 & 112 & 6 & 11 & 0 & 172 & 2 & 0 & 0 & 15 \\
\hline 3 & 416 & 0 & 16 & 41 & 1 & 29 & 0 & 5 & 4 & 65 & 0 & 2 \\
\hline 4 & 426 & 0 & 113 & 221 & 0 & 0 & 0 & 2 & 33 & 32 & 41 & 26 \\
\hline 5 & 398 & 0 & 175 & 170 & 0 & 0 & 0 & 124 & 25 & 10 & 5 & 23 \\
\hline 6 & 417 & 1 & 0 & 170 & 0 & 0 & 0 & 31 & 7 & 43 & 2 & 21 \\
\hline 7 & 366 & 0 & 81 & 152 & 0 & 0 & 0 & 27 & 11 & 2 & 23 & 2 \\
\hline 8 & 399 & 0 & 1 & 9 & 0 & 0 & 0 & 2 & 2 & 0 & 0 & 11 \\
\hline 9 & 420 & 22 & 14 & 472 & 0 & 0 & 0 & 46 & 18 & 2 & 2 & 3 \\
\hline 10 & 399 & 1 & 1 & 128 & 0 & 0 & 0 & 43 & 18 & 0 & 14 & 17 \\
\hline 11 & 401 & 0 & 0 & 4 & 0 & 0 & 0 & 0 & 0 & 0 & 1 & 6 \\
\hline 12 & 379 & 0 & 28 & 83 & 0 & 0 & 0 & 9 & 1 & 0 & 0 & 23 \\
\hline 13 & 408 & 2 & 2 & 191 & 0 & 0 & 0 & 1 & 2 & 0 & 0 & 0 \\
\hline 14 & 367 & 0 & 0 & 6 & 0 & 0 & 0 & 0 & 24 & 0 & 14 & 42 \\
\hline 15 & 409 & 2 & 2 & 57 & 0 & 0 & 0 & 8 & 32 & 0 & 24 & 6 \\
\hline 16 & 406 & 1 & 24 & 43 & 10 & 126 & 0 & 47 & 1 & 0 & 2 & 3 \\
\hline 17 & 382 & 0 & 0 & 46 & 0 & 0 & 0 & 5 & 32 & 3 & 79 & 18 \\
\hline 18 & 414 & 0 & 0 & 89 & 0 & 0 & 0 & 1 & 6 & 0 & 2 & 47 \\
\hline 19 & 396 & 0 & 0 & 36 & 0 & 0 & 0 & 9 & 1 & 0 & 0 & 8 \\
\hline 20 & 414 & 0 & 1 & 1 & 0 & 0 & 0 & 4 & 2 & 0 & 4 & 5 \\
\hline 21 & 367 & 0 & 1 & 9 & 0 & 1 & 0 & 5 & 1 & 0 & 2 & 8 \\
\hline 22 & 408 & 8 & 1 & 4 & 0 & 30 & 0 & 37 & 0 & 0 & 0 & 2 \\
\hline 23 & 396 & 1 & 1 & 20 & 0 & 0 & 0 & 26 & 4 & 1 & 2 & 31 \\
\hline 24 & 402 & 1 & 57 & 4 & 8 & 65 & 3 & 15 & 2 & 0 & 1 & 1 \\
\hline 25 & 406 & 0 & 1 & 43 & 0 & 0 & 0 & 11 & 25 & 1 & 11 & 25 \\
\hline 26 & 402 & 1 & 0 & 7 & 0 & 3 & 0 & 10 & 19 & 3 & 8 & 14 \\
\hline 27 & 334 & 0 & 0 & 12 & 0 & 0 & 0 & 2 & 9 & 1 & 10 & 22 \\
\hline 28 & 402 & 38 & 2 & 123 & 0 & 0 & 0 & 94 & 25 & 31 & 24 & 9 \\
\hline 29 & 417 & 7 & 0 & 146 & 4 & 36 & 0 & 55 & 44 & 6 & 33 & 12 \\
\hline 30 & 417 & 4 & 0 & 83 & 0 & 0 & 0 & 78 & 5 & 0 & 1 & 16 \\
\hline 31 & 408 & 0 & 0 & 53 & 0 & 0 & 0 & 0 & 2 & 1 & 0 & 12 \\
\hline 32 & 397 & 0 & 3 & 2 & 9 & 80 & 0 & 13 & 1 & 0 & 0 & 2 \\
\hline 33 & 390 & 0 & 0 & 45 & 0 & 0 & 0 & 59 & 0 & 0 & 0 & 5 \\
\hline 34 & 401 & 0 & 4 & 0 & 0 & 6 & 0 & 5 & 6 & 0 & 3 & 7 \\
\hline 35 & 447 & 0 & 0 & 221 & 0 & 1 & 0 & 36 & 2 & 0 & 0 & 41 \\
\hline 36 & 420 & 14 & 0 & 27 & 0 & 0 & 0 & 44 & 0 & 0 & 0 & 4 \\
\hline 37 & 420 & 0 & 0 & 53 & 0 & 0 & 0 & 35 & 0 & 0 & 0 & 2 \\
\hline 38 & 433 & 0 & 11 & 122 & 0 & 0 & 0 & 3 & 3 & 0 & 2 & 3 \\
\hline 39 & 423 & 0 & 1 & 163 & 2 & 32 & 0 & 21 & 0 & 0 & 0 & 5 \\
\hline 40 & 369 & 3 & 2 & 9 & 0 & 0 & 0 & 4 & 4 & 0 & 0 & 57 \\
\hline 41 & 420 & 4 & 0 & 6 & 3 & 37 & 1 & 7 & 0 & 0 & 0 & 9 \\
\hline 42 & 382 & 1 & 10 & 32 & 2 & 189 & 0 & 22 & 0 & 0 & 0 & 6 \\
\hline 43 & 411 & 1 & 0 & 165 & 0 & 0 & 0 & 24 & 5 & 0 & 3 & 54 \\
\hline 44 & 417 & 9 & 0 & 129 & 1 & 41 & 0 & 49 & 53 & 1 & 265 & 25 \\
\hline 45 & 360 & 1 & 0 & 70 & 0 & 0 & 0 & 24 & 9 & 1 & 0 & 23 \\
\hline 46 & 420 & 0 & 15 & 7 & 3 & 50 & 0 & 6 & 10 & 0 & 11 & 9 \\
\hline 47 & 398 & 6 & 3 & 152 & 0 & 18 & 0 & 96 & 4 & 1 & 0 & 326 \\
\hline
\end{tabular}


Appendix 4.7 Average daily capture rates of mammals per site based on independent events of 30 minutes over an entire year of monitoring in Wellington, New Zealand and the percentage difference of these daily capture rates compared to daily capture rates based on independent events of 10, 60 and 120 minutes.

\begin{tabular}{lcccc} 
Species & $\begin{array}{c}\text { Daily capture } \\
\text { rates (30 mins) }\end{array}$ & $\begin{array}{c}\Delta \text { capture rates } \\
(10 \text { mins })\end{array}$ & $\begin{array}{c}\Delta \text { capture rates } \\
(60 \text { mins })\end{array}$ & $\begin{array}{c}\Delta \text { capture rates } \\
(120 \text { mins })\end{array}$ \\
\hline Dog & 0.003 & $7.69 \%$ & $-4.62 \%$ & $-6.92 \%$ \\
\hline Cat & 0.014 & $6.55 \%$ & $-5.00 \%$ & $-10.69 \%$ \\
\hline Hare & 0.089 & $3.20 \%$ & $-2.75 \%$ & $-6.40 \%$ \\
\hline Rabbit & 0.001 & $0.00 \%$ & $0.00 \%$ & $-1.72 \%$ \\
\hline Mustelid & 0.019 & $6.33 \%$ & $-4.99 \%$ & $-9.74 \%$ \\
\hline Hedgehog & 0.000 & $0.00 \%$ & $0.00 \%$ & $0.00 \%$ \\
\hline Rat & 0.035 & $5.01 \%$ & $-4.53 \%$ & $-9.40 \%$ \\
\hline Norway rat & 0.005 & $3.03 \%$ & $-4.11 \%$ & $-7.79 \%$ \\
\hline Ship rat & 0.014 & $14.43 \%$ & $-10.02 \%$ & $-19.19 \%$ \\
\hline Mouse & 0.024 & $19.59 \%$ & $-8.07 \%$ & $-14.57 \%$ \\
\hline
\end{tabular}




\section{CONCLUDING DISCUSSION}

\section{Urban ecology}

Urban ecology is an emerging discipline that investigates the interactions between people, nature, and their geo-physical environment. Urban ecologists have traditionally investigated the biological characteristics of towns and cities applying major ecological concepts developed in non-urban environments, a research approach known as the ecology in the cities (Pickett et al. 2016). These major ecological concepts include species-area relationships (Hobbs 1988), urbanisation gradient (McDonnell \& Pickett 1990) and meta-population dynamics (Soulé et al. 1988). Over the last three decades, however, urban ecologists have integrated new methodologies and concepts from other disciplines, particularly social and physical sciences (Mcphearson et al. 2016). Through this more inclusive approach, known as the ecology of the cities paradigm, ecologists started to study cities as socio-ecological systems within which humans and their social institutions are integrated with their environment (Goddard et al. 2010). This interdisciplinary approach has enabled researchers to better understand ecosystem processes of urban environments, including the cultural ecosystem services associated with biodiversity (Elmqvist et al. 2015), the influence of urban vegetation on human health and wellbeing (Shanahan et al. 2015), and novel bio-geochemical cycles (Kaye et al. 2006). Despite such recent advances, urban ecology is still in its early stages, for cities continue providing researchers with opportunities to gain further social and biophysical insights. 


\section{Citizen science}

Citizen science, involving the general public in scientific research, offers new opportunities to undertake efficient and cost-effective ecological research in urban environments (Cooper et al. 2007). Compared to other ecosystems, urban environments facilitate the implementation of citizen science initiatives more effectively because of the higher human population, their higher environmental awareness, the often limited number of species present in urban environments, the familiarity of city dwellers with urban biodiversity, and the geographic accessibility to study sites (Chapter 0). Engaging city dwellers with scientific research also increases their direct and indirect interactions with nature, sensitising the community to the importance of conserving biodiversity (Braubach et al. 2017; Williams et al. 2017).

Data collection is the most common task undertaken by citizen scientists (Parsons et al. 2018). Yet volunteers can also assist professional researchers at other stages of the scientific process (Wiggins \& Crowston 2011). For example, the results presented in my thesis demonstrated how people unable to collect data in the field can still get engaged with ecological research by identifying animals from remote camera data (Chapter 0 ).

There are some challenges associated with citizen science that should be taken into consideration to ensure successful research projects. For example, data quality is a common drawback in this scientific approach. Citizen scientists can inconsistently collect information, making the data difficult or sometimes impossible to analyse or interpret (Kosmala et al. 2016). However, researchers can use different methods and techniques to maximise the accuracy and efficiency of citizen scientists. These methods include weighting citizen scientists based on previous accuracy of performing tasks, providing 
them with adequate training and the spatial-temporal replication of the data (Chapter 0 ). Expert validation, however, might still be required in tasks for which the accuracy of citizen scientists does not meet scientific standards (Kosmala et al. 2016). Another potential drawback is the low engagement of citizen scientists with the project. Keeping citizen scientists motivated with the project is crucial to achieve high number of participants and sustainable engagement over long periods of time. For example, to keep citizen scientists engaged with my research I constantly moderated the discussion forums of the website and provided regular feedback and research updates. Understanding the motivations, expertise and demographics of the target audience can facilitate project managers to identify the most efficient method to keep citizen scientists engaged (Morais et al. 2015). In summary, iterative periods of design, evaluation, and revision are crucial to ensure citizen scientists achieve the project-specific education and research goals (Dickinson et al. 2012).

Citizen science projects within an urban context have enabled ecologists to evaluate the impacts of pollution on biodiversity (Welden et al. 2018; Wilson et al. 2018), the distribution of invasive mammals (Chapter 1 and 4), and causes of human-wildlife conflicts (Wine et al. 2014; Kummer et al. 2016). Further advances in statistical and modelling tools will facilitate the use of citizen science to expand our current understanding of understudied urban topics (Figure 5.1). Topics might include the influence of private properties and informal green spaces in urban biodiversity, the ecosystem services provided by riparian corridors or the influence of green areas in human wellbeing and health (Shanahan et al. 2015; Schröter et al. 2017; Feltynowski et al. 2018). 

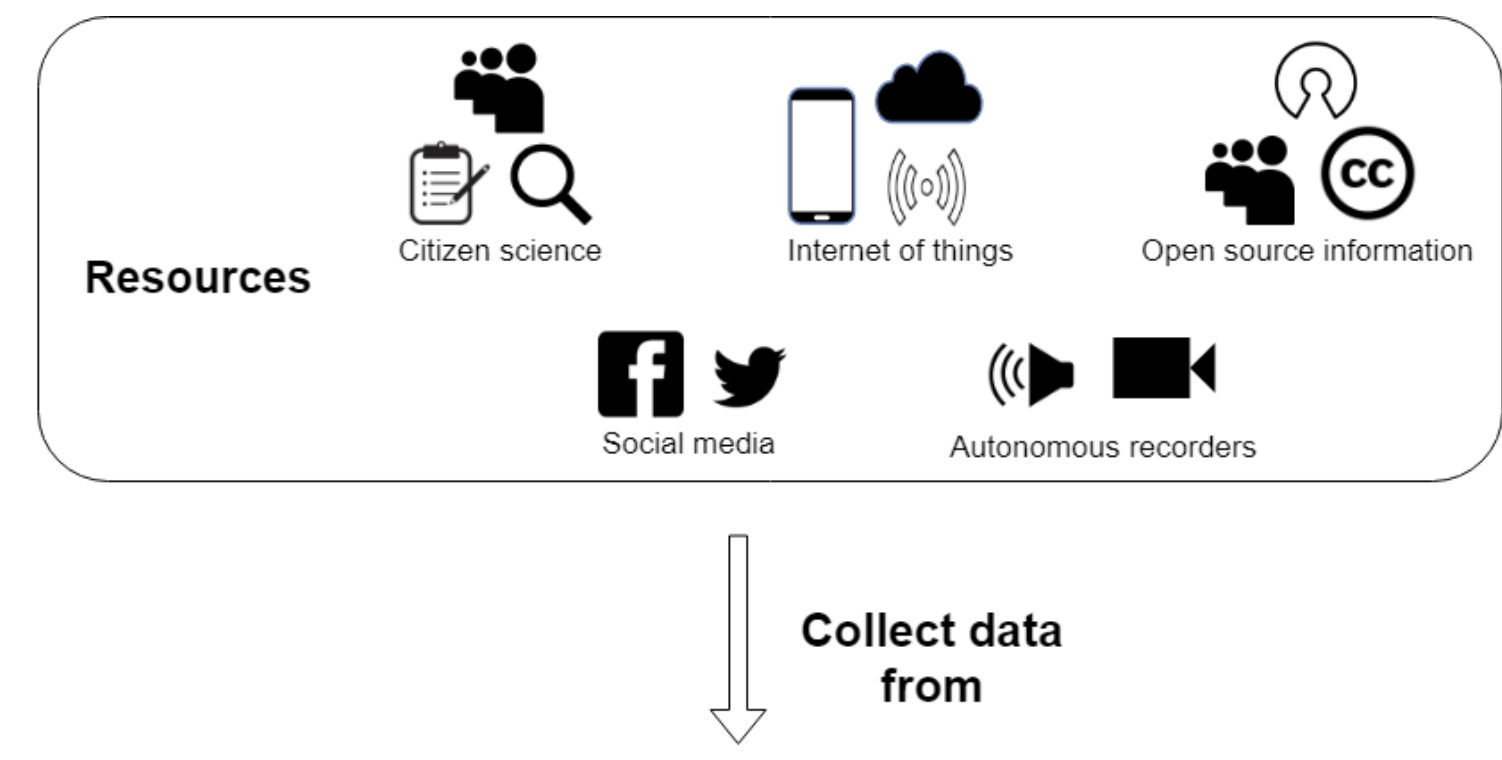

\section{Elements of the cities}

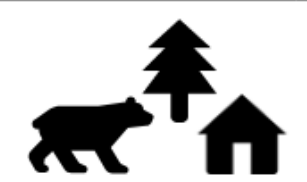

Biophysical environrment

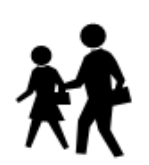

Urbanites

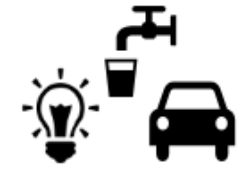

Anthropogenic activities

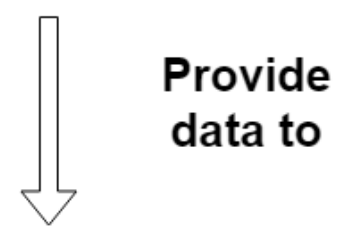

\section{Climatology \\ Sociology \\ Economics \\ Ecology}

Disciplines

$$
\text { Hydrology }
$$

Political sciences

Forestry

Health Sciences

\section{Architecture \\ Engineering \\ Environmental science \\ Geography}

Figure 5.1 Resources available for researchers of multiple disciplines to collect environmental and social data of cities. 


\section{Novel technologies}

Ecologists are increasingly reliant on low-cost, user-friendly technology to monitor a range of biological, chemical and physical parameters worldwide (Marvin et al. 2016). Novel technologies (e.g. remote sensors, unmanned aerial vehicles, and GPS devices) that passively collect ecological data with little to no required maintenance are replacing the intensive labour commonly associated with ecological research (Crutsinger et al. 2016; Steenweg et al. 2017; Taylor et al. 2017). Using data collected with novel technologies, ecologists can investigate the spatial, temporal and behavioural activity of wildlife in ways conventional monitoring systems do not allow (Wall et al. 2014). Compared to remote areas, cities are preferential environments for using novel monitoring technologies because of the infrastructure available (e.g. mobile data and electricity coverage) and the relative proximity of the study sites. Yet, the use of remote devices and other novel technology in urban research is still rare (Steenweg et al. 2017). This is surprising because using passivelycollected data can be more efficient and rapid than traditional wildlife monitoring techniques (Chapter 1).

The use of remote cameras to investigate the ecology of populations, communities, and landscapes is becoming increasingly popular throughout the world (Sueur \& Farina 2015; Steenweg et al. 2017). Using remote cameras, I was able to investigate the influence of residential areas, forest edge, habitat quality, interspecies interactions and anthropogenic activities on the distribution of invasive species in urban environments (Chapter 1 and 4). The use of remote cameras in urban environments is expected to increase due to continued technological improvements (Nazir et al. 2017) and the reduction of the initial costs associated with these monitoring devices (Burton et al. 2015). However, there are limitations that need to be considered when using remote cameras in urban environments. For example, the classification of the footage or photos, the inability to detect ectothermic animals, the 
difficulties of comparing results with other more commonly used techniques, the sounds and infrared lights that can be perceived by different species, privacy issues, vandalism and theft (Chapter 2; Glen et al. 2016; Meek et al. 2016). Despite these constraints, remote cameras are likely to enable ecologists to better understand a range of urban processes including the impacts of anthropogenic activities on medium-sized and small mammals, the ecology of understudied taxa (e.g. amphibians, reptiles or invertebrates), and the ecological role of urban pets (Shannon et al. 2016; Mcruer et al. 2017; Hobbs \& Brehme 2017).

The ubiquitous technology of cities provides urban researchers with vast amounts of data already collected and ready to be analysed (Figure 5.1). Globally, managers and researchers of urban environments are promoting the use of positive feedback loops between human users and technology to achieve sustainable cities (McClellan et al. 2017). This 'smart cities' movement provides unprecedented research opportunities in the field of ecology, technology and social sciences. An example is the use of online social network data to evaluate human interactions and emotional responses to green areas in the city (Roberts et al. in press). Private companies, non-governmental and governmental organisations are increasingly making their data publicly available with the purpose of achieving sustainable cities through data-driven approaches (e.g. the Urban Big Data Centre (UBDC) (http://ubdc.ac.uk/) and the Australian Urban Research Infrastructure Network (AURIN) (http://aurin.org.au/)). The rise of open-access information introduces numerous social and logistic challenges. For example, ownership, management and validation of the data, and privacy and issues. However, if administered accordingly, open-access information can facilitate ecologists to implement innovative methods to investigate urban environments using data initially collected for non-scientific purposes (Yarime 2017). Some examples of ecological studies using data initially collected for non-scientific purposes include Mcruer et al. (2017), who used medical records of wild birds and mammals admitted for rehabilitation 
to better understand the predation impacts of free-roaming cats, and Hardion et al. (2016) and Burr et al. (2018) who used online street-view services to study species distribution and assess residential vegetation composition, respectively. 


\section{Urban invasive mammals}

Invasive mammals are among the most detrimental invasive species in cities (Gaertner et al. 2017b). Invasive mammals can be found in different habitat types within cities, including patches of habitat that are crucial for the persistence of native biota (Chapter 1 and 4). The location of invasive mammals in urban environments can be influenced by numerous socioecological characteristics of the city and the autecology of the species. For example, while urbanization benefits cats and rodents it negatively influences possums and rabbits (Chapter 4). Control of urban invasive mammals, thus, needs to be undertaken on a species-specific basis and at adequate spatial and temporal scale.

Current management of invasive mammals in urban environments involves trapping and poisoning (Doherty \& Ritchie 2017). The design and implementation of these management approaches are not without social debate and logistic difficulties (Lioy et al. 2016; Gaertner et al. 2017a). To minimise the challenges associated with the control of invasive mammals, professionals in charge of suppressing their detrimental impacts require a better understanding of their distribution in cities. Understanding the ecology of these species in urban environments can facilitate the design and implementation of more efficient techniques aiming to minimise their negative socio-ecological impacts. For example, restoring native habitat might favour the dominance of native small mammals over invasive species (Villaseñor et al. 2014) or accounting for the physical elements that limit the dispersal of invasive rodents (e.g. roads and mayor waterways) might prevent these species from invading areas where they are absent or have been eradicated (Combs et al. 2018).

In recent years, the control of invasive mammals in New Zealand urban environments has increased in both effort and support by government and community (MacLeod et al. 2015). Using remote cameras, I investigated the main driving forces of the distribution of mammalian species in urban environments of New Zealand (Chapter 4). I summarise the 
results into three major findings that could guide management of urban invasive mammals, particularly mammalian predators of native species. First, cats and hedgehogs are the most abundant species I recorded in my study, independently of habitat type. Their high numbers in urban environments are of particular conservation concern due to the vulnerability of native birds and lizards to their predation (Heber et al. 2008; Gordon et al. 2010). Management programmes aiming to suppress the abundance of domestic and stray cats, and hedgehogs, particularly during spring, may be required to minimise the impact these species pose on native biota. Second, management control should be species-specific. In my study, I modelled the species-specificity efforts required to achieve low probabilities of forest patches being occupied by invasive mammals. For example, the intensity of management efforts, measured as density of traps and poison baits, to control rodents should at least double the efforts required to control possums at the same levels. Third, despite being specific-specific, control management efforts are required to account for interspecies interactions. In my study, cats played an important role in the occupancy of rats, while Norway rats favoured the occupancy of ship rats. The importance of these urban interspecific interactions in invasive mammals has been poorly studied (Gallo et al. 2017). Thus, further studies aiming at disentangling their influence in the dynamics of invasive species communities are, thus, needed because underestimating the influence of these interactions can led to detrimental conservation outcomes for the native biota (e.g. Ballari et al. 2016). 


\section{Conclusion}

Urban ecologists require further advances in academic knowledge and practical solutions to achieve sustainable cities. A thorough understanding of the urban environment will not only benefit urban ecologists but the concepts, theories and methodologies can be extrapolated to different ecosystems and disciplines. The development of more efficient monitoring techniques, the involvement of the community in scientific research and the open access to urban-related data will facilitate research at unprecedented temporal and spatial scales in the field of urban ecology. For example, using data collected with remote cameras and a citizen science approach, I investigated the underlying processes influencing the occupancy and abundance of mammalian non-native invasive species within the urban environment. However, understanding the spatial ecology of invasive species is just one of the multiple ecological, social and technological research topics facilitated by the ecological research opportunities cities have to offer. 


\section{BIBLIOGRAPHY}

Aceves-Bueno E et al. 2015. Citizen science as an approach for overcoming insufficient monitoring and inadequate stakeholder buy-in in adaptive management: Criteria and evidence. Ecosystems 18:493-506.

Aceves-Bueno E, Adeleye AS, Feraud M, Huang Y, Tao M, Yang Y, Anderson SE. 2017. The accuracy of citizen science data: A quantitative review. The Bulletin of the Ecological Society of America 98:278-290.

Adams AL, Dickinson KJM, Robertson BC, van Heezik Y. 2013. Predicting summer site occupancy for an invasive species, the common brushtail possum (Trichosurus vulpecula), in an urban environment. PLOS One 8:e58422.

Adams AL, Recio MR, Robertson BC, Dickinson KJM, van Heezik Y. 2014a. Understanding home range behaviour and resource selection of invasive common brushtail possums (Trichosurus vulpecula) in urban environments. Biological Invasions 16:1791-1804.

Adams AL, van Heezik Y, Dickinson KJM, Robertson BC. 2014b. Identifying eradication units in an invasive mammalian pest species. Biological Invasions 16:1481-1496.

Aguilar GD, Farnworth MJ. 2012. Stray cats in Auckland, New Zealand: Discovering geographic information for exploratory spatial analysis. Applied Geography 34:230238.

Aguilar GD, Farnworth MJ, Winder L. 2015. Mapping the stray domestic cat (Felis catus) population in New Zealand: Species distribution modelling with a climate change scenario and implications for protected areas. Applied Geography 63:146154.

Ahlers AA, Heske EJ, Schooley RL. 2016. Prey distribution, potential landscape supplementation, and urbanization affect occupancy dynamics of American mink in streams. Landscape Ecology 31:1601-1613.

Allen ML, Wilmers CC, Elbroch LM, Golla JM, Wittmer HU. 2016a. The importance of motivation, weapons, and foul odors in driving encounter competition in carnivores. Ecology 97:1905-1912.

Allen ML, Wittmer HU, Setiawan E, Jaffe S, Marshall AJ. 2016b. Scent marking in 
Sunda clouded leopards (Neofelis diardi): Novel observations close a key gap in understanding felid communication behaviours. Scientific Reports 6:35433.

Andersson E, Barthel S, Borgström S, Colding J, Elmqvist T, Folke C, Gren Å. 2014. Reconnecting cities to the biosphere: Stewardship of green infrastructure and urban ecosystem services. Ambio 43:445-453.

Andren H. 1994. Effects of habitat fragmentation on birds and mammals of suitable habitat: a review landscapes with different proportions. Oikos 71:355-366.

Anton V, Hartley S, Geldenhuis A, Wittmer HU. 2018a. Monitoring the mammalian fauna of urban areas using remote cameras and citizen science. Journal of Urban Ecology 4:juy002.

Anton V, Hartley S, Wittmer HU. 2018b. Evaluation of remote cameras for monitoring multiple invasive mammals in New Zealand. New Zealand Journal of Ecology 42:16

Anton V, Hartley S, Wittmer HU. 2015. Survival and growth of planted seedlings of three native tree species in urban forest restoration in Wellington, New Zealand. New Zealand Journal of Ecology 39:170-178.

Archibald CL, McKinney M, Mustin K, Shanahan DF, Possingham HP. 2017. Assessing the impact of revegetation and weed control on urban sensitive bird species. Ecology and Evolution 7:4200-4208.

Arnold TW. 2010. Uninformative parameters and model selection using Akaike's Information Criterion. The Journal of Wildlife Management 74:1175-1178.

Aronson MF, Lepczyk CA, Evans KL, Goddard MA, Lerman SB, MacIvor JS, Nilon CH, Vargo T. 2017. Biodiversity in the city: key challenges for urban green space management. Frontiers in Ecology and the Environment 15:189-196.

Aronson MFJ et al. 2014. A global analysis of the impacts of urbanization on bird and plant diversity reveals key anthropogenic drivers. Proceedings of the Royal Society B: Biological Sciences 281:20133330.

Auckland Council. 2012. Auckland Council's indigenous biodiversity strategy. Available from https://www.aucklandcouncil.govt.nz/environment/what-we-do-to-helpenvironment/Documents/indigenous-biodiversity-strategy.pdf (accessed July 30, 2018). 
Baker PJ, Harris S. 2007. Urban mammals: What does the future hold? An analysis of the factors affecting patterns of use of residential gardens in Great Britain. Mammal Review 37:297-315.

Ballari SA, Kuebbing SE, Nuñez MA. 2016. Potential problems of removing one invasive species at a time: a meta-analysis of the interactions between invasive vertebrates and unexpected effects of removal programs. PeerJ 4:e2029.

Banks PB, Smith HM. 2015. The ecological impacts of commensal species: Black rats, Rattus rattus, at the urban-bushland interface. Wildlife Research 42:86-97.

Barton K. 2015. MuMIn: multi-model inference. R Package Version 1.15.6.

Bates AJ et al. 2014a. Garden and landscape-scale correlates of moths of differing conservation status: Significant effects of urbanization and habitat diversity. PLOS One 9:e86925.

Bates D, Mächler M, Bolker B, Walker S. 2014b. Fitting linear mixed-effects models using lme4. Journal of Statistical Software 67:1-48.

Beninde J, Veith M, Hochkirch A. 2015. Biodiversity in cities needs space: A metaanalysis of factors determining intra-urban biodiversity variation. Ecology Letters 18:581-592.

Beumer C, Martens P. 2015. Biodiversity in my (back)yard: towards a framework for citizen engagement in exploring biodiversity and ecosystem services in residential gardens. Sustainability Science 10:87-100.

Blackie HM et al. 2014. Innovative developments for long-term mammalian pest control. Pest Management Science 70:345-351.

Bonney R, Cooper CB, Dickinson J, Kelling S, Phillips T, Rosenberg K V., Shirk J. 2009. Citizen science: A developing tool for expanding science knowledge and scientific literacy. BioScience 59:977-984.

Bonnington C, Gaston KJ, Evans KL. 2014. Squirrels in suburbia: Influence of urbanisation on the occurrence and distribution of a common exotic mammal. Urban Ecosystems 17:533-546.

Botzat A, Fischer LK, Kowarik I. 2016. Unexploited opportunities in understanding liveable and biodiverse cities. A review on urban biodiversity perception and valuation. Global Environmental Change 39:220-233. 
Braaker S, Moretti M, Boesch R, Ghazoul J, Obrist MK, Bontadina F. 2014. Assessing habitat connectivity for ground-dwelling animals in an urban environment. Ecological Applications 24:1583-1595.

Braubach M, Egorov A, Mudu P, Wolf T, Ward Thompson C, Martuzzi M. 2017. Effects of urban green space on environmental health, equity and resilience. Pages 187-205 Nature-based solutions to climate change adaptation in urban areas: Linkages between science, policy and practice. Springer. 342 pp.

Bray SR, Hoyt AM, Yang Z, Arthur MA. 2017. Non-native liana, Euonymus fortunei, associated with increased soil nutrients, unique bacterial communities, and faster decomposition rate. Plant Ecology 218:329-343.

Brockie RE, Duncan C. 2012. Long term trends in Wellington City bird counts: 19692006. Notornis 59:1-6.

Brumby A, Hartley S, Salmon R. 2015. Evaluation of the great kererū count 2014 and recommendations for future citizen science projects. Wellington, New Zealand. Available from https://wellington.govt.nz/ /media/about-wellington/research-andevaluation/natural-environment/eval-great-kereru-count-2014.pdf (accessed July 30, 2018).

Brzeziński M, Ignatiuk P, Żmihorski M, Zalewski A. 2018. An invasive predator affects habitat use by native prey: American mink and water vole co-existence in riparian habitats. Journal of Zoology 304:109-116.

Burge OR, Kelly D, Wilmshurst JM. 2017. Interspecies interference and monitoring duration affect detection rates in chew cards. Austral Ecology 42:522-532.

Burnham KP, Anderson DR. 2002. Model selection and multimodel inference: a practical information-theoretic approach. Springer. 488 pp.

Burr A, Schaeg N, Hall DM. 2018. Assessing residential front yards using Google Street View and geospatial video: A virtual survey approach for urban pollinator conservation. Applied Geography 92:12-20.

Burton AC, Neilson E, Moreira D, Ladle A, Steenweg R, Fisher JT, Bayne E, Boutin S. 2015. Wildlife camera trapping: a review and recommendations for linking surveys to ecological processes. Journal of Applied Ecology 52:675-685.

Cadotte MW, Yasui SLE, Livingstone S, MacIvor JS. 2017. Are urban systems 
beneficial, detrimental, or indifferent for biological invasion? Biological Invasions 19:3489-3503.

Calver M, Thomas S, Bradley S, McCutcheon H. 2007. Reducing the rate of predation on wildlife by pet cats: The efficacy and practicability of collar-mounted pounce protectors. Biological Conservation 137:341-348.

Carter A, Barr S, Bond C, Paske G, Peters D, van Dam R. 2016. Controlling sympatric pest mammal populations in New Zealand with self-resetting, toxicant-free traps: a promising tool for invasive species management. Biological Invasions 18:17231736.

Carthew SM, Yáñez B-M, Ruykys L. 2015. Straddling the divide: Den use by brushtail possums (Trichosurus vulpecula) in urban parklands. Urban Ecosystems 18:525538.

Catlin-Groves CL. 2012. The citizen science landscape: From volunteers to citizen sensors and beyond. International Journal of Zoology 2012:1-14.

Cavin JS, Kull CA. 2017. Invasion ecology goes to town: from disdain to sympathy. Biological Invasions 19:3471-3487.

Cerra JF. 2017. Emerging strategies for voluntary urban ecological stewardship on private property. Landscape and Urban Planning 157:586-597.

Chandler M, See L, Buesching CD, Cousins JA, Gillies C, Kays RW, Newman C, Pereira HM, Tiago P. 2017. Involving citizen scientists in biodiversity observation. Pages 211-237 The GEO handbook on biodiversity observation networks. Springer. 326 pp.

Cohn JP. 2008. Citizen science: Can volunteers do real research? BioScience 58:192197.

Combs M, Byers KA, Ghersi BM, Blum MJ, Caccone A, Costa F, Himsworth CG, Richardson JL, Munshi-South J. 2018. Urban rat races: spatial population genomics of brown rats (Rattus norvegicus) compared across multiple cities. Proceedings of the Royal Society B: Biological Sciences 285:20180245.

Connolly JJ, Svendsen ES, Fisher DR, Campbell LK. 2013. Organizing urban ecosystem services through environmental stewardship governance in New York City. Landscape and Urban Planning 109:76-84. 
Cooper CB, Dickinson JL, Phillips T, Bonney R. 2007. Citizen science as a tool for conservation in residential ecosystems. Ecology and Society 12:1-12.

Crall AW, Newman GJ, Stohlgren TJ, Holfelder KA, Graham J, Waller DM. 2011. Assessing citizen science data quality: An invasive species case study. Conservation Letters 4:433-442.

Crowley SL, Hinchliffe S, McDonald RA. 2017a. Invasive species management will benefit from social impact assessment. Journal of Applied Ecology 54:351-357.

Crowley SL, Hinchliffe S, McDonald RA. 2017b. Conflict in invasive species management. Frontiers in Ecology and the Environment 15:133-141.

Crutsinger GM, Short J, Sollenberger R. 2016. The future of UAVs in ecology: an insider perspective from the Silicon Valley drone industry. Journal of Unmanned Vehicle Systems 4:161-168.

Dearborn DC, Kark S. 2010. Motivations for conserving urban biodiversity. Conservation Biology 24:432-440.

Delaney DG, Sperling CD, Adams CS, Leung B. 2008. Marine invasive species: validation of citizen science and implications for national monitoring networks. Biological Invasions 10:117-128.

Dénes F V., Silveira LF, Beissinger SR. 2015. Estimating abundance of unmarked animal populations: Accounting for imperfect detection and other sources of zero inflation. Methods in Ecology and Evolution 6:543-556.

Department of Conservation and Ministry for the Environment. 2000. The New Zealand Biodiversity Strategy. Available from https://www.doc.govt.nz/Documents/conservation/new-zealand-biodiversitystrategy-2000.pdf (accessed July 30, 2018).

Department of Internal Affairs. 2016. Sustainable urban development: setting the scene. Available from https://www.dia.govt.nz/diawebsite.nsf/Files/SUDUSettingtheScene/\$file/SUDUSett ingtheScene.pdf (accessed July 30, 2018).

Diamond JM, Veitch CR. 1981. Extinctions and introductions in the new zealand avifauna: cause and effect? Science 211:499-501.

Dickinson JL, Shirk J, Bonter D, Bonney R, Crain RL, Martin J, Phillips T, Purcell K. 
2012. The current state of citizen science as a tool for ecological research and public engagement. Frontiers in Ecology and the Environment 10:291-297.

Dickinson JL, Zuckerberg B, Bonter DN. 2010. Citizen science as an ecological research tool: Challenges and benefits. Annual Review of Ecology, Evolution, and Systematics 41:149-172.

Dillon J, Stevenson RB, Wals AEJ. 2016. Introduction to the special section moving from citizen to civic science to address wicked conservation problems. Conservation Biology 30:450-455.

Doherty TS, Dickman CR, Nimmo DG, Ritchie EG. 2015. Multiple threats, or multiplying the threats? Interactions between invasive predators and other ecological disturbances. Biological Conservation 190:60-68.

Doherty TS, Glen AS, Nimmo DG, Ritchie EG, Dickman CR. 2016. Invasive predators and global biodiversity loss. Proceedings of the National Academy of Sciences of the United States of America 113:11261-11265.

Doherty TS, Ritchie EG. 2017. Stop jumping the gun: A call for evidence-based invasive predator management. Conservation Letters 10:15-22.

Dolan RW, Harris KA, Adler M. 2015. Community involvement to address a longstanding invasive species problem: Aspects of civic ecology in practice. Ecological Restoration 33:316-325.

Ehlers Smith YC, Ehlers Smith DA, Ramesh T, Downs CT. 2018. Forest habitats in a mixed urban-agriculture mosaic landscape: patterns of mammal occupancy. Landscape Ecology 33:59-76.

Ellwood ER, Crimmins TM, Miller-Rushing AJ. 2017. Citizen science and conservation: Recommendations for a rapidly moving field. Biological Conservation 208:1-4.

Elmqvist $\mathrm{T}$ et al. 2013. Urbanization, biodiversity and ecosystem services: challenges and opportunities. Springer. 755 pp.

Elmqvist T, Setälä H, Handel S, van der Ploeg S, Aronson J, Blignaut J, GómezBaggethun E, Nowak D, Kronenberg J, de Groot R. 2015. Benefits of restoring ecosystem services in urban areas. Current Opinion in Environmental Sustainability 14:101-108.

Estévez RA, Anderson CB, Pizarro JC, Burgman MA. 2015. Clarifying values, risk 
perceptions, and attitudes to resolve or avoid social conflicts in invasive species management. Conservation Biology 29:19-30.

Exelis Visual Information Solutions. 2010. ENVI. Boulder, Colorado.

Faeth SH, Warren PS, Shochat E, Marussich W. 2005. Trophic dynamics in urban communities. BioScience 55:399.

Fancourt BA. 2016. Avoiding the subject: the implications of avoidance behaviour for detecting predators. Behavioral Ecology and Sociobiology 70:1535-1546.

Farinha-Marques P, Lameiras JM, Fernandes C, Silva S, Guilherme F. 2011. Urban biodiversity: a review of current concepts and contributions to multidisciplinary approaches. Innovation: The European Journal of Social Science Research 24:247271.

Feltynowski M, Kronenberg J, Bergier T, Kabisch N, Łaszkiewicz E, Strohbach MW. 2018. Challenges of urban green space management in the face of using inadequate data. Urban Forestry \& Urban Greening 31:56-66.

Feng AYT, Himsworth CG. 2014. The secret life of the city rat: A review of the ecology of urban Norway and black rats (Rattus norvegicus and Rattus rattus). Urban Ecosystems 17:149-162.

Fernández IC, Simonetti JA. 2013. Small mammal assemblages in fragmented shrublands of urban areas of Central Chile. Urban Ecosystems 16:377-387.

Flockhart DTT, Norris DR, Coe JB. 2016. Predicting free-roaming cat population densities in urban areas. Animal Conservation 19:472-483.

Flux JEC. 2007. Seventeen years of predation by one suburban cat in New Zealand. New Zealand Journal of Zoology 34:289-296.

Flux JEC. 2017. Comparison of predation by two suburban cats in New Zealand. European Journal of Ecology 3:85-90.

Forrester TD, Baker M, Costello R, Kays R, Parsons AW, McShea WJ. 2017. Creating advocates for mammal conservation through citizen science. Biological Conservation 208:98-105.

Francis RA, Chadwick MA. 2015. Invasions : Non-native and invasive species in cities. Geography 100:144-151.

Francis RA, Lorimer J. 2011. Urban reconciliation ecology: The potential of living roofs 
and walls. Journal of Environmental Management 92:1429-1437.

Fuller RA, Irvine KN, Devine-Wright P, Warren PH, Gaston KJ. 2007. Psychological benefits of greenspace increase with biodiversity. Biology Letters 3:390-394.

Gaertner M, Larson BMH, Irlich UM, Holmes PM, Stafford L, van Wilgen BW, Richardson DM. 2016. Managing invasive species in cities: A framework from Cape Town, South Africa. Landscape and Urban Planning 151:1-9.

Gaertner M, Novoa A, Fried J, Richardson DM. 2017a. Managing invasive species in cities: a decision support framework applied to Cape Town. Biological Invasions 19:3707-3723.

Gaertner M, Wilson JRU, Cadotte MW, MacIvor JS, Zenni RD, Richardson DM. 2017b. Non-native species in urban environments: patterns, processes, impacts and challenges. Biological Invasions 19:3461-3469.

Gallo T, Fidino M, Lehrer EW, Magle SB. 2017. Mammal diversity and metacommunity dynamics in urban green spaces: implications for urban wildlife conservation. Ecological Applications 27:2330-2341.

Gelman A, Hill J. 2007. Data analysis using regression and multilevel/hierarchical models. Cambridge University Press. 625 pp.

Gillies C, Clout M. 2003. The prey of domestic cats (Felis catus) in two suburbs of Auckland City, New Zealand. Journal of Zoology 259:309-315.

Gillies CA, Williams D. 2013. DOC tracking tunnel guide v2.5.2: Using tracking tunnels to monitor rodents and mustelids. Available from https://www.doc.govt.nz/Documents/science-and-technical/inventorymonitoring/im-toolbox-animal-pests-using-tracking-tunnels-to-monitor-rodents-andmustelids.pdf (accessed July 30, 2018).

Glen AS, Anderson D, Veltman CJ, Garvey PM, Nichols M. 2016. Wildlife detector dogs and camera traps: a comparison of techniques for detecting feral cats. New Zealand Journal of Zoology 43:127-137.

Glen AS, Cockburn S, Nichols M, Ekanayake J, Warburton B. 2013. Optimising camera traps for monitoring small mammals. PLOS One 8:e67940.

Glen AS, Warburton B, Cruz J, Coleman M. 2014. Comparison of camera traps and kill traps for detecting mammalian predators: a field trial. New Zealand Journal of 
Zoology 41:155-160.

Goddard M a., Dougill AJ, Benton TG. 2010. Scaling up from gardens: biodiversity conservation in urban environments. Trends in Ecology and Evolution 25:90-98.

Goldson S, Bourdôt G, Brockerhoff E, Byrom AE, Clout M, McGlone M, Nelson W, Popay A, Suckling D, Templeton M. 2015. New Zealand pest management: current and future challenges. Journal of the Royal Society of New Zealand 45:31-58.

Goodman H, Egizi A, Fonseca DM, Leisnham PT, Ladeau SL. 2018. Primary blood-hosts of mosquitoes are influenced by social and ecological conditions in a complex urban landscape. Parasites and Vectors 11:218.

Gordon JK, Matthaei C, van Heezik Y. 2010. Belled collars reduce catch of domestic cats in New Zealand by half. Wildlife Research 37:372-378.

Graham MH. 2003. Confronting multicollinearity in ecological multiple regression. Ecology 84:2809-2815.

Greater Wellington Regional Council. 2007. Greater Wellington-Regional pest management strategy. Available from http://www.gw.govt.nz/assets/OurEnvironment/Biosecurity/Pest-plants/GreaterWellingtonRPMS2009.pdf (accessed July 30, 2018).

Groffman PM et al. 2017. Ecological homogenization of residential macrosystems. Nature Ecology and Evolution 1:1-3.

Guénard B, Cardinal-De Casas A, Dunn RR. 2015. High diversity in an urban habitat: are some animal assemblages resilient to long-term anthropogenic change? Urban Ecosystems 18:449-463.

Güneralp B, Seto KC. 2013. Futures of global urban expansion: Uncertainties and implications for biodiversity conservation. Environmental Research Letters 8:014025.

Hahs AK et al. 2009. A global synthesis of plant extinction rates in urban areas. Ecology Letters 12:1165-1173.

Hardion L, Leriche A, Schwoertzig E, Millon A. 2016. Species Distribution 2.0: An accurate time- and cost-effective method of prospection using street view imagery. PLOS One 11:e0146899.

Harper MJ. 2005. Home range and den use of common brushtail possums (Trichosurus 
vulpecula) in urban forest remnants. Wildlife Research 32:681-687.

Harper MJ, McCarthy MA, Van Der Ree R. 2008. Resources at the landscape scale influence possum abundance. Austral Ecology 33:243-252.

Haverland MB, Veech JA. 2017. Examining the occurrence of mammal species in natural areas within a rapidly urbanizing region of Texas, USA. Landscape and Urban Planning 157:221-230.

Hawthorne TL, Elmore V, Strong A, Bennett-Martin P, Finnie J, Parkman J, Harris T, Singh J, Edwards L, Reed J. 2015. Mapping non-native invasive species and accessibility in an urban forest: A case study of participatory mapping and citizen science in Atlanta, Georgia. Applied Geography 56:187-198.

He Z, Kays R, Zhang Z, Ning G, Huang C, Han TX, Millspaugh J, Forrester T, McShea W. 2016. Visual informatics tools for supporting large-scale collaborative wildlife monitoring with citizen scientists. IEEE Circuits and Systems Magazine 16:73-86.

Heber S, Wilson K, Molles L. 2008. Breeding biology and breeding success of the blue penguin (Eudyptula minor) on the West Coast of New Zealand's South Island. New Zealand Journal of Zoology 35:63-71.

Hess GR, Moorman CE, Thompson J, Larson CL. 2014. Integrating wildlife conservation into urban planning. Pages 239-278 Urban wildlife conservation: Theory and practice. Springer Science \& Business Media. 406 pp.

Himsworth CG, Parsons KL, Feng AYT, Kerr T, Jardine CM, Patrick DM. 2014. A mixed methods approach to exploring the Relationship between Norway Rat (Rattus norvegicus) abundance and features of the urban environment in an inner-city neighborhood of Vancouver, Canada. PLOS One 9:e97776.

Hobbs ER. 1988. Species richness of urban forest patches and implications for urban landscape diversity. Landscape Ecology 1:141-152.

Hobbs MT, Brehme CS. 2017. An improved camera trap for amphibians, reptiles, small mammals, and large invertebrates. PLOS One 12:e0185026.

Hooker S, Innes J. 1995. Ranging behaviour of forest-dwelling ship rats, Rattus rattus, and effects of poisoning with brodifacoum. New Zealand Journal of Zoology 22:291-304.

Horn G Van, Branson S, Farrell R, Barry J, Tech C. 2015. Building a bird recognition 
app and large scale dataset with citizen scientists: the fine print in fine-grained dataset collection. Proceedings of the IEEE Conference on Computer Vision and Pattern Recognition, pp. 595-604.

Hosaka T, Numata S. 2016. Spatiotemporal dynamics of urban green spaces and humanwildlife conflicts in Tokyo. Scientific Reports 6:30911.

Howe AG, Ravn HP, Pipper CB, Aebi A. 2016. Potential for exploitative competition, not intraguild predation, between invasive harlequin ladybirds and flowerbugs in urban parks. Biological Invasions 18:517-532.

Howe J. 2008. Crowdsourcing: How the power of the crowd is driving the future of business. Random House. 312 pp.

Hubert P, Julliard R, Biagianti S, Poulle ML. 2011. Ecological factors driving the higher hedgehog (Erinaceus europeaus) density in an urban area compared to the adjacent rural area. Landscape and Urban Planning 103:34-43.

Hui C, Richardson DM. 2017. Invasion dynamics. Oxford University Press. 322 pp. Hulme PE. 2014. Invasive species challenge the global response to emerging diseases. Trends in Parasitology 30:267-270.

Inger R, Cox DTC, Per E, Norton BA, Gaston KJ. 2016. Ecological role of vertebrate scavengers in urban ecosystems in the UK. Ecology and Evolution 6:7015-7023.

Isaac NJB, van Strien AJ, August T a, de Zeeuw MP, Roy DB. 2014. Statistics for citizen science: Extracting signals of change from noisy ecological data. Methods in Ecology and Evolution 5:1052-1060.

Ives CD et al. 2016. Cities are hotspots for threatened species. Global Ecology and Biogeography 25:117-126.

Jackman S, Tahk A, Zeileis A, Maimone C, Fearon J, Meers Z. 2017. pscl: Political Science Computational Laboratory. R package version 1.5.2. Available from https://cran.r-project.org/web/packages/pscl/index.html (accessed July 30, 2018).

Jarvie S, Monks J. 2014. Step on it: can footprints from tracking tunnels be used to identify lizard species? New Zealand Journal of Zoology 41:210-217.

Jennett $C$ et al. 2016. Motivations, learning and creativity in online citizen science. Journal of Science Communication 15:1-23.

Johnson S, Bragdon C, Olson C. 2014. Characteristics of the built environment and the 
presence of the Norway rat in New York City: Results from a neighborhood rat surveillance program, 2008 - 2010. Journal of Environmental Health 78:22-29.

Jones C, Moss K, Sanders M. 2005. Diet of hedgehogs (Erinaceus europaeus) in the upper Waitaki Basin, New Zealand: Implications for conservation. New Zealand Journal of Ecology 29:29-35.

Jones HP et al. 2016. Invasive mammal eradication on islands results in substantial conservation gains. Proceedings of the National Academy of Sciences 113:40334038.

Kahle LQ, Flannery ME, Dumbacher JP. 2016. Bird-window collisions at a west-coast urban park museum: analyses of bird biology and window attributes from Golden Gate Park, San Francisco. PLOS One 11:e0144600.

Kauhala K, Talvitie K, Vuorisalo T. 2015. Free-ranging house cats in urban and rural areas in the north: Useful rodent killers or harmful bird predators? Folia Zoologica 64:45-55.

Kaye JP, Groffman PM, Grimm NB, Baker LA, Pouyat R V. 2006. A distinct urban biogeochemistry? Trends in Ecology and Evolution 21:192-199.

Kelling S et al. 2015. Can observation skills of citizen scientists be estimated using species accumulation curves? PLOS One 10:e0139600.

Kikillus HK, Chambers GK, Farnworth MJ, Hare KM. 2017. Research challenges and conservation implications for urban cat management in New Zealand. Pacific Conservation Biology 23:15-24.

King CM, Powell RA. 2011. Managing an invasive predator pre-adapted to a pulsed resource: A model of stoat (Mustela erminea) irruptions in New Zealand beech forests. Biological Invasions 13:3039-3055.

Klimant P, Klimantová A, Baláž I, Jakab I, Tulis F, Rybanský L, Vadel L', Krumpálová Z. 2017. Small mammals in an urban area: Habitat preferences and urban-rural gradient in Nitra City, Slovakia. Polish Journal of Ecology 65:144-157.

Kobori H et al. 2016. Citizen science: a new approach to advance ecology, education, and conservation. Ecological Research 31:1-19.

Kolowski JM, Forrester TD. 2017. Camera trap placement and the potential for bias due to trails and other features. PLOS One 12:e186679. 
Kosmala M, Wiggins A, Swanson A, Simmons B. 2016. Assessing data quality in citizen science. Frontiers in Ecology and the Environment 14:551-560.

Kowarik I. 2011. Novel urban ecosystems, biodiversity, and conservation. Environmental pollution 159:1974-1983.

Kumar YHS, Manohar N, Chethan HK. 2015. Animal classification system: a block based approach. Procedia Computer Science 45:336-343.

Kummer JA, Bayne EM, Machtans CS. 2016. Use of citizen science to identify factors affecting bird-window collision risk at houses. The Condor 118:624-639.

Latham AD, Nugent G, Warburton B. 2012. Evaluation of camera traps for monitoring European rabbits before and after control operations in Otago, New Zealand. Wildlife Research 39:621-628.

Laut J, Cappa F, Nov O, Porfiri M. 2017. Increasing citizen science contribution using a virtual peer. Journal of the Association for Information Science and Technology 68:583-593.

Lazenby BT, Mooney NJ, Dickman CR. 2015. Detecting species interactions using remote cameras: effects on small mammals of predators, conspecifics, and climate. Ecosphere 6:1-18.

Lee WG, Allen RB, Tompkins DM. 2006. Paradise lost - the last major colonization. Pages 1-13 Biological invasions in New Zealand. Springer. 451 pp.

Lewandowski E, Specht H. 2015. Influence of volunteer and project characteristics on data quality of biological surveys. Conservation Biology 29:713-723.

Lincoln S. 2016. Indirect impacts of mammalian pest control; behavioural responses of cats (Felis catus) to rodent control in urban forest fragments. Master's Thesis, University of Auckland. Auckland, New Zealand.

Lioy S, Mori E, Wauters LA, Bertolino S. 2016. Weight operated see-saw feeding hoppers are not selective for red squirrels when greys are present. Mammalian Biology 81:365-371.

Lucaccioni H, Granjon L, Dalecky A, Fossati O, Le Fur J, Duplantier JM, Handschumacher P. 2016. From human geography to biological invasions: The black rat distribution in the changing southeastern of Senegal. PLOS One 11:e0163547. 
Lye GC, Osborne JL, Park KJ, Goulson D. 2011. Using citizen science to monitor Bombus populations in the UK: nesting ecology and relative abundance in the urban environment. Journal of Insect Conservation 16:697-707.

MacKenzie D, Hines J. 2018. RPresence: R Interface for Program PRESENCE. R package version 2.12.9.

MacKenzie DI, Bailey LL. 2004. Assessing the fit of site-occupancy models. Journal of Agricultural, Biological, and Environmental Statistics 9:300-318.

Mackenzie DI, Nichols JD, Lachman GB, Droege S, Andrew J, Langtimm CA. 2002. Estimating site occupancy rates when detection probabilities are less than one. Ecology 83:2248-2255.

MacKenzie DI, Nichols JD, Royle JA, Pollock KH, Bailey L, Hines JE. 2017. Occupancy Estimation and Modeling: Inferring Patterns and Dynamics of Species Occurrence. Elsevier Science. 643 pp.

MacLeod LJ, Dickson R, Leckie C, Stephenson BM, Glen AS. 2015. Possum control and bird recovery in an urban landscape, New Zealand. Conservation Evidence 12:4447.

Magle SB, Simoni LS, Lehrer EW, Brown JS. 2014. Urban predator-prey association: coyote and deer distributions in the Chicago metropolitan area. Urban Ecosystems 17:875-891.

Maistrello L, Dioli P, Bariselli M, Mazzoli GL, Giacalone-Forini I. 2016. Citizen science and early detection of invasive species: phenology of first occurrences of Halyomorpha halys in Southern Europe. Biological Invasions 18:3109-3116.

Martin J, Hall DB. 2016. $\mathrm{R}^{2}$ measures for zero-inflated regression models for count data with excess zeros. J Stat Comput Simul 86:3777-3790.

Marvin DC, Koh LP, Lynam AJ, Wich S, Davies AB, Krishnamurthy R, Stokes E, Starkey R, Asner GP. 2016. Integrating technologies for scalable ecology and conservation. Global Ecology and Conservation 7:262-275.

McClellan S, Jimenez JA, Koutitas G. 2017. Smart cities: Applications, technologies, standards, and driving factors. Springer International Publishing. 239 pp.

McDonald JL, Maclean M, Evans MR, Hodgson DJ. 2015. Reconciling actual and perceived rates of predation by domestic cats. Ecology and Evolution 5:2745-2753. 
Mcdonald RI, Kareiva P, Forman RTT. 2008. The implications of current and future urbanization for global protected areas and biodiversity conservation. Biological Conservation 141:1695-1703.

McDonnell MJ, Pickett STA. 1990. Ecosystem structure and function along urban-rural gradients: an unexploited opportunity for ecology. Ecology 71:1232-1237.

McIntyre NE. 2014. Wildlife responses to urbanization: Patterns of diversity and community structure in built environments. Pages 103-115 Urban wildlife conservation: Theory and practice. Springer Science \& Business Media. 406 pp.

McKinley DC et al. 2017. Citizen science can improve conservation science, natural management, and environmental protection. Biological Conservation 208:15-28.

McKinney ML. 2002. Urbanization, biodiversity, and conservation: The impacts of urbanization on native species are poorly studied, but educating a highly urbanized human population about these impacts can greatly improve species conservation in all ecosystems. BioScience 52:883-890.

McKinney ML. 2006. Urbanization as a major cause of biotic homogenization. Biological Conservation 127:247-260.

Mcphearson T, Pickett STA, Grimm NB, Niemelä J, Alberti M, Elmqvist T, Weber C, Haase D, Breuste J, Qureshi S. 2016. Advancing urban ecology toward a science of cities. BioScience 66:198-212.

Mcruer DL, Gray LC, Horne LA, Clark EE. 2017. Free-roaming cat interactions with wildlife admitted to a wildlife hospital. Journal of Wildlife Management 81:163173.

McShea WJ, Forrester T, Costello R, He Z, Kays R. 2016. Volunteer-run cameras as distributed sensors for macrosystem mammal research. Landscape Ecology 31:5566.

Meek P, Ballard G, Fleming P, Falzon G. 2016. Are we getting the full picture? Animal responses to camera traps and implications for predator studies. Ecology and Evolution 6:3216-3225.

Meek P, Fleming P, Ballard G, Banks P, Claridge AW, Sanderson JJG, Swann D. 2014. Camera trapping: wildlife management and research. Csiro Publishing. 392 pp. Morais AMM, Santos RDC, Raddick MJ. 2015. Visualization of citizen science 
volunteers' behaviors with data from usage logs. Computing in Science and Engineering 17:42-50.

Morgan DK, Waas JR, Innes JG. 2009. An inventory of mammalian pests in a New Zealand city. New Zealand Journal of Zoology 36:23-33.

Muhly TB, Semeniuk C, Massolo A, Hickman L, Musiani M. 2011. Human activity helps prey win the predator-prey space race. PLOS One 6:e17050.

Müller N, Ignatieva M, Nilon CH, Werner P, Zipperer WC. 2013. Patterns and trends in urban biodiversity and landscape design. Pages 123-174 Urbanization, biodiversity and ecosystem services: Challenges and opportunities: A global assessment. Springer. 755 pp.

Murray MH, Hill J, Whyte P, St. Clair CC. 2016. Urban compost attracts coyotes, contains toxins, and may promote disease in urban-adapted wildlife. EcoHealth 13:285-292.

Nakagawa S, Schielzeth H. 2013. A general and simple method for obtaining R 2 from generalized linear mixed-effects models. Methods in Ecology and Evolution 4:133142.

Nazir S, Newey S, Irvine RJ, Verdicchio F, Davidson P, Fairhurst G, Wal R van der. 2017. WiseEye: next generation expandable and programmable camera trap platform for wildlife research. PLOS One 12:e0169758.

Newson SE, Evans HE, Gillings S. 2015. A novel citizen science approach for large-scale standardised monitoring of bat activity and distribution, evaluated in eastern England. Biological Conservation 191:38-49.

Nichols M, Glen AS, Garvey P, Ross J. 2017. A comparison of horizontal versus vertical camera placement to detect feral cats and mustelids. New Zealand Journal of Ecology 41:145-150.

Nilon $\mathrm{CH}$ et al. 2017. Planning for the future of urban biodiversity: A global review of city-scale initiatives. BioScience 67:332-342.

Norouzzadeh MS, Nguyen A, Kosmala M, Swanson A, Packer C, Clune J. 2017.

Automatically identifying wild animals in camera trap images with deep learning. Proceedings of the National Academy of Sciences:201719367.

Norton BA, Evans KL, Warren PH. 2016a. Urban biodiversity and landscape ecology: 
Patterns, processes and planning. Current Landscape Ecology Reports 1:178-192. Norton DA, Young LM, Byrom AE, Clarkson BD, Lyver PO, McGlone MS, Waipara NW. 2016b. How do we restore New Zealand's biological heritage by 2050 ? Ecological Management \& Restoration 17:170-179.

Novoa A, Dehnen-Schmutz K, Fried J, Vimercati G. 2017. Does public awareness increase support for invasive species management? Promising evidence across taxa and landscape types. Biological Invasions 19:3691-3705.

O’Connell AFJ, Talancy NW, Bailey LL, Sauer JR, Cook R, Gilbert AT. 2006.

Estimating site occupancy and detection probability parameters for meso-and large mammals in a coastal ecosystem. Journal of Wildlife Management 70:1625-1633. O’Connor KM, Nathan LR, Liberati MR, Tingley MW, Vokoun JC, Rittenhouse TAG. 2017. Camera trap arrays improve detection probability of wildlife: Investigating study design considerations using an empirical dataset. PLOS One 12:e175684. Padayachee AL, Irlich UM, Faulkner KT, Gaertner M, Procheş Ş, Wilson JRU, Rouget M. 2017. How do invasive species travel to and through urban environments? Biological Invasions 19:3557-3570.

Parkes JP, Nugent G, Forsyth DM, Byrom AE, Pech RP, Warburton B, Choquenot D. 2017. Past, present and two potential futures for managing New Zealand's mammalian pests. New Zealand Journal of Ecology 41:151-161.

Parsons AW, Goforth C, Costello R, Kays R. 2018. The value of citizen science for ecological monitoring of mammals. PeerJ 6:e4536.

Parsons MH, Banks PB, Deutsch MA, Corrigan RF, Munshi-South J. 2017. Trends in urban rat ecology: a framework to define the prevailing knowledge gaps and incentives for academia, pest management professionals (PMPs) and public health agencies to participate. Journal of Urban Ecology 3:1-8.

Pech R, Maitland M. 2016. Conservation of native fauna in highly invaded systems: managing mammalian predators in New Zealand. Restoration Ecology 24:816-820.

Peters MA, Hamilton D, Eames C. 2015. Action on the ground: A review of community environmental groups' restoration objectives, activities and partnerships in New Zealand. New Zealand Journal of Ecology 39:179-189.

Pickerell GA, O’Donnell CF, Wilson DJ, Seddon PJ. 2014. How can we detect 
introduced mammalian predators in non-forest habitats? A comparison of techniques. New Zealand Journal of Ecology 38:86-102.

Pickett STA, Cadenasso ML, Childers DL, McDonnell MJ, Zhou W. 2016. Evolution and future of urban ecological science: ecology in , of , and for the city. Ecosystem Health and Sustainability 2:e01229.

Pocock MJO, Roy HE, Preston CD, Roy DB. 2015. The biological records centre: a pioneer of citizen science. Biological Journal of the Linnean Society 115:475-493. R Core Team. 2016. R: a language and environment for statistical computing. $\mathrm{R}$ Foundation for Statistical Computing. Version 3.1.2. Vienna, Austria. www.Rproject.org/.

Ramírez-Cruz GA, Mendoza-Hernández PE, Solano-Zavaleta I, Zúñiga-Vega JJ. 2018. How widespread are nonnative species? Estimating habitat occupancy in an ecological reserve within a megacity. Natural Areas Journal 38:68-87.

Ramsey DSL, Caley P a., Robley A. 2015. Estimating population density from presenceabsence data using a spatially explicit model. The Journal of Wildlife Management 79:491-499.

Rich LN et al. 2017. Assessing global patterns in mammalian carnivore occupancy and richness by integrating local camera trap surveys. Global Ecology and Biogeography 26:918-929.

Roberts H, Sadler J, Chapman L. (in press). The value of Twitter data for determining the emotional responses of people to urban green spaces: A case study and critical evaluation. Urban Studies.

Rocha DG, Ramalho EE, Magnusson WE. 2016. Baiting for carnivores might negatively affect capture rates of prey species in camera-trap studies. Journal of Zoology 300:205-212.

Rodewald AD, Kearns LJ, Shustack DP. 2011. Anthropogenic resource subsidies decouple predator-prey relationships. Ecological Applications 21:936-943.

Rowcliffe JM, Carbone C, Jansen PA, Kays R, Kranstauber B. 2011. Quantifying the sensitivity of camera traps: an adapted distance sampling approach. Methods in Ecology and Evolution 2:464-476.

Rowcliffe JM, Field J, Turvey ST, Carbone C. 2008. Estimating animal density using 
camera traps without the need for individual recognition. Journal of Applied Ecology 45:1228-1236.

Ruffell J, Didham RK. 2016. Towards a better mechanistic understanding of edge effects. Landscape Ecology 31:2205-2213.

Ruffell J, Innes J, Bishop C, Landers T, Khin J, Didham RK. 2015. Using pest monitoring data to inform the location and intensity of invasive-species control in New Zealand. Biological Conservation 191:640-649.

Russell JC, Innes JG, Brown PH, Byrom AE. 2015. Predator-free New Zealand: Conservation country. BioScience 65:520-525.

Russell JC, Taylor CN, Aley JP. 2018. Social assessment of inhabited islands for wildlife management and eradication. Australasian Journal of Environmental Management 25:24-42.

Saito MU, Sonoda Y. 2017. Symptomatic raccoon dogs and sarcoptic mange along an urban gradient. EcoHealth 14:318-328.

Sam SA. 2011. New monitoring and control tools for simultaneously managing possums, rats and mice in New Zealand. PhD thesis, Lincoln University, Christchurch, New Zealand. 149 pp.

Schneider A, Friedl MA, Potere D. 2010. Mapping global urban areas using MODIS 500$m$ data: New methods and datasets based on "urban ecoregions." Remote Sensing of Environment 114:1733-1746.

Schröter M, Kraemer R, Mantel M, Kabisch N, Hecker S, Richter A, Neumeier V, Bonn A. 2017. Citizen science for assessing ecosystem services: Status, challenges and opportunities. Ecosystem Services 28:80-94.

Secretariat of the Convention on Biological Diversity. 2012. Cities and biodiversity outlook: A global assessment of the links between urbanization, biodiversity, and ecosystem services. Available from https://www.cbd.int/doc/health/cbo-actionpolicy-en.pdf (accessed July 30, 2018).

Shanahan DF, Fuller RA, Bush R, Lin BB, Gaston KJ. 2015. The health benefits of urban nature: How much do we need? BioScience 65:476-485.

Shannon $\mathrm{G}$ et al. 2016. A synthesis of two decades of research documenting the effects of noise on wildlife. Biological Reviews 91:982-1005. 
Singh NJ, Danell K, Edenius L, Ericsson G. 2014. Tackling the motivation to monitor : success and sustainability of a participatory monitoring program. Ecology and Society 19:7.

Smith HM, Dickman CR, Banks PB. 2017. Exotic black rats increase invertebrate Ordinal richness in urban habitat remnants. Biological Invasions 19:1315-1328.

Soulé ME, Bolger DT, Alberts AC, Sauvajot RS, Wright J, Sorice M, Scott H. 1988.

Reconstructed dynamics of rapid extinctions of chaparral-requiring birds in urban habitat islands. Conservation Biology 2:75-92.

Soulsbury CD, White PCL. 2015. Human-wildlife interactions in urban areas: A review of conflicts, benefits and opportunities. Wildlife Research 42:541.

Specht H. 2018. Biased assumptions and oversimplifications in evaluations of citizen science data quality. The Bulletin of the Ecological Society of America 99:251-256.

Sprinks J, Wardlaw J, Houghton R, Bamford S, Morley J. 2017. Task workflow design and its impact on performance and volunteers' subjective preference in virtual citizen science. International Journal of Human-Computer Studies 104:50-63.

Statistics New Zealand. 2013. New Zealand Census 2013. Available from http://archive.stats.govt.nz/Census/2013-census.aspx (accessed July 30, 2018).

Steenweg R et al. 2017. Scaling up camera traps: monitoring the planet's biodiversity with networks of remote sensors. Frontiers in Ecology and the Environment 15:2634.

Sueur J, Farina A. 2015. Ecoacoustics: the ecological investigation and interpretation of environmental sound. Biosemiotics 8:493-502.

Swanson A, Kosmala M, Lintott C, Packer C. 2016. A generalized approach for producing, quantifying, and validating citizen science data from wildlife images. Conservation Biology 30:520-531.

Swinnen KRR, Reijniers J, Breno M, Leirs H. 2014. A novel method to reduce time investment when processing videos from camera trap studies. PLOS One 9:e98881.

Tamayo-Uria I, Mateu J, Escobar F, Mughini-Gras L. 2014. Risk factors and spatial distribution of urban rat infestations. Journal of Pest Science 87:107-115.

Taylor MD, Babcock RC, Simpfendorfer CA, Crook DA. 2017. Where technology meets ecology: Acoustic telemetry in contemporary Australian aquatic research and 
management. Marine and Freshwater Research 68:1397-1402.

Tompkins DM, Byrom AE, Pech RP. 2013. Predicted responses of invasive mammal communities to climate-related changes in mast frequency in forest ecosystems. Ecological Applications 23:1075-1085.

van Heezik Y, Smyth A, Adams AL, Gordon J. 2010. Do domestic cats impose an unsustainable harvest on urban bird populations? Biological Conservation 143:121130.

Villaseñor NR, Blanchard W, Driscoll DA, Gibbons P, Lindenmayer DB. 2014. Strong influence of local habitat structure on mammals reveals mismatch with edge effects models. Landscape Ecology 30:229-245.

Wagstaff K, Cardie C, Rogers S, Schroedl S. 2001. Constrained K-means clustering with background knowledge. Proceedings of the Eighteenth International Conference on Machine Learning:577-584.

Walker GA, Robertson MP, Gaertner M, Gallien L, Richardson DM. 2017. The potential range of Ailanthus altissima (tree of heaven) in South Africa: the roles of climate, land use and disturbance. Biological Invasions 19:3675-3690.

Wall J, Wittemyer G, Klinkenberg B, Douglas-Hamilton I. 2014. Novel opportunities for wildlife conservation and research with real-time monitoring. Ecological Applications 24:593-601.

Wang Y, Allen ML, Wilmers CC. 2015. Mesopredator spatial and temporal responses to large predators and human development in the Santa Cruz Mountains of California. Biological Conservation 190:23-33.

Weckel ME, Mack D, Nagy C, Christie R, Wincorn A. 2010. Using citizen science to map human-coyote interaction in suburban New York, USA. Journal of Wildlife Management 74:1163-1171.

Wei JW, Lee BPY, Wen LB. 2016. Citizen science and the urban ecology of birds and butterflies - A systematic review. PLOS One 11:e0156425.

Welbourne DJ, Claridge AW, Paull DJ, Lambert A. 2016. How do passive infrared triggered camera traps operate and why does it matter? Breaking down common misconceptions. Remote Sensing in Ecology and Conservation 2:77-83.

Welden NA, Wolseley PA, Ashmore MR. 2018. Citizen science identifies the effects of 
nitrogen deposition, climate and tree species on epiphytic lichens across the UK. Environmental Pollution 232:80-89.

Wellington City Council. 2015. Our Natural Capital. Wellington's biodiversity strategy and action plan 2015. Available from http://wellington.govt.nz/ /media/yourcouncil/plans-policies-and-bylaws/plans-and-policies/a-toz/biodiversity/files/2015/our-natural-capital-entire.pdf (accessed July 30, 2018).

Widdows CD, Ramesh T, Downs CT. 2015. Factors affecting the distribution of large spotted genets (Genetta tigrina) in an urban environment in South Africa. Urban Ecosystems 18:1401-1413.

Wiggins A, Crowston K. 2011. From conservation to crowdsourcing: A typology of citizen science. Proceedings of the Annual Hawaii International Conference on System Sciences:1-10.

Williams CR, Hawthorn-Jackson D, Orre-Gordon S, O’Sullivan S. 2017. Some cautions in the use of citizen science: A case study of urban insect collection. Transactions of the Royal Society of South Australia 141:57-69.

Wilson JF et al. 2018. A role for artificial night-time lighting in long-term changes in populations of 100 widespread macro-moths in UK and Ireland: a citizen-science study. Journal of Insect Conservation 22:189-196.

Wine S, Gagné SA, Meentemeyer RK. 2014. Understanding human-coyote encounters in urban ecosystems using citizen science data: What do socioeconomics tell us? Environmental Management 55:159-170.

Wood V, Seddon PJ, Beaven B, Heezik Y Van. 2016. Movement and diet of domestic cats on Stewart Island / Rakiura, New Zealand. New Zealand Journal of Ecology 40:186-190.

World Health Organisation. 2016. Urban health. Global health observatory data. Available from http://www.who.int/gho/urban_health/en/ (accessed March 12, 2018).

Yarime M. 2017. Facilitating data-intensive approaches to innovation for sustainability: opportunities and challenges in building smart cities. Sustainability Science 12:881885.

Yemshanov D, Haight RG, Koch FH, Lu B, Venette R, Fournier RE, Turgeon JJ. 2017. 
Robust surveillance and control of invasive species using a scenario optimization approach. Ecological Economics 133:86-98.

Zabala J, Zuberogoitia I, González-Oreja JA. 2010. Estimating costs and outcomes of invasive American mink (Neovison vison) management in continental areas: A framework for evidence based control and eradication. Biological Invasions 12:2999-3012. 